\title{
Fire History and Natural Succession After Forest Fires in Pine-OAK Forests
}

An Investigation in the Ecological Park "Chipinque", Northeast Mexico

\author{
Dissertation \\ zur Erlangung des Doctorgrades \\ der Fakultät für Forstwissenschaften und Waldökologie \\ der Georg-August-Universität Göttingen
}

\author{
vorgelegt von \\ Marco Aurelio González Tagle \\ geboren in Ciudad Victoria, Tamaulipas, Mexiko
}

Göttingen 2005 


\section{D7}

1. Berichterstatter: Prof. Dr. Burkhard Müller-Using

2. Berichterstatter: Prof. Dr. h.c. Klaus von Gadow

Tag der mündlichen Prüfung: 24.02.2005

Umschlagmotiv: (c) 2005 Wibke Himmelsbach

Sprachliche Überarbeitung: Jessica Gee 


\section{Contents}

Acknowledgments $\quad$ xi

Glossary of Wildland Fire Terminology xiii

1 Introduction $\quad 1$

1.1 Research Gaps and Objectives . . . . . . . . . . . . . . . . . . . 2

2 Literature Review 5

$2.1 \quad$ Fire Ecology . . . . . . . . . . . . . . . . . . . . . 5

2.1.1 Fire Ecology, Terms and Classification . . . . . . . . . . 5

2.1.2 Inferences of Fire Occurrence . . . . . . . . . . . . . 7

2.1.3 Wildland Fire Within the International Context . . . . . . . . 13

2.2 Forest Fire Situation in Mexico . . . . . . . . . . . . . . . . . 15

2.3 Forest Succession . . . . . . . . . . . . . . . . . . . . . . . . 20

2.3.1 Succession Models . . . . . . . . . . . . . . . . . . 22

2.4 Biodiversity Analysis . . . . . . . . . . . . . . . . . . . . . . . 23

2.4 .1 Alpha Diversity $(\alpha) \ldots \ldots \ldots . \ldots \ldots 24$

2.4.2 Beta Diversity $(\beta) \ldots \ldots . \ldots . \ldots 30$

2.5 Potential Solar Radiation (PSR) . . . . . . . . . . . . . . . 31

2.5.1 The Geometry of Radiation . . . . . . . . . . . . . . 31

2.5.2 Radiation Sources . . . . . . . . . . . . . . 33

2.5.3 Radiation Models . . . . . . . . . . . . . . . . . . 34

2.5.4 Digital Elevation Model (DEM) . . . . . . . . . . 35

$3 \quad$ Material and Methods $\quad 37$

3.1 General Description of the Research Area . . . . . . . . . . . . . . . . 37 
3.1 .1 Topography and Soils . . . . . . . . . . . . . . 38

3.1 .2 Climate . . . . . . . . . . . . . . . . 39

3.1.3 Vegetation . . . . . . . . . . . . . . 41

3.2 Stand Inventory and Plot characteristics . . . . . . . . . . . . . . . 42

3.2.1 Identification of Burned Areas . . . . . . . . . . . . . . . . . . 42

3.2 .2 Plot Layout . . . . . . . . . . . . . . . . . . 46

3.3 Forest Structure . . . . . . . . . . . . . . . . . . . . . . . . . . 49

3.3.1 Diameter Distribution . . . . . . . . . . . . . . . 49

3.3.2 Stand Height . . . . . . . . . . . . . . . . . . . . 50

3.3.3 Mean Height . . . . . . . . . . . . . . . . . . . . 50

3.3.4 Stand Density . . . . . . . . . . . . . . . . . . 50

3.3.5 Stand Volume . . . . . . . . . . . . . . . 51

3.3.6 Importance Value Index (IVI) . . . . . . . . . . . . . . . 52

3.4 Estimation of the Potential Solar Radiation . . . . . . . . . . . 53

3.5 Measurement of Ecological Diversity . . . . . . . . . . . . . 54

3.5.1 Alpha Diversity $(\alpha) \ldots \ldots \ldots . \ldots . \ldots 54$

3.5.2 Beta Diversity $(\beta) \ldots \ldots \ldots 56$

3.6 Multivariate Analysis and Statistics . . . . . . . . . . . . . . 58

3.6.1 Multivariate Analysis . . . . . . . . . . . . . . 58

3.6 .2 Statistics . . . . . . . . . . . . . . . 61

4 Results $\quad 63$

4.1 Fire Chronology Based on Fire Scars . . . . . . . . . . . . . . . 63

4.2 Fire Cohorts . . . . . . . . . . . . . . . . . . . 64

4.3 Forest Structure . . . . . . . . . . . . . . . . . . . . . 65

4.3 .1 Mean Diameter $(\bar{d}) \ldots \ldots . \ldots . \ldots 65$

4.3 .2 Mean Height $(\bar{h}) \quad \ldots \ldots . \ldots . \ldots 67$

4.3.3 Stand Density and Volume . . . . . . . . . . . . 68

4.3.4 Importance Value Index (IVI) . . . . . . . . . . . . . . . 70

4.4 Potential Solar Radiation . . . . . . . . . . . . . . . . . . 77

4.5 Changes in Species Diversity . . . . . . . . . . . . . . 80

4.5.1 Alpha Diversity . . . . . . . . . . . . . . 80

4.5.2 Species Abundance Models . . . . . . . . . . . . . . . 87

4.5 .3 Beta Diversity . . . . . . . . . . . . . . . . . . . 92 
4.6 Multivariate Analysis . . . . . . . . . . . . . . . . . . . 97

4.6.1 Classification . . . . . . . . . . . . . . 97

4.6 .2 Ordination . . . . . . . . . . . . . . . 102

4.6.3 Direct Gradient Analysis . . . . . . . . . . . . . . . . 106

5 Discussion 111

5.1 Fire History and Management Implications . . . . . . . . . . . . . . 111

5.2 Changes in Forest Structure after Fire . . . . . . . . . . . . . . . 117

5.3 Forest Biodiversity . . . . . . . . . . . . . . . . . . . . . . 120

5.4 Multivariate Analysis and Factors Influencing Succession after Fire . 124

$\begin{array}{llr}6 & \text { Summary } & 129\end{array}$

$\begin{array}{lll}7 & \text { Zusammenfassung } & 135\end{array}$

$\begin{array}{ll}\text { A Tables } & 143\end{array}$

$\begin{array}{ll}\text { Bibliography } & 147\end{array}$

$\begin{array}{ll}\text { Curriculum vitae } & 163\end{array}$ 



\section{List of Figures}

2.1 Possible variations in group of individuals (cohorts) . . . . . . . . . 9

2.2 Visible traces left by fires on Pinus teocote and Quercus sp. . . . . . . 10

2.3 Process of fire scars on the tree stem and disk with several fire scars. 11

2.4 Sequence of fire scars observed in a disk . . . . . . . . . . . . . . . 11

2.5 A scar-boring procedure for a tree with a single visible fire-scars. . . . 12

2.6 Types of vegetation in Mexico . . . . . . . . . . . . . . . . . 16

2.7 Comparison of burned areas in $1998 \ldots \ldots \ldots$. . . . . . . . 17

2.8 Forest fire statistics in Mexico from 1970 to 2004 . . . . . . . . . . . 18

2.9 Detection of hot spots by satellite images . . . . . . . . . . . . . 19

2.10 Causes of wildland fires in Mexico . . . . . . . . . . . . . . 20

2.11 An hypothetical curve for species richness, as a function of time after fire. . . . . . . . . . . . . . . . . 25

2.12 Alternatives within phases for $S$-t curves . . . . . . . . . . . 26

2.13 Abundance rank curves showing typical shape of four abundance models 27

2.14 Three models of change in plant species diversity with time after disturbance. . . . . . . . . . . . . . . . . . 30

2.15 Illustration of the three components of radiation. . . . . . . . . . . 32

3.1 Satellite image of Mexico with the localization of the study area . . . 38

3.2 Climatic diagram for Monterrey based on Walter and Lieth, 1967 . . 40

3.3 Schematic representation of stand structure as a function of the stand age ................................ 42

3.4 Location of the plots where post-fire succession is studied in the Ecological Park Chipinque. . . . . . . . . . . . . . . . . . . . . 44 
3.5 Transects in the delimited burned area. Traces of fire were marked and core samples were obtained from the oldest individuals of Pinus teocote and Pinus pseudotrobus. . . . . . . . . . . . . . 45

3.6 Plot layout for concentric circular sampling plots. . . . . . . . . . . . 47

3.7 Concentric circular sample plots design. . . . . . . . . . . . . . . 48

4.1 Reconstructed master fire chronology for the PECH from 1868 to 2002.63

4.2 Condition of a burned areas in the $\mathrm{PECH} \ldots \ldots$. . . . . . . . . . . 64

4.3 Diameters histograms for each post-fire cohorts on both slopes sides. . 66

4.4 Height histograms for the post-fire stands PECH-098 and PECH-084. . 67

4.5 Height histograms for the post-fire stands PECH-072 and PECH-040. . 68

4.6 Changes in abundance of selected species in time after a forest fire. . 76

4.7 Variations of potential solar radiation over the year and the vegetation period over the north and south-facing slopes . . . . . . . 78

4.8 Maps of Potential Solar Radiation for the PECH _ . . . . . . . . . . 79

4.9 Species rank abundance curves for the north and south-facing slopes for the post-fire cohort PECH-098. . . . . . . . . . . . . . 82

4.10 Species rank abundance curves for the north and south-facing slopes for the post-fire cohort PECH-084. . . . . . . . . . . . . 83

4.11 Species rank abundance curves for the north and south-facing slopes for the post-fire cohort PECH-072. . . . . . . . . . . . . . . 84

4.12 Species rank abundance curves for the north and south-facing slopes for the post-fire cohort PECH-040 . . . . . . . . . . . 85

4.13 Species rank abundance curves for the north -facing slope for the postfire $\mathrm{PECH}-868 \ldots \ldots$. . . . . . . . . . . . . . . . . . . . 86

4.14 Species abundance at the post-fire cohort PECH-098 and the shape of the four abundance models. For abbreviations c.f. Table A.2 . . . . . . . .

4.15 Species abundance at the post-fire cohort PECH-084. and the shape of the four abundance models. For abbreviations c.f. Table A.2 . . . . . . . .

4.16 Species abundance at the post-fire cohort PECH-072 and the shape of the four abundance models. For abbreviations c.f. Table A.2 . . . . . . . . 91

4.17 Species abundance at the post-fire cohort PECH-040 and the shape of the four abundance models. For abbreviations c.f. Table A.2 . . . . . . . . 91 
4.18 Species abundance at the post-fire cohort PECH-868 and the shape of the four abundance models. For abbreviations c.f. Table A.2 . . . . . . . . 92

4.19 Connectedness and minimum spanning tree for similarities for both slopes and post-fire cohort. . . . . . . . . . . . . 96

4.20 Dendrogram of hierarchical cluster classification for the post-fire cohorts and species . . . . . . . . . . . . . . . . . . . . . 98

4.21 Dendrogram of hierarchical cluster classification for south facing slope. 99

4.22 Dendrogram of hierarchical cluster classification for both the northand south-facing slopes. . . . . . . . . . . . . . . . . 101

4.23 DCA ordination diagram for stands and species for the north-facing slopes. . . . . . . . . . . . . . . . . . 103

4.24 DCA diagram for the post-fire cohorts and species for the south-facing slope. . . . . . . . . . . . . . . . . . . 105

4.25 CCA diagram for the post-fire cohorts and species for the $\mathrm{PECH}$, north and south-facing slope. For abbreviations c.f. Table A.2 . . . . . . 108 



\section{List of Tables}

2.1 Classification of fire regimes based on wildland fire frequency and intensity .......................... 7

3.1 Important species of flora present in the Park . . . . . . . . . . . . . 41

3.2 Characteristics of five fire history sites in the PECH. . . . . . . . . . . 46

3.3 The Measures of alpha diversity . . . . . . . . . . . . . . . . . . 55

4.1 The mean diameters $(\bar{d})$ in $\mathrm{cm}$ of the post-fire cohorts on both, north and south-facing slopes. . . . . . . . . . . . . . .

4.2 The mean height $(\bar{h})$ of the post-fire cohorts on both north and southfacing slopes. . . . . . . . . . . . . . . 67

4.3 Basal area and tree number per hectare in post-fire cohorts. . . . . . 69

4.4 Calculated Importance value indices (IVI) for north-facing slopes. . . 70

4.5 Calculated Importance value indices (IVI) for south-facing slopes. . . 71

4.6 Horizontal distribution and silvicultural importance of species in the PECH. . . . . . . . . . . . . . . . . . 73

4.7 Potential solar radiation (latitude $25^{\circ}$ ) in the PECH. . . . . . . . . . . 77

4.8 Diversity indices of the post-fire stands located on north- and southfacing slopes. . . . . . . . . . . . . . . . . . . 81

4.9 Fit of four abundance models in the post-fire cohorts . . . . . . . . 88

4.10 Complexity index (CI) and it components in both north and southfacing slopes of the PECH. . . . . . . . . . . . . . . . . . .

4.11 Sorensen quantitative index, based on the number of species for both, north and south-facing slopes. . . . . . . . . . . . . . . . .

4.12 Eigenvalues defining the detrended correspondence analysis and correlations for the species and post-fire stands for the north-facing slope. 
4.13 Eigenvalues defining the detrended correspondence analysis and correlations for the species and post-fire stands for the south-facing slope. 104

4.14 Summary statistics for canonical correspondence analysis. . . . . . . . 106

4.15 Summary statistics for canonical correspondence analysis of species abundance and environmental variables. . . . . . . . . . . . . 107

A.1 Occurrence of the species recorded on both north- and south-facing slopes during 1860-1998. . . . . . . . . . . . . . . . . . . 144

A.2 Scientific names and abbreviations . . . . . . . . . . . . . 145 


\section{Acknowledgments}

First of all, I express my thanks to the numerous people who helped me to realize my doctoral dissertation with success.

Every research cost money and without financial support it would have been very difficult to continue my professional career. The funding for my Ph.D.-Studies was provided by the Mexican National Council for Science and Technology (CONACYT). The contact with the CONACYT-Team was always pleasent and people have demonstrated their understanding for some critical situations. Furthermore I express my thanks to the German Academic Exchange Service (DAAD) for financing my German language course at the Goethe Institute in Göttingen over six months. I appreciate especially the help of Ms. Büchel, who was my contact at the DAAD and always at my disposal. She contributed amongst other things to the good communication with CONACYT in Mexico.

For professional advice and expertice, I express my thanks and appreciation to Prof. Dr. Burkhard Müller-Using. He iniciated my doctorate in Germany and his professional feedback was always important for the progress of my thesis, even if it was often difficult to communicate with him over the Atlantic.

For his spontanous deputize, I thank very much Prof. Dr. Burghard von Lüpke, Institute of Silviculture, who represented Prof. Müller-Using in my final examination. Furthermore, he provided not only an office but also equipment and infrastructure, that were decisive for the optimal development of my dissertation.

A deep thank goes to Prof. Dr. h.c. Klaus von Gadow, Institute of Forest Management, and Prof. Dr. Gode Gravenhorst, Institute of Bioclimatology, for having reviewed my work and for having been fair examiners in my final examination.

For the most part of my academic career, I have to thank Prof. Javier Jiménez Pérez. He encouraged me strongly to participate in the Ph.D.-Program in Germany. A really 
good advice, since I was able to broaden my horizons studying abroad. Moreover, he contributed to the carrying out of the field work, not only by providing equipment and a competent field crew, but also with valuable ideas.

The permission from Ing. Jorge Garza Esparza, former Director of the Ecological Park Chipinque, is also appreciated. He showed great interest in the research and data collection within the Park, which motivated me strongly.

Special thanks and appreciation go to Dr. Luitgard Schwendemann, whose criticism and good advice contributed considerably to the successful outcome of my thesis. She was always available for discussion, consultancy and proof-reading. Without her effort, I would not have been able to finish my thesis in the given period of time.

Dr. Rainer Schulz has contributed with his expertice in GIS and Digital Terrain Models to important parts of my thesis. A great thank you to him for his remarkable patience and support.

This work could not have been completed without the invaluable help of my enthusiastic collegues and friends at the Faculty of Forestry in Linares, who spent days with me in the forest collecting the data for my research. Their enormous patience and resourcefulness in dealing with unexpected events often encouraged me to continue with the research work.

A heartfelt thank you to my parents, Marco Aurelio González Acevedo and Juana Inés Tagle Beltrán, who always cared for my professional career, even in difficult times, and encouraged me to follow my plans and to make my dreams come true. With their open minded attitude, they represented great examples and laid the foundations for my curiosity and courage to take up new challenges.

An immense and particular thank you to my girlfriend Wibke Himmelsbach for her strong support and understanding in extreme situations, especially during the final stage of my thesis. Taking her precious and invalubable time for an excellent review and linguistic corrections, she furthermore contributed mainly with her professional expertice and - sometimes hard - criticism to the improvement of my thesis.

Finally, special thanks to all the friends who have supported me throughout my Ph.D.-Studies. Some good idea came by diverting myself with them and their good humor contributed definitively to my pleasant life in Göttingen. 


\section{Glossary}

Biplot: An ordination diagram which simultaneously plots species scores and sample scores.

Digital elevation model (DEM): A computer representation of the earth's surface, and as such, provides a base data set from which topographic parameters can be digitally generated.

Environmental Gradient: A spatially varying aspect of the environment which is expected to be related to the species composition.

Environmental Variable: The straight line distance between two points in a Cartesian coordinate system.

Fire Behavior: The manner in which a wildland fire reacts to the influences of fuel, weather, and topography.

Fire management: The activities concerned with the protection of people, property, and forest areas from wildland fire and the use of prescribed burning for the attainment of forest management and other land use objectives, all conducted in a manner that considers environmental, social, and economic criteria.

Flaming front or fire front: That zone of a moving fire where the combustion is primarily flaming. Behind this flaming zone, combustion is primarily glowing or involves the burning out of larger fuels (greater than about 3 inches in diameter). Light fuels typically have a shallow flaming front, whereas heavy fuels have a deeper front.

Forest fire: An uncontrolled wildland fire on lands covered wholly or in part by timber, brush, grass, grain, or other flammable vegetation. Types of forest fires are ground, surface, and crown fires. 
Heavy fuels: Fuels of large diameter such as snags, logs, and large limbwood, which ignite and are consumed more slowly than flash fuels. Also called course fuels.

Hot spot: The minimum spatial element in the image (pixel) reporting an elevated temperature. With night images, the minimum value to consider a pixel a heat point is $25^{\circ} \mathrm{C}$. In the case of day images, the minimum temperature is $38^{\circ} \mathrm{C}$. Therefore, a hot spot is any source of elevated temperature (above $38^{\circ} \mathrm{C}$ and significantly higher than background temperature), that is strong enough to be detected by a satellite sensor.

Light (fine) fuels: Fast-drying fuels, generally with a comparatively high surface area-to volume ratio, which are less than $1 / 4$ inch in diameter and have a timelag of 1 hour or less. These fuels readily ignite and are rapidly consumed by fire when dry.

Natural fire: Of natural origin (such as lightning) and not human-caused.

Sample score, Site score, Stand score: A coordinate along an ordination specifying the location of a sample.

Species score: A coordinate along an ordination axis specifying the location of a species. In weighted-averaging ordinations methods such as CCA and DCA.

Wildfire: A fire occurring on wildland that is not meeting management objectives and thus requires a suppression response.

Wildland: An area in which development is essentially non-existent, except for roads, railroads, powerlines, and similar transportation facilities. Structures, if any, are widely scattered.

Wildland fire is any fire occurring in the wildlands, regardless of ignition source, damages, or benefits.

Wildland/Urban interface is the line, area, or zone where structures and other human development meet or intermingle with undeveloped wildland or vegetative fuels. 


\section{Chapter 1}

\section{Introduction}

Scientific investigations on wildland fires are carried out in many countries, especially in the USA, Canada and Australia. These countries have developed strategies to manage and suppress wildland fires, but have also learned to accept wildland fires as a natural occurrence that must be integrated into restoration programs, conservation, and management. In contrast, the ecology of wildland fires and their impact on Mexican mixed forest ecosystems has hardly been investigated. Hence, there is a great demand for research on wildland fires in Mexico (Jardel 2003, Jiménez 1997, Rodriguez-Trejo 2003) [74, 77, 125].

Nowadays, human activities influence natural fire regimes by increasing fires in forest that would seldom burn under natural conditions, and by suppressing natural fire, which causes ecological impacts that lead to infrequent, catastrophic fires due to a build up of flammable material (Arborvitæ 2003) [155].

A higher frequency of wildland fires due to human activities is certainly the case in many mixed pine-oak forests in Mexico (Rodriguez-Trejo 2003) [125]. These pineoak forests are exposed to a large number of anthropogenic and a small number of occasional natural fires (Rodriguez-Trejo and Fulé 2003) [126]. Since the extraordinary fires in 1998, the government and professional foresters have expressed the need for research and experimentation on wildland fire management and its influence on Mexican forest ecosystems (Jardel 2003, Rodriguez-Trejo 2003) [74, 125]. This investigation is focusing on post-fire conditions and biodiversity, especially with respect to the influence of wildland fire at different temporal and spatial scales, as a contribution to the experiences and information in Mexican forests. 
Pine-oak forests cover a great part of the mountain range "Sierra Madre Oriental", which reaches from northeast Mexico (Nuevo Leon) to southern Mexico (Veracruz) at an altitude between 1,000 and 3,500 m above sea level. Conifers like Pinus nelsonii, P. cembroides, P. pseudostrobus, and P. arizonica and deciduous trees like Quercus castanea, Q. affinis, and Q. virginiana are representative species for the mountainous forests of the Sierra Madre Oriental (Müller-Using 1994) [102].

Extraction and agricultural activities are, or rather were, extensive in the native pine-oak forests. Therefore, protected areas have been established in this ecoregion. The Ecological Park Chipinque (PECH), is one of the completely protected areas and part of the National Park "Cumbres de Monterrey", which is, with an extension of $2,465 \mathrm{~km}^{2}$, one of the largest national parks in Mexico. Due to its high protection status and the occurrences of wildland fires, the PECH provides an excellent opportunity to investigate and evaluate natural post-fire succession.

Ecological succession is influenced by many factors. With regard to fire ecology, solar radiation is one important factor and fundamental for physical and biophysical processes. Insolation has an influence on energetic processes on the earth's surface, such as air and soil heating, evapotranspiration, and photosynthesis. At landscape scales, topography is the main factor modifying the distribution of radiation. Different gradients in altitude, surface orientation (slope and aspect), and obstruction by surrounding topographic features generate strong local gradients of insolation (Fu 1999) [45]. This research aims to describe and discuss ecological processes after a wildland fire, in order to contribute to the understanding of biodiversity patterns and the way in which physical conditions may affect the rate of vegetation recovery in pine-oak forests in northeast Mexico.

\subsection{Research Gaps and Objectives}

The pine-oak forests in northern Mexico have important ecological and social functions. On one hand, they prevent erosion and protect valuable water reservoirs. On the other hand, they produce valuable timber and provide nearby recreation areas for the local population. As long as humans have been using natural resources, they have left behind a trail of degraded and diminished landscapes. Rehabilitation of these landscapes started as soon as human beings figured out that land and resources 
are not inexhaustible, and that we had to repair some of the damage. During the last decades, the mixed pine-oak forests were managed without full knowledge of the facts of forest fire ecology. High budgets were assigned to restoration activities and no follow up studies were made in burned areas. It is important to investigate the ecological processes after wildland fires, in order to develop sustainable forest management strategies for Mexican pine-oak forests. The Ecological Park Chipinque has a protected status; there have been no logging activities carried out for about 16 years and the anthropogenic influence is minimal. Due to its protection status, the PECH provides an excellent research area for the evaluation of succession and changes in species composition after a forest fire event. Owing to the current state of knowledge and the increasing demand for detailed information about wildland fires in Mexico, this research will describe and generate information with regard to forest fire ecology, including natural succession and biodiversity in pine-oak forests in northeast Mexico. The scope of this research is divided in two sections:

1. Documentation of forest fire frequency in pine-oak forests using dendrochronological analysis.

2. Evaluation of forest succession patterns after a forest fire.

(a) How does succession take place in different plant communities after forest fires, distinguishing between north- and south-facing slopes?

(b) How do environmental factors (potential solar radiation) affect the species richness and the composition of a pine-oak forest?

To answer these questions, the spatial-temporal variation of species and density of forest on both north- and south- facing slopes were monitored in the Ecological Park Chipinque. 


\section{Chapter 2}

\section{Literature Review}

\subsection{Fire Ecology}

The wildland fire disturbance factor is present in many landscapes all over the world and is part of forest ecosystem dynamics as well as the evolutionary environment (Goldammer 1996) [62]. According to intensity, frequency, and physical characteristics of the landscape or ecosystem, wildland fire is (along with other biotic conditions), a factor that shapes the species composition, age, and canopy structure of many ecosystems (Agee 1993, Fall 1998, Johnson 1992, Norton 2003, Pyne 1996, Thonicke 2001, Whelan 1995) [1, 38, 79, 105, 122, 144, 152]. The potential force of a wildland fire turns it into a complex phenomenon, which, if employed (or excluded) without adequate knowledge, can threaten the biological productivity, biodiversity, and sustainability of ecosystems (World Conservation Union 2003) [155].

\subsubsection{Fire Ecology, Terms and Classification}

To understand the effects of this natural force on ecosystems, scientists and fire managers have created a new discipline, "fire ecology", in order to consider both practical and scientific experiences concerning wildland fire (Goldammer 2003) [60].

According to the "Pacific Biodiversity Institute" (2003) [111] Fire ecology is a branch of ecology that studies the origins of wildland fires and their relationship to the living and nonliving environment. In fire ecology there are three key concepts to understand: fire history, fire regime, and fire dependence. 
Fire history is the way fires have historically behaved and how fire seasons are distributed (Pyne 1984) [123]. A fire history consists of events; such an event in the history of a specified area is referred to as a fire occurrence. The number of years between two fire occurrences is considered a fire interval. The average of all fire intervals within a specified area and designated time period is the mean fire interval. The number of fire occurrences per unit time in some specified area is the fire frequency. When all fire occurrences are assembled into a general time frame, a master fire chronology is created.

The necessary data for the reconstruction of a fire history is derived from the components of a fire regime, which describes a pattern of wildland fires occurring over time or periods and the immediate effects of these fires on the ecosystem (Agee 1993, Pyne 1996) [1, 122]. Once the historical fire regime for a particular ecosystem or set of ecosystems is defined, the occurrence of fire can be calculated and it can be determined whether the fire occurrence in an area is increasing or decreasing (Caprio 1993, 2000) $[20,21]$.

Heinselman (1981) [122] developed a classification of wildland fire regimes for specific ecosystems in North America, which is based on the combination of the wildland fire history data (fire frequency or return interval) and the description of fire intensity. Heinselman's scheme has been widely accepted as a basic system for describing the nature of historic wildland fires. Heinselman's classification of fire regimes is shown in Table 2.1 .

In the past, forests were burned and converted into agricultural fields in China and Europe. In Australia, America, and Africa, fire was a tool used to clean grasslands (Nature Conservancy 2003) [143]. Today, fire is still used in traditional land-use systems, such as agriculture and pastoralism. Consequently, the natural fire regimes have been severely altered (Goldammer 2003, 2004) [60, 61]. For humans, altered fire regimes can have an impact on natural resources, for example water supply and forest products. In nature, this alterations of fire regimes can cause damages or losses of fire-dependent species (Goldammer 2004) [61].

Some tree species in North America are know to be fire dependent, for example, Jack pine (Pinus banksiana) and lodgepole pine (Pinus contorta). They have serotinous (late-opening) cones. While closed, these cones hold a viable seed bank in the canopy that remains protected until fire appears in the area. After a fire, the cone 
Table 2.1: Classification of fire regimes based on wildland fire frequency and intensity (Heinselmann, 1981) [122].

\begin{tabular}{ccl}
\hline Fire regime & Fire frequency & Description \\
\hline 0 & No natural fire & no natural fire \\
1 & $>25$ years & infrequent light surface fires \\
2 & $1-25$ years & frequent light surface fires \\
3 & $<25$ years & infrequent, severe surface fires \\
4 & $25-100$ years & combination of short return in- \\
& & terval crown fire and severe \\
& & surface fires \\
& & combination of long return in- \\
5 & $100-300$ years & terval crown fires and severe \\
& & fires \\
& & combination of very long re- \\
6 & & turn interval crown fires and \\
& &
\end{tabular}

scales open, releasing the seeds into a freshly prepared ash bed. Other adaptations, such as thick bark, enables a species to withstand recurrent low intensity fires. Many plant species also have the ability to resprout after being burned, either from the rootstock or the stem (Agee 1993) [1]. An example is the Mountain ash (Eucalyptus regnans), a eucalyptus species of temperate Australia that requires a site that has burned completely and is exposed to full sun in order to regenerate prolifically (IUCN 2000) [98].

\subsubsection{Inferences of Fire Occurrence}

Many techniques and methods have been developed for the detection of historic forest fires. As a first step, main indicators for past forest fires are:

- Age-class evidence: plants that appear to have germinated after forest fires and form even aged stands, so called post-fire cohorts,

- Charcoal which can be found in the surface soil, often in contact with the roots of the current stand, 
- Black burnt spots or charcoal on the stems of living trees, so called bole scars (Agee 1993, Fall 1998) [1, 38].

Furthermore, inferences of fire occurrence may also be made from charcoal rests on the stems of living trees, depending on the species characteristics. Based on evidence from stands in the Olympic Mountains, charcoal on the bark of coastal Douglas-fir, for example, remains for centuries. Hence, occasional residual trees in 200 year old stands still show substantial charcoal on their bark, which was caused by the fire that once created the stand (Agee 1993) [1]. In contast, vigorous individuals of Ponderosa pine may loose most of their burnt bark within several years; therefore almost no forest fire evidence may be found at the trees a few years later. In this case, the occurrence of past forest fires must be established by finding charred bark plates on the forest floor (Agee 1993) [1].

\section{Post-Fire Cohorts}

Plant populations are often divided into subpopulations called cohorts, which are homogeneous regarding their time of origin (Johnson 1992) [78]. In the case of postfire cohorts, a forest stand was burnt almost completely due to an intensive forest fire. That means, just a few trees survived the fire and forest restoration or succession started from zero. Consequently, the form of the new, young stand is homogeneous and even-aged a few years after fire occurrence, since most of the stand's trees started growing at the same time. Only in time do forest stands become more heterogeneous with regard to tree height, diameter, and age (Fig. 2.1).

Even aged forest stands are not necessarily post-fire cohorts. Therefore, identification of even-aged stands is not sufficient to determine forest fire occurrence; however it is important and helpful, in detecting formerly burnt forest stands especially at the beginning. Nevertheless, further methods must be employed to identify fire cohorts with certain.

When completely burnt forest areas are overlapping, having been burnt by forest fires occurring at different points in time. It is not possible to determine if the more recently burnt area was also affected by a former forest fire. In other words, the lack of a scar could be the result of: (a) the area not having been burnt, (b) past forest fires having left no records because they were superficial and of low intensity, (c) the 



Figure 2.1: (a) An even-aged cohort which arose after an intense fire. (b) A series of separate cohorts which arose after low intensity fires. (c) Mixture of uneven-aged cohorts (d) Multi-aged cohorts in open stands with vegetative reproduction (Johnson 1992).

scars recorded in the year rings not being included in the core samples, or (d) scarred trees being destroyed by subsequent forest fires.

These facts are important with regard to the reconstruction of the fire history by the employment of forest fire chronology or year ring analysis. These methods only include the past forest fire events that are recorded in the year rings of surviving trees. Frequent, intensive forest fires that occur in the same area but at different points in time and that destroy the whole forest stand can not be detected by these methods. Consequently, these forest fires are not included in the fire history. Therefore, the reconstructed fire history may represent only a minimal number of forest fires occurring in the area. However, the possibility of missing forest fire events in the fire history of an area is not disturbing, as it does not negatively affect the investigation on forest succession after forest fires.

\section{Bole Scars}

Formerly burned forests can also be identified by searching the stand's tree for fire marks. Trees which survive may show visible traces of fire on the stem, so called bole scars (Agee 1993) [1]. Bole scars are specific fire scars visible at a tree's surface (Fig. 2.2). 




Figure 2.2: Visible traces left by fires on Quercus sp. and Pinus teocote present in the stands.

In natural fire ecosystems, like the Mexican pine-oak forests, trees are protected against fire by their bark. A bole scar is, therefore, only caused by high heat that penetrates the bark and kills part of the cambium. Maximum temperatures arise at the bole on the opposite of the fire direction, since the heat of a fire persists around the tree bole and meets at the backside of the stem, the point of maximum heat. Thus, bole scars give also information about the direction of the past forest fire (Fig. 2.3).

Bole scars do not provide information about the frequency of forest fires or the year they occurred. However, precise information about the number of forest fires and their point in time is a precondition for the reconstruction of forest fire history.

\section{Fire Scars and Tree Ring Analysis}

Fire scars are an excellent source of fire frequency data and their interpretation is a widespread method for the reconstruction of wildland fire history worldwide, especially in Canada and the United States of America (Agee 1993, Brown 1999, 1999a, 1994 Fulé 1994, Stephens 2003, 2001) [1, 13, 14, 16, 47, 136, 137]. 


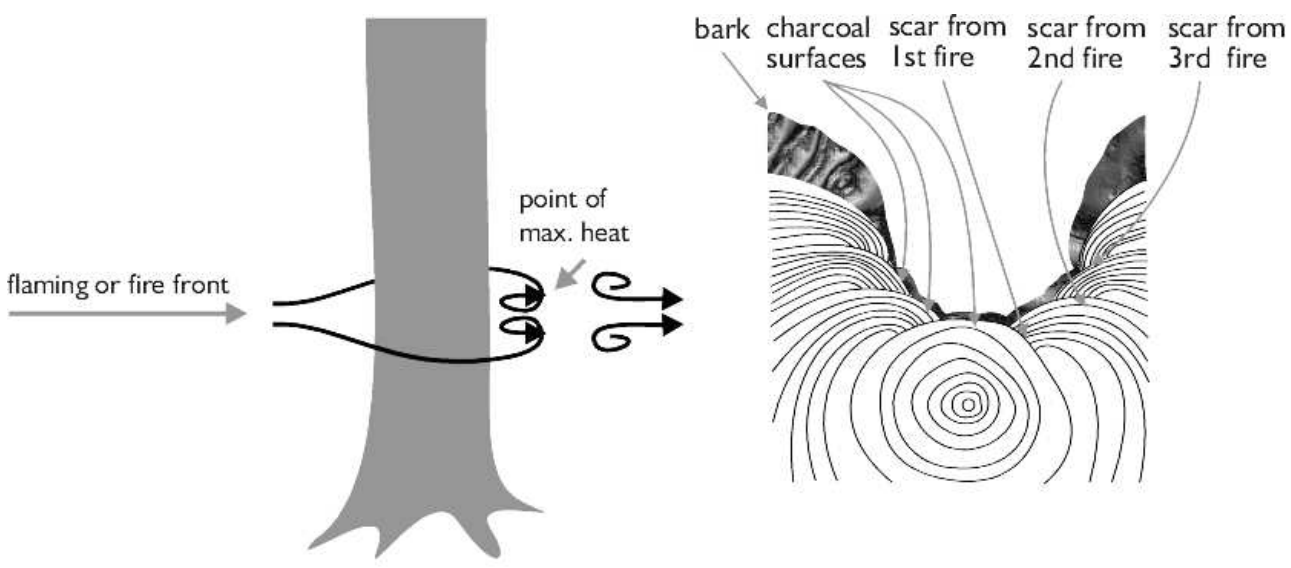

Figure 2.3: Process of fire scars on the tree stem and disk with several fire scars.

Like bole scars, fire scars are also caused by high heat, which kills the cambial tissue along a portion of a tree's growing circumference. In contrast to bole scars, fire scars are not necessarily visible on the surface of a tree's stem, even though they do exist. The adjacent live cambium of a fire injured tree expands slowly over the surface of the burned area and may eventually close the cambial lesion completely. In this case, fire scars are not visible on the tree's surface, but the burned tissue is recorded as a dark and dense mark (tip) in the year rings (Fig. 2.4) (Agee 1993, Brown 1993, Swetnam 2000, 2001) [1, 16, 140, 141].
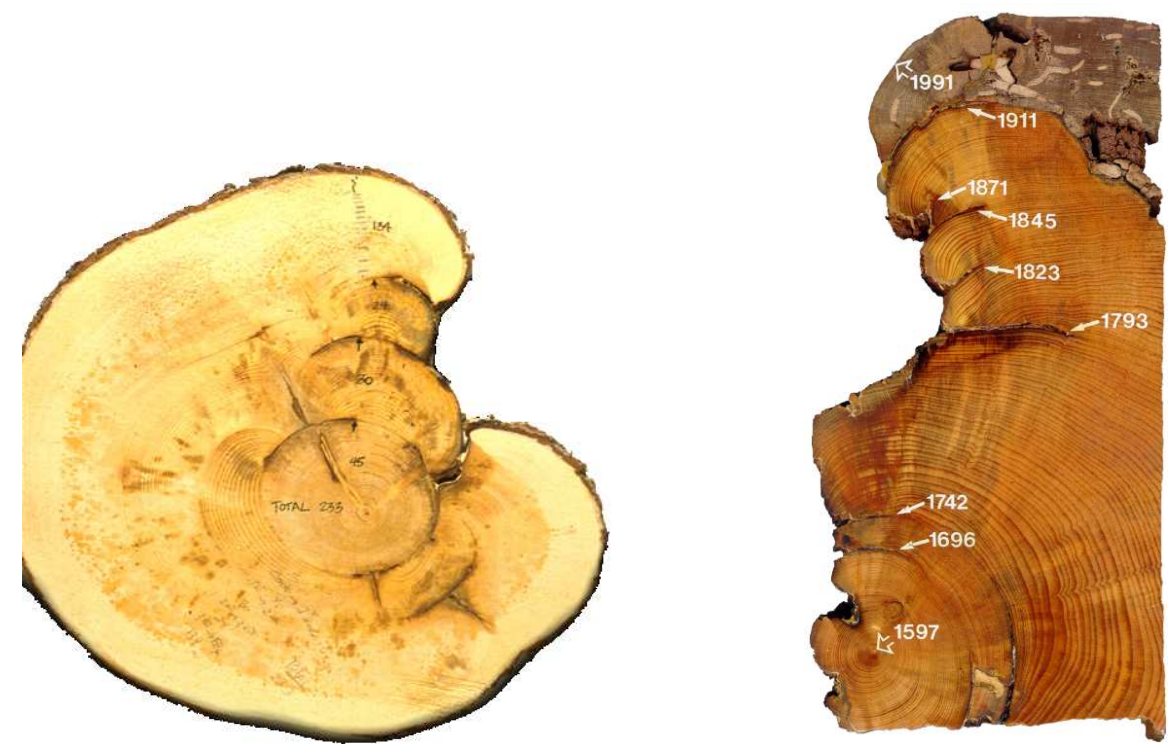

Figure 2.4: Several forest fires caused a sequence of fire scars in the disk. 
Precise years of past fire events can be established by the interpretation of fire scars recorded in tree rings. Scientific studies in the western USA have proved the high resolution and precision of this method by estimating past fire occurrences over a period of 300 to 400 years (Heyerdahl et al. 1995, Skinner 1996) [66, 134]. However, it is important to make sure that a scar was caused by fire (Agee 1993) [1].

In order to acquire info about tree scars, core samples or stem disks are taken from fire scarred trees. Stem disks can only be extracted by cutting the tree, whereas core samples can be taken without killing the tree or causing great damage. Stem disks have the advantage that all characteristic lesions due to past fires are recorded. Core samples, in comparison, do not necessarily include all the records of past fire events, because the flaming front of different fires do not always have the same direction (Fig. 2.4). Especially in mountainous areas, forest fires tend to burn uphill, causing fire scars on the hillside of the stems (Swetnam 2001) [140].

In this reagrd, core samples are best taken from the sides of a bole scar to make sure that all possible scars are included in the sample. Furthermore, the sample should include the first year ring, otherwise it is not possible to determine the tree's age and the exact time that the forest fires occurred (Fig 2.5).
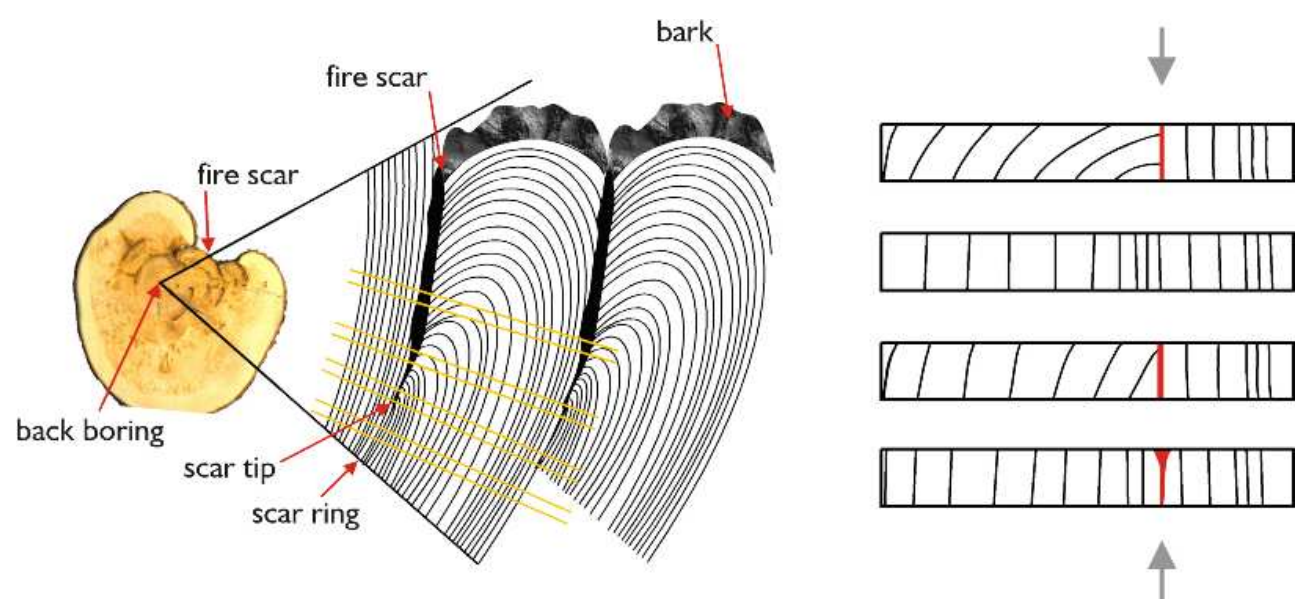

Figure 2.5: A scar-boring procedure for a tree with a single visible fire-scars.

Figure 2.5 should make this method more clear. On the opposite side from where the sample was taken, another year ring shows a scar which is not included in the sample. This is a disadvantage of this method. 


\subsubsection{Wildland Fire Within the International Context}

At present, most wildland fires worldwide are caused directly or indirectly by humans. This assertion is confirmed by international statistics, which show that more then $90 \%$ of the wildland fires registered around the globe are attributed to anthropogenic causes (Goldammer 2004) [61]. In the last century, most of the forests around the world have become increasingly accessible to humans, resulting in natural resource exploitation and recreation (Goldammer 2003) [60].

For instance, in Boreal forests, the occurrence of fire is a natural part of the ecosystem and has some particular characteristics. The Boreal forest exists as a nearly continuous belt of coniferous trees across North America and Eurasia and covers approximately 12 million $\mathrm{km}^{2}$. The Boreal forest of Canada is divided into six sub-regions based on distinctive climate, topography, soil, and vegetation (Dry Mixedwood, Central Mixedwood, Wetland Mixedwood, Boreal Highlands, Peace River Lowlands, and Subarctic). These regions present different fire regimes (Parks and Protected Areas of Canada - internet source 2004) [4]. The largest boreal forest fires are extreme events of high-intensity, due to their high rate of propagation and intensive levels of fuel consumption.

In Eurasia, wildland fire has been an important tool for land clearing (conversion of boreal forest), silviculture (site preparation and improvement), and agricultural systems for a long time (Goldammer 1996) [62].

Forest fires in tropical evergreen forests are considered under natural conditions to be impossible, inconsequential or at least rare enough to play an important role in the ecosystem (Arborvitæ 2003) [155]. The tropical evergreen forests grow in a band around the earth between the Tropic of Capricorn (about $23^{\circ} \mathrm{S}$. latitude) and the Tropic of Cancer (about $23^{\circ} \mathrm{N}$. latitude). The major continental jungles are found in Central America and the northern half of South America, in the central two thirds of Africa, in India and Southeast Asia. In recent decades, due to population growth and economic necessity, rainforest conversion to rangeland and agricultural systems has proliferated throughout the tropics (Müller-Dombois 1990) [101]. The slash and burn practice involves cutting rainforests to harvest valuable timber, and then burning the remaining biomass repeatedly to convert the landscape into permanent grassland agriculture (Goldammer 2003) [60]. 
The mixed-conifer forests are the most complex set of forest types, because they include a wide variety of coniferous and hardwood tree species (Agee 1993) [1]. They differ in their specific mix of species, their fire regime, and the successional patterns after forest fires. For instance, in most of the drier forest types located in the western United States, lightning is a common factor of ignition. The variable fire history in these areas, together with complex geology, land use history, and the rough environmental gradients has prevented generalizations about fire and its ecological effects. An example is the chaparral vegetation that coexists with coniferous dry forests in southern California. These forests have a high incidence of forest fire, which can often replace forest with grass. Less frequent burning can expand the rang of the brush, change the composition, and consequently change the fire regime of dry forest (Pyne 1984) [123]. Throughout western North America and northern Mexico, the exclusion of fire associated with Euro-American settlement caused a shift from open forest to dense forest. This change has caused the fire regime to shift from frequent fires with low intensity to a regime of large and severe crown-fires (Fule 1994) [47]. 


\section{$2.2 \quad$ Forest Fire Situation in Mexico}

\section{Mexican Biodiversity}

There are more than 170 countries in the World. Out of these, 12 alone harbor between 60 and $70 \%$ of the total biodiversity of the planet and thus earn the privilege to being called megadiverse. With a territorial extension of $1,964,375 \mathrm{~km}^{2}$, Mexico is (together with Brazil, Colombia and Indonesia), at the very top of the list, taking first place in reptile diversity, second for mammals, fourth for amphibians and vascular plants and tenth for birds. It is estimated that more than $10 \%$ of all the species in the world live in Mexico $\left(\mathrm{CONABIO}^{1} 2002\right)$ [24]. The complex topography of the country, and the changes running along the latitudinal continuum create an enormous number of environmental variants. The changes in altitude produce climatic variations such as the intensity of solar radiation, atmospherical humidity, and diurnal oscillation of temperature (CONABIO 2002) [24].

\section{Natural Resources Framework}

Coniferous forest dominated by pines, mixed conifer-hardwood forest, and hardwood forest cover 32.8 millon ha. If tropical rain forest is included, about 50 millon ha of the land is covered by forest (Fig. 2.6). Around $80 \%$ of the forest surface belongs to ejidos ${ }^{2}$ and communities, $15 \%$ is privately owned, and $5 \%$ belongs to the federal government. The main wood species in the country, in terms of the surface covered and economic importance, are Pinus and Quercus species, which represent approximately $80 \%$ and $5 \%$ of the total national timber production in Mexico, respectively (CONAFOR 2001) [27].

\footnotetext{
${ }^{1}$ National Commission for the Knowledge and Use of Biodiversity

${ }^{2} \mathrm{An}$ Ejido is agricultural land expropriated from large private holdings and redistributed to communal farms (Bartleby, 2003) [124]. While the concept of the ejido in Mexico is prehispanic, most of the fundamental ideas and concepts that created what an ejido is today stem from the theories of democratic communism.
} 


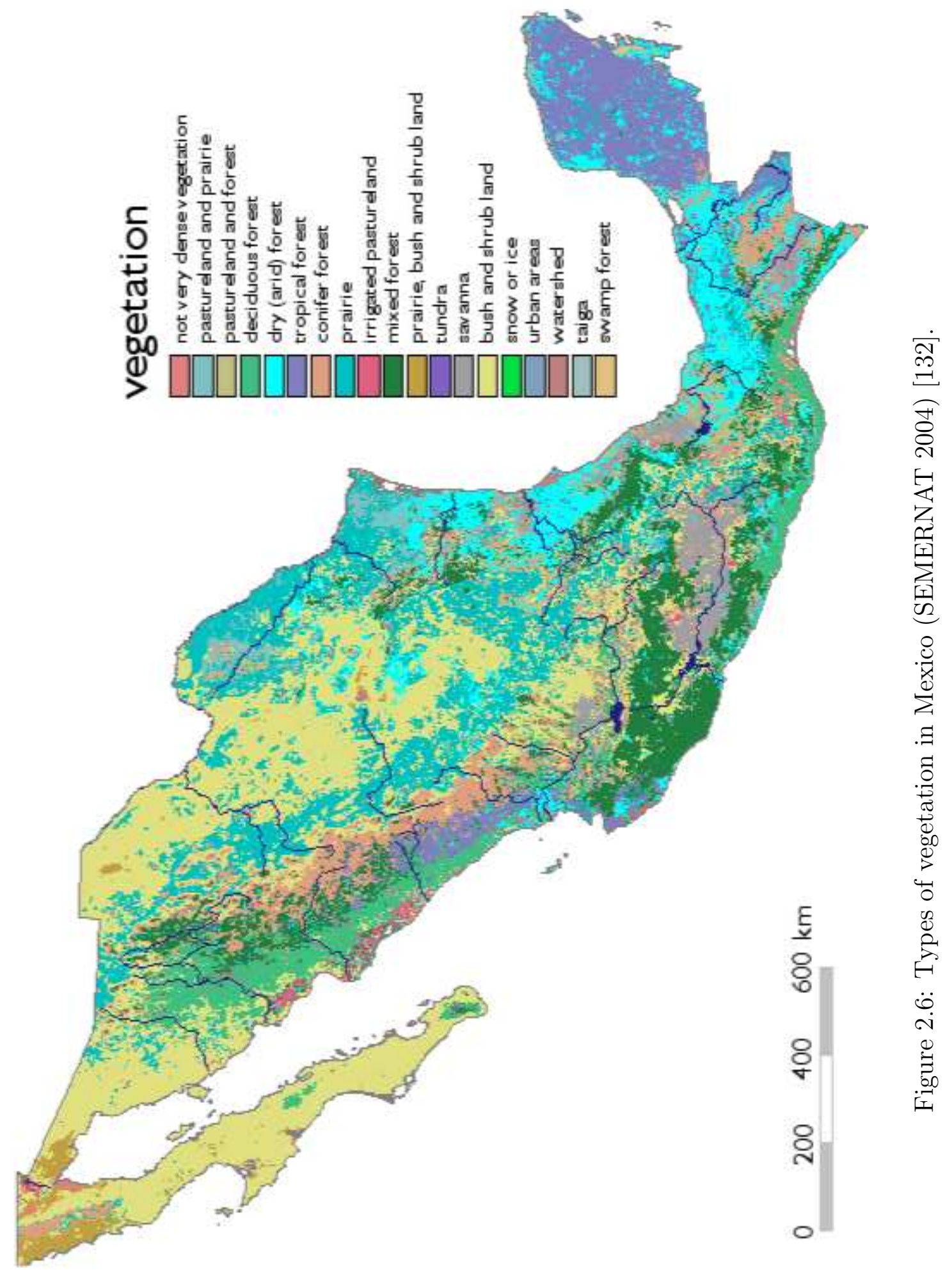




\section{Forest Fires and Political Response}

Nationwide, temporal and spatial occurrences of forest fires vary widely depending on local and topographic conditions. Another important factor is the accessibility for humans beings, which influences the utilization of natural resources. In the last decade, fire has become a more frequent phenomenon in protected areas such as national parks and biosphere reserves, as a consequence of the increased frequency of visitors (Jardel 2001) [73]. Furthermore, wildland fires tend to be associated with deforestation and degradation processes, since fire was and still is utilized to convert forests and other types of vegetation into agricultural fields or pastures.

In 1998, Mexico experienced the worst drought in 70 years and an extraordinary fire season. Meteorological conditions associated with the extreme dry conditions of "El Niño" facilitated the occurrence of forest fires. Wildland fire incidences in 1998 exceeded the recorded incidences of the five previous years combined and caused severe damage in different regions of the country. Near the end of the regular fire season in the majority of the territory, approximately 13,000 fires affected 440,000 hectares (Fig. 2.7) (IFFN 1998, 1999) [57, 58].

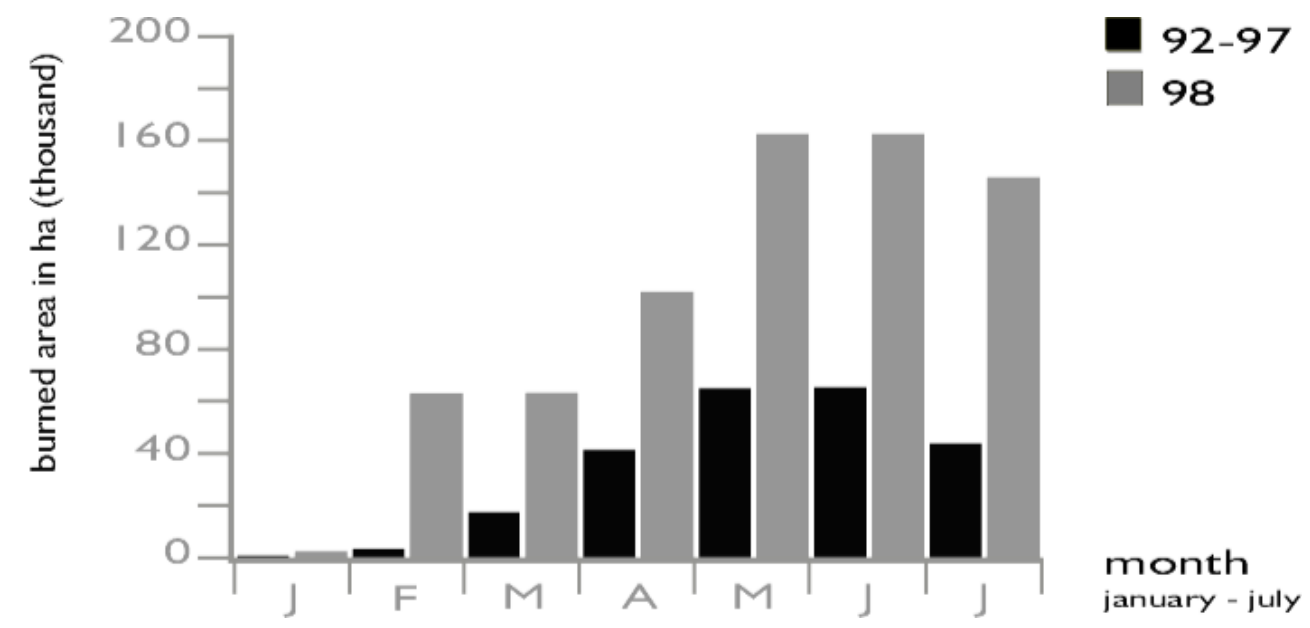

Figure 2.7: Comparison of burned areas in 1998 to those of the previous five years from 1992-97 (Global Fire Monitoring Center 1999) [58].

It is estimated that $26 \%$ of the burned landscapes were forests, $32 \%$ grasslands, and $42 \%$ shrublands. Around $94 \%$ of the wildland fires were of human origin and $6 \%$ of the causes were unknown (CONABIO 2004, IFFN 1998) [25, 57]. 
The awareness of the ecological role of fire has risen in Mexico following the devastating wildfires of 1998. Numerous authors have noted that fire is an important ecological process (Fernández and García-Gil 1998) [40]. But in the aftermath of harmful fires, some initial reactions have focused on law enforcement which attempts to control human-caused ignitions, irrespective of the complex social problems that lead to deforestation (Curiel Ballesteros 1998) [6]. Since 1998, the Mexican government has begun a campaign to increase forest fire suppression capacity. Prevention, combat, and suppression are the new policy approaches to wildland fires in Mexican forests and protected areas. This policy seems to be based on a negative perception of the role of forest fires in forest ecosystems among the environmental sector, and public opinion (Jardel 2001) [73].

Before 1998, the occurrence of wildland fire was not recorded systematically and important investigations on the frequency (or intervals), the intensity, and the effects of wildland fires on biodiversity or vegetation succession were not carried out in Mexico. Hence, the knowledge in Mexico about fire history, dependence, and the regime of wildland fires was insufficient for the development or design of adequate forest fire management strategies (Fule 1994, Jardel 2003, Rodriguez-Trejo 2003) $[47,74,125]$.

According to the records and extrapolations to the statistics of the Mexican agencies CONABIO (2004) and $\operatorname{CONAFOR}^{3}$ (2004) [25, 28], there exists an increasing tendency with respect to the occurrence of forest fires in the last 30 years (Fig 2.8).

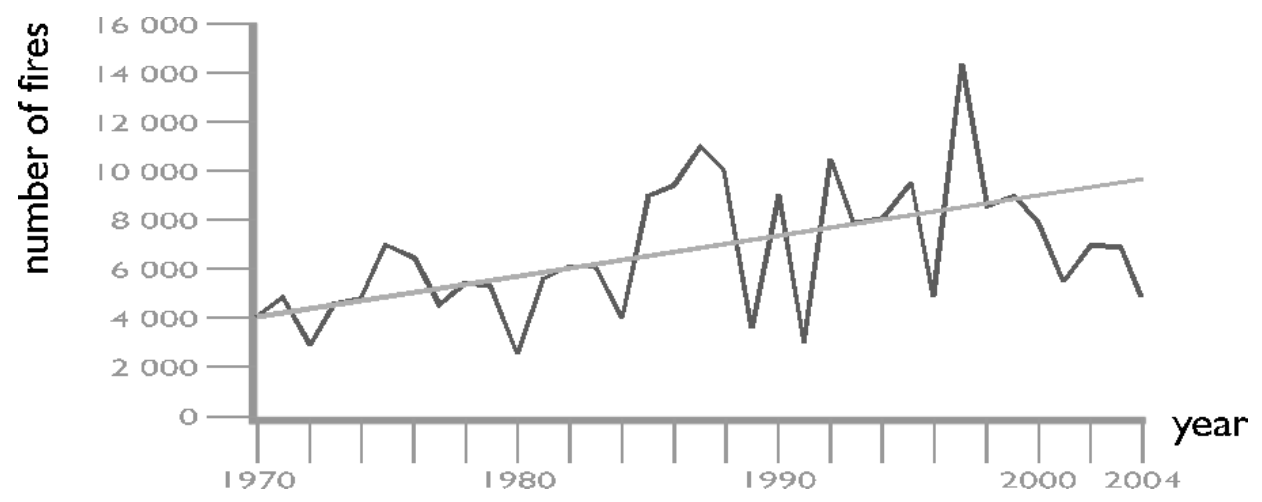

Figure 2.8: Number of wildland fires per year from 1970-2004 based on records and extrapolations (CONABIO 2004, CONAFOR) [25, 28].

\footnotetext{
${ }^{3}$ Forest National Commission
} 
Mexico is currently starting a collaboration project with the NGO (non-governmental organization) "The Nature Conservancy's Fire Initiative", and together with other Mexican conservation partners, they have established the "National Fire Management Forum". This forum includes government officials, land managers, scientists, and fire experts. It is now creating a network and a monitoring program with international teams of fire experts, mainly from USA and Mexico, in order to develop ecological and socially adequate fire management strategies.

Another important program that emerged from the fire season of 1998 was initiated by the Mexican agency CONABIO. They established a software program which detects so called hot spots by remote sensoring techniques. A hot spot may be caused by camp fires, factories, insolated soils, or active volcanoes, just to mention some examples. The use of satellite images provides the spatial and temporal location of hot spots on the earth's surface. This information reflected on a map registers areas where hot spots were detected but does not provide accurate data as to the number of fires and the size of the affected surface (Fig 2.9).

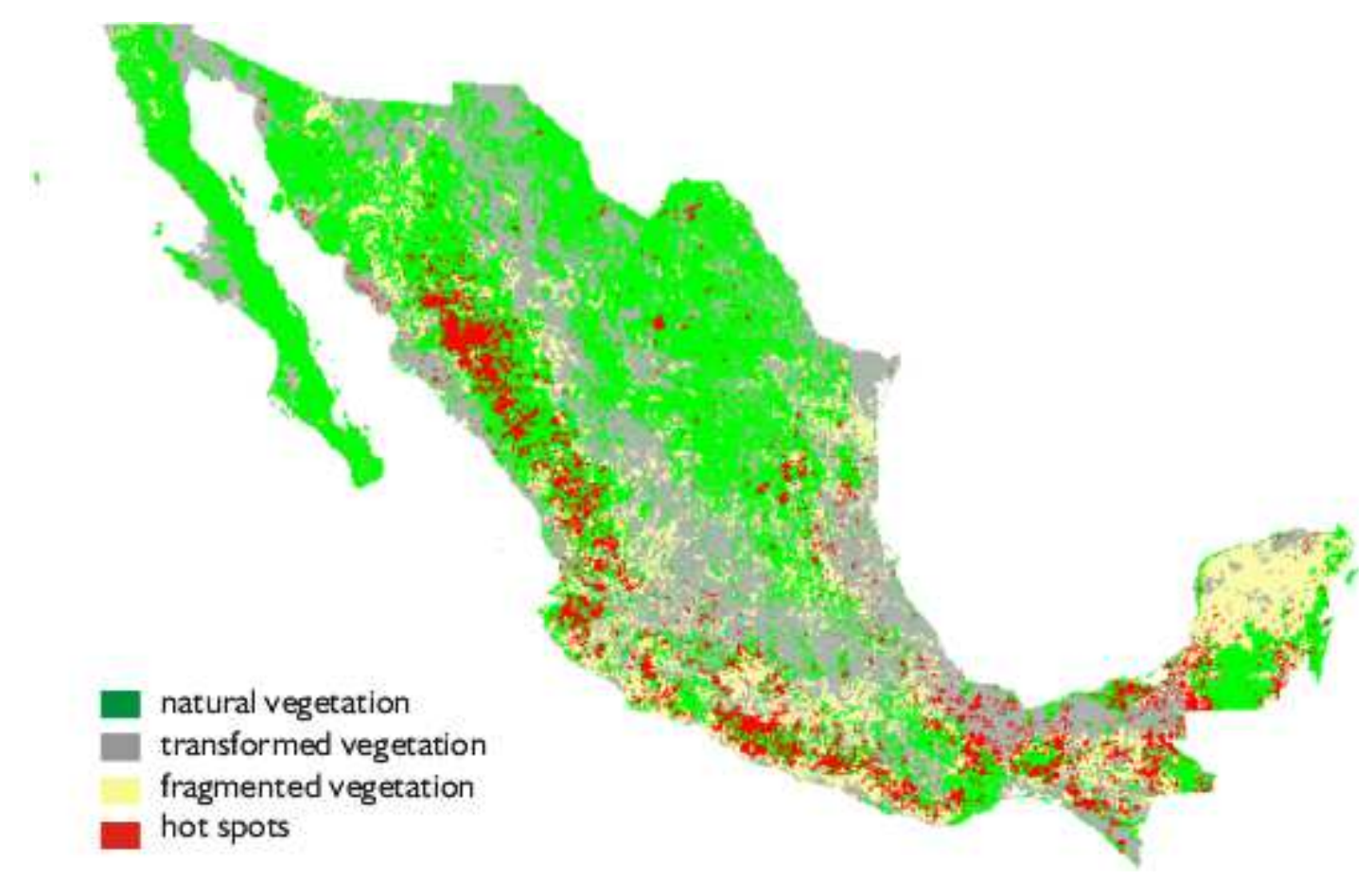

Figure 2.9: Detection of hot spots by satellite images (CONABIO 1999) [26]. 


\section{Fire Causes}

The forest fire season normally occurs between January and July. March and April are the most susceptible fire months, because they coincide with the peak dry season. About $94 \%$ of all wildland fires are caused by human activities, of which $48 \%$ are associated with agricultural activities and cattle breeding (Fig 2.10). In tropical zones, the main cause of wildland fires is the intensive use of slash and burn agriculture (FAO 2001, SEMERNAP 1999) [39, 130]. Some studies carried out by SEMERNAP (2002) [131], revealed that only $6 \%$ of fires are cause by lightning and undefined causes.

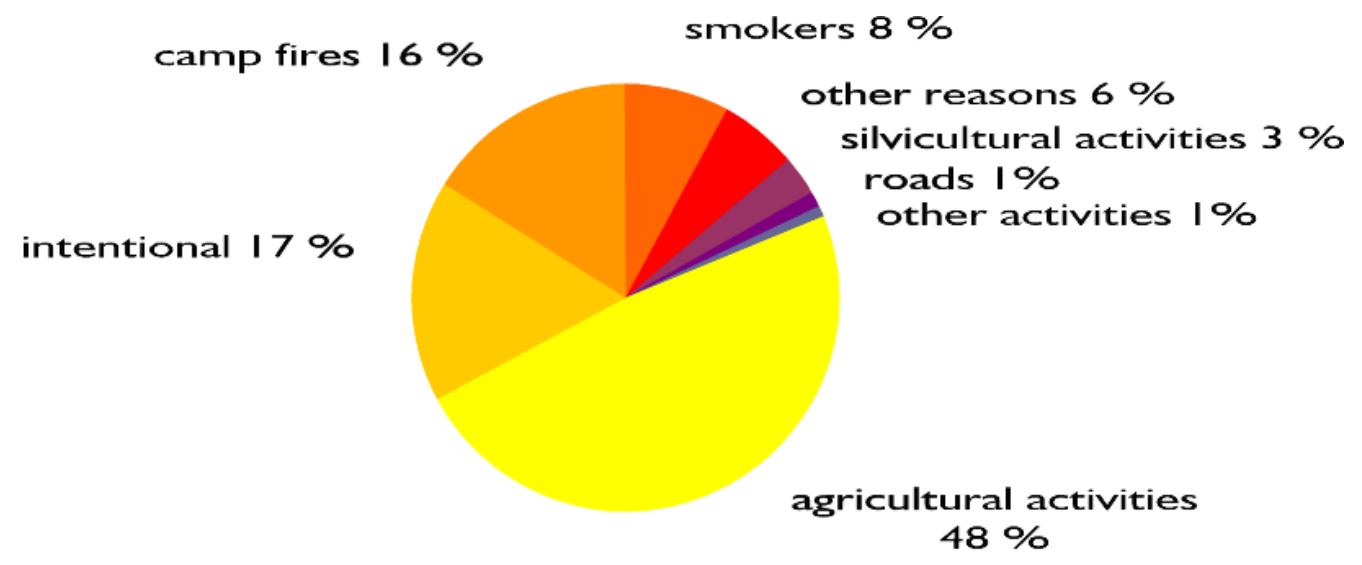

Figure 2.10: Causes of wildland fires in Mexico (CONABIO 2004) [25].

\subsection{Forest Succession}

Disturbances of plant communities are usually followed by recovery, which is called succession (Holmes 2003) [71]. In general, species succession in plant communities can be considered to be a temporal sequence of appearance and disappearance of species. The presence of species depends on interactions between biotic and abiotic processes, which influence different stages of a species's life history over time (Holmes 2003) [71].

Foresters distinguish between pioneer, or early successional, tree species and late successional species. Each type, shares a suite of correlated characteristics. Typical pioneer traits are high fecundity, large dispersal, rapid growth when resources are abundant, and slow growth and low survivorship when resources are scarce (Pacala and Rees 1998) [110]. 
In comparison late successional species usually have the opposite characteristics and in the absence of disturbances will eventually exclude pioneer species since they reduce resources below the levels required by early successional species (Pacala and Rees 1998) [110].

\section{Definition}

Ecological succession can be very diverse, hence there is also great variation in its definition.

Succession is ...

- "a continuous process of change in vegetation, which can be separated into a series of phases" (Holmes 2003) [71],

- "the non-seasonal, directional and continuous pattern of colonization and extinction on a site by species populations" (Holmes 2003) [71],

- "the directional change in vegetation during ecological time" (Holmes 2003) [71],

- "the representation of a sequence of populations, that replace each other resulting in community change; this orderly progression of change is called a "sere" and each of the communities characterizing succession represent serial stages" (Holmes 2003) [71],

- "a process of opportunity, since it occurs where death of a plant community, e.g. caused by an intensive forest fire, creates an opening to be conquered by new plant species" (Holmes 2003) [71].

All definitions imply that succession is not a random fluctuation in plant community structures, but a directed change of the species composition in plant communities. Furthermore, succession has also been used to describe cyclic changes in plant communities, such as forests. In forests, for example, there is always a mosaic of mini successions occurring, even when the forest seems to be a climax community (Holmes 2003) [71].

Two types of succession are distinguished, primary and secondary succession. Primary succession describes a sequence of species appearing on newly exposed areas that 
is not influenced by a previous plant community e.g. areas exposed by glacial retreat, lava flows, or newly formed sand dunes (Holmes 2003) [71]. Secondary succession is the vegetational recovery of an area that has been partially or completely removed, but where well developed soils, seeds, and spores remained. In those areas, the resulting sequence of species is driven principally by interactions such as competition between different plant species and herbivores (Holmes 2003) [71]. Forest succession after a forest fire is classified as secondary succession, since fertilized soils, vigorous seeds, and stump sprouts remain in the burnt area. Hence, the following stand is to some degree influenced by the previously existing forest stand.

\subsubsection{Succession Models}

Forest succession can be predicted, or rather estimated, by using transition matrices (Horn 1981, quoted in Holmes) [71]. It is possible to estimate:

- the probability for each tree species that, within a particular time interval, an individual will be replaced by another of the same species or a different species, and

- the initial species composition of the forest, assuming that the proportional representation of various species of saplings established beneath an adult tree reflects the probability of the tree's replacement by each of those species.

Another way to predict forest succession is through models of succession. These models can be divided into four main successional models:

- Facilitation: The presence of the early stage allows the later successional species to become established and grow. This model is important during primary succession.

- Tolerance: Tolerant species are successful regardless of whether earlier species have preceded or not. These species do not require conditions produced by earlier species, nor are they inhibited by them. A predictable sequence of species replacements results because species have different strategies for exploiting resources. The later species tolerate lower resource levels then early species and grow to maturity is the presence of early species. 
- Inhibition: This model is characterized by later species which cannot grow to maturity when accompanied by early species, because early species suppress the establishment of later ones.

- Random colonization: This is called a null model, which suggests that succession involves only the chance survival of different species and the random colonization by new species.

In Facilitation, Tolerance, and Inhibition models, early species cannot invade and grow once the site is fully occupied by their own or later species. The models differ in the way species become established after their propagules arrive in the site. According to the models of facilitation and tolerance, early species are replaced through competition for resources, especially light and nutrients. In the model of inhibition, the early colonist species are replaced by physical conditions and not by resource competition.

\subsection{Biodiversity Analysis}

Biodiversity analysis provides a means to quantify variation in forest composition, productivity, and fundamental ecological processes across regional landscapes.

\section{Definitions}

The United Nations Environment Programme (UNEP) [92] defines biological diversity or biodiversity as "the variability among living organisms from all sources, including terrestrial, marine and other aquatics systems and the ecological complexes of which they are part; this includes diversity within and between species and ecosystems". Gaines (1999) [52], proposes another definition: Biodiversity is the variety, distribution, and structure of plant and animal communities, including all vegetative stages, arranged in space over time, which support self-sustaining populations.

Plant communities in ecosystems are not isolated; they are present in a geographical area or landscape that interacts with many variables. The way in which biodiversity is measured affects the way that changes after disturbance such as wildland fire are documented and how the results are interpreted (Gill 1999) [59]. One Method of documentation could be through the separation of diversity components 
(alfa, beta and gamma), in order to document and evaluate the changes in diversity and structure in a landscape (Moreno 2001) [99]. Whittaker (1972) [154] discussed these three levels of diversity:

alpha diversity $(\alpha)$ is the number of species within a single community (within habitat diversity),

beta diversity $(\beta)$ is the comparison of diversity among ecosystems, usually measured as the number of species which differs between the ecosystems (differentiation diversity), and

gamma diversity $(\gamma)$ is a measure of the overall diversity within a large region. (geographic-scale species diversity).

\subsubsection{Alpha Diversity $(\alpha)$}

There have been a wide range of indices adapted by various researchers in order to measure changes within a community. The differences between them lie in the relative weight given to the richness and evenness components (Magurran 2004) [92]. In general, three main categories of measurements are used to assess alpha diversity: (a) Species richness indices, which measure the number of species in a sample unit, (b) Species abundance models, which have been developed to describe the distribution of species abundances and $(c)$ Indices that are based on the proportional abundances of species.

\section{Species Richness Indices}

These indices are a measure of the number of species in a defined sampling unit (Magurran 2004) [92]. Species richness as a measure of alpha diversity has been employed in many studies. Curves of species richness related to time are useful measure of diversity and also a common way of representing the changes in communities that take place after wildland fires.

Some indices have been derived using combinations of the number of species recorded $(S)$ and the total number of individuals $(N)$. For example, the Margalef's diversity index $\left(D_{M g}\right)$ (Magurran, 1998) [91]. 
Margalef's Index $\left(\mathbf{D}_{M g}\right)$

$$
D_{M g}=(S-1) \ln N
$$

Where $S$ is the number of species recorded and $N$ is the total number of individuals summed over all $S$ species.

Evenness (E) Species evenness, or equability, is the relative abundance of species in a unit area. High evenness may be interpreted when species are equal in abundance; low evenness exist when one or a few species are dominant in a community. Communities with low evenness have step vertical curves approximating a geometric series. Intermediate evenness communities have a sigmoid shape, approximating the log series or log normal model. The more horizontal slope, the larger the number of subordinate species and the greater the evenness, thus approximated by the broken stick model (Whittaker 1977) [153]. The ratio of observed diversity (H') to maximum diversity $\left(\mathrm{H}_{\max }\right)$ can be represented as a measure of evenness (E)(Pielou 1969) [118].

$$
E(\%)=100 * H^{\prime} / \ln H_{\max }
$$

Where $H^{\prime}$ is the Shannon Index (c.f. equation 2.9).

Gill (1999) [59] describes three main periods in species richness after fire disturbance ( $S$ - $t$ curves) Figure 2.11.

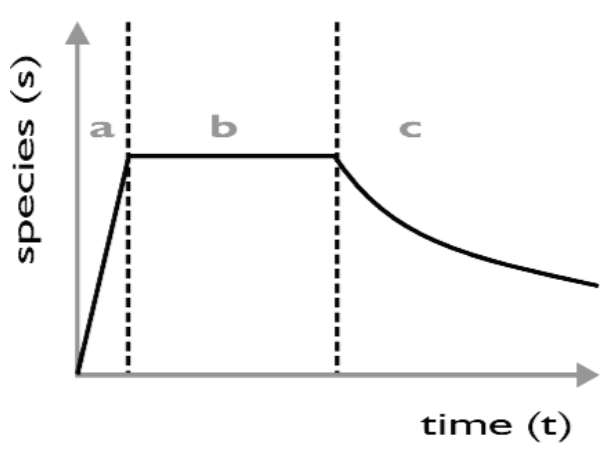

Figure 2.11: An hypothetical curve for species richness, $(S)$, as a function of time after fire, $(t)$, in years, where $a, b$, and $c$ represent successive phases of change.

Three main periods are detected in the $S$ - $t$ curves (Fig 2.11), " $a$ " is the initial period after a fire, in which species number increase from low values; " $b$ " is the period that shows a plateau in richness (a relatively stable period); and "c" is a period of decrease with fluctuating richness. The three periods $a, b$, and $c$ vary in a way that 
is described by Figure 2.12, which shows the variations that could occur in the initial phase "a" of re-establishment after a fire.


Figure 2.12: Alternatives within phases for $S$ - $t$ curves. (a) indicates possible variants of phase "a" (b) shows either increasing, fluctuating or declining richness in phase "c".

With a low-intensity fire, some species of trees, for example, may not be greatly affected by the fire and remain in the area. In this case (1), the curve would have a positive $y$ intercept. If all above-ground parts of the plants are killed, the apparent number of species begins at the origin (2). In the third case, there is a delay to reestablishment, perhaps after an event such as a severe drought (3). Phase "b" is the stable period in species richness and is considered to be present or absent. Phase "c" illustrates a circumstance in which the species richness either increases, fluctuates or decreases, for example, as a result of different competition forces between species.

\section{Species Abundance Models}

Species abundance models can be used to describe the distribution of species abundance. Dominance diversity curves show the importance of each species plotted in sequential order from highest (most abundant or dominant) to lowest (least common or rare species) (Odum 1993) [108]. Some species found in a community are very abundant, some have a medium abundance, while most of the species are represented by only few individuals. The abundance data registered are graphed according to rank of abundance and then examined in relation to four models which describe diversity (Figure 2.13).

At any time after a wildland fire, there exists a range of possible relationships between the number of plants of the species presented (cover, biomass or height) and 

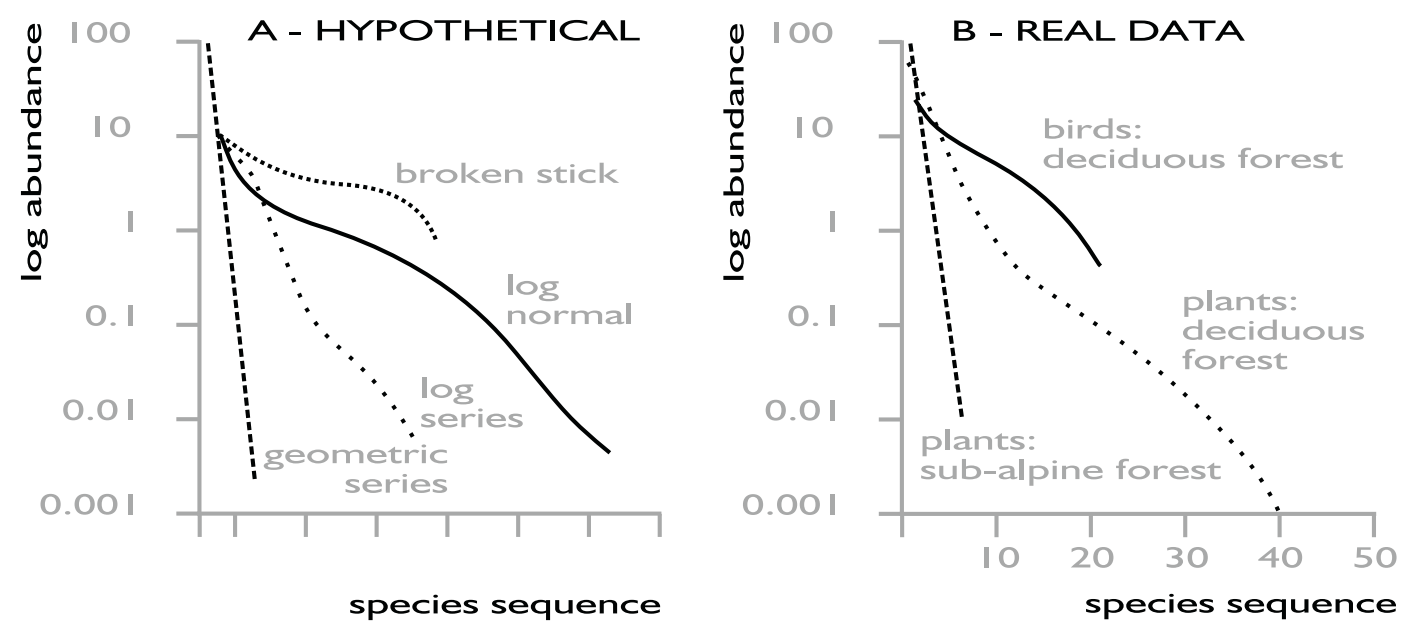

Figure 2.13: a) Hypothetical abundance rank curves, illustrating four models, b) Curves for real plant communities (Magurran, 1998).

their rank. Changes in the curves show only trends, because all components of the curves may change with time (Gill 1999) [59].

Diversity and the distribution of species abundance are examined in relation to four main models (Magurran 1988) [91]. In the geometric series, only a few dominant species are represented; the remaining species are uncommon. In the log series and log normal distributions, intermediate species become more common. Finally, the broken stick model shows species with relatively equal abundance.

The geometric series: The abundances of species are ranked from the most to the least abundant.

$$
n_{i}=N C_{k}(1-k)^{i-1}
$$

where $n_{i}=$ the number of individuals in the $i$ th species, $N=$ the total number of individuals, and $C_{k}=\left[1-(1-k)^{s}\right]^{-1}$ and is a constant which ensures that $\sum n_{i}=N$.

The log series: The distribution takes the form

$$
\alpha x, \frac{\alpha x^{2}}{2}, \frac{\alpha x^{3}}{3} \ldots \frac{\alpha x^{n}}{n}
$$

Where $\alpha x$ is the number of species predicted to have one individual, $\frac{\alpha x^{2}}{2}$ those with two and so on. 
The log normal distribution: The distribution is usually written in the form

$$
S(R)=S_{0} \exp \left(-a^{2} R^{2}\right)
$$

where $S(R)=$ the number of species in the $R$ th octave (class) to the right and left of the symmetrical curve, $S_{0}=$ the number of species in the modal octave, and $a=\left(2 \sigma^{2}\right)^{1 / 2}=$ the inverse width of the distribution.

The broken stick model: This distribution is conventionally written in terms of rank order abundance; where the number of individuals in the $i$ th most abundant of $S$ species $\left(N_{i}\right)$, is obtained from the term

$$
S_{(n)}=\left[\frac{S(S-1)}{N}\right]\left(\frac{1-n}{N}\right)^{s-2}
$$

where $S_{(n)}=$ the number of species in the abundance class with $n$ individuals, $N=$ total number of individuals, and $S$ total number of species.

\section{Proportional Abundance Indices}

Indices based on proportional abundance of species are heterogeneity indices. These can be classified in two groups: dominance indices and information statistical indices (Magurran 1998) [91]. Dominance indices for example, the Simpson index, are weighted towards the common species and are sensitive to changes in dominant species. Information statistical indices are the most widely used and are sensitive to changes in rare species. The information statistical index most commonly applied to alpha diversity is the Shannon diversity index $\left(\mathrm{H}^{\prime}\right)$.

Simpson Index (D) The diversity index proposed by Simpson (1949) describes the probability of any two individuals drawn at random from an infinitely large community belonging to different species.

$$
D=\sum_{i}^{S_{o b s}} p_{i}^{2}
$$

where $p_{i}$ equals the proportion of individuals in the $i$ th species and is calculated as follows: 


$$
p_{i}^{2}=\frac{n_{i}\left(n_{i}-1\right)}{N_{t}\left(N_{t}-1\right)}
$$

where, $n_{i}$ equals the number of individuals in the $i$ th species and $N_{t}$ equals the total number of individuals.

Shannon index $\left(\mathbf{H}^{\prime}\right)$ The Shannon index assumes that individuals are randomly sampled from an "indefinitely large" population (Pielou 1969) [118]. The index also assumes that all species are represented in the sample. It is calculated from the equation:

$$
H^{\prime}=-\sum p_{i} \ln p_{i}
$$

where the quantity $p_{i}$ is the proportion of individuals found in the $i$ th species $\left(\frac{n_{i}}{N}\right)$.

The intrinsic variance of $\mathrm{H}^{\prime}$ is calculated with the equation (2.10). In order to detect significant differences between samples, the Hutcheson ( $t$ Test) method described by Magurran (1988) [91] was applied (eq. 2.11).

$$
\begin{gathered}
\operatorname{Var} H^{\prime}=\frac{\sum p_{i}\left(\ln p_{i}\right)^{2}}{N}+\frac{S-1}{2 N^{2}} \\
t=\frac{H_{1}^{\prime}-H_{2}^{\prime}}{\left(\operatorname{Var} H_{1}^{\prime}+\operatorname{Var} H_{2}^{\prime}\right)^{1 / 2}}
\end{gathered}
$$

where, $H_{1}^{\prime}$ is the diversity of site 1 and Var. $H_{1}^{\prime}$ is its variance. Degrees of freedom are calculated using the equation

$$
d f=\frac{\left(\operatorname{Var} H_{1}^{\prime}+\operatorname{Var} H_{2}^{\prime}\right)^{2}}{\frac{\left(\operatorname{Var} H_{1}^{\prime}\right)^{2}}{N_{1}}+\frac{\left(\operatorname{Var} H_{2}^{\prime}\right)^{2}}{N_{2}}}
$$

$N_{1}$ and $N_{2}$ being the total number of individuals in the two samples respectively. 


\subsubsection{Beta Diversity $(\beta)$}

Beta, or differentiation, diversity is a measurement of the differentiation or similarity of species found in a range of habitats or samples. A common approach to measuring $\beta$ diversity is to analyse the change of species diversity along a gradient (Magurran 1998) [91]. Another possibility to express $\beta$ diversity is to compare the species compositions of different communities. Consequently, the fewer species that the different communities or gradient positions share, the higher $\beta$ diversity will be. The term $\beta$ diversity was first employed by Whittaker (1977) [153] and distinguishes three levels of inventory diversity. These levels can be assigned to a precise scale: habitat, landscape and biogeographic area.

\section{Spatial Change (turnover) and Species Diversity}

The patterns of species distribution and composition following disturbances have been described by many authors. For example, some analyses have demonstrated that diversity increases after disturbance and then decreases during community development (Odum 1969, Haug 1997) [108, 145].

Pielou (1966) [117] has concluded that diversity may decrease later in community development. Peet (1978) [115], in contrast, proposes that diversity may rise again even in later succession and suggests the presence of more than one peak during succession, depending on site characteristics. These results have been summarized in three models of species diversity change with time (Figure 2.14).



Figure 2.14: Three models of change in plant species diversity with time after disturbance. 


\subsection{Potential Solar Radiation (PSR)}

Plants are affected and respond to solar radiation through multiple pathways (Pierce 2004) [120]. Several examples have shown that Photosynthetically active radiation (PAR) provides the driving energy for photosynthesis. In this study special attention is paid in the effects of potential solar radiation on the composition of vegetation. This parameter undergoes a predictable pattern of change, due to changes is stand age, density, under and overstory composition. Radiation affects the water demand components of the water balance (Schulz 2003, Stephenson 1998) [129, 138], and has been demonstrated to have a significant effect on the distribution of surface water through simulation modeling (Vertessy et al. 1990) [149]. These multiple influences can result in complex responses to radiation loads. The strong association between radiation and plant processes has been reported to shape the landscape-scale distribution of plants (Davis and Goetz 1990, Gallegos 1997, Swanson et al. 1998) $[30,53,139]$. In contrast, some authors have not been able to document a strong correlation between radiation estimates and plant pattern (Brown 1994, Park 2001) $[11,112]$.

Direct measurements of radiation are rare in topographically rugged terrain. Acquiring fine-scale information about climatic factors over large areas is logistically problematic. This has lead to many attempts to find alternatives to actual measurements of solar radiation. According to the literature, two approaches are used to estimate radiation affects on landscape scales. One approach relies on static topographic proxies based on slope and aspect, either from field measurements or from digital terrain data. A more complicated approach involves numerical integration of radiation values through modeling terrain and climate data (Fu and Rich 1999) [44].

\subsubsection{The Geometry of Radiation}

The radiation affecting the surface of the Earth is the sum of three components: direct, diffuse, and reflected radiation (Pierce 2004) [120]. Direct-beam radiation is the fraction of extra-atmospheric solar radiation which reaches the earth's surface without being scattered by molecules in the atmosphere (Figure 2.15a). Diffuse-beam radiation is the component resulting from atmospheric scattering. Reflected radiation bounces off other surfaces before hitting a target (Pierce 2004) [120]. 
Under clear sky conditions, direct radiation is largely a function of the geometry between the earth's surface and the sun. Topography acts as a filter on radiation loads in two different ways: (1) through shading effects and (2) through attenuation of the solar flux by altering the solar illumination angle. Therefore, the orientation between a slope and the sun's position can be calculated with a high degree of precision given position and time (Pierce 2004) [120]. The rotation of the earth causes the daily solar orientation to change, affecting irradiance and shading (Figure 2.15a-b). The inclination and orbit of the earth cause an annual change in the topographic orientation of a site in relation to the sun, which affects the solar period and the solar illumination angle, the angle between the sun's position relative to the earth an a vector normal to the earth's surface (Dubayah and Rich 1995) [34] (Figure 2.15c-d).

a)

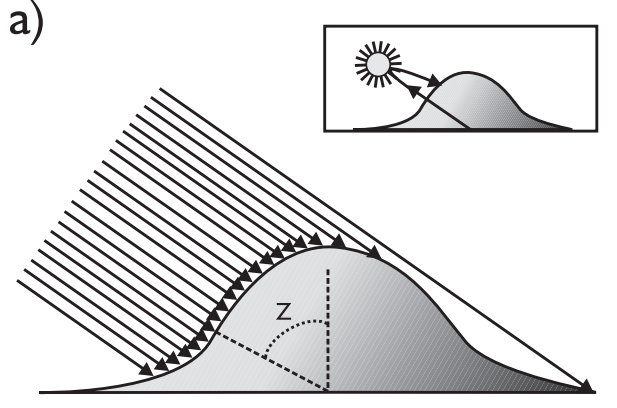

c)

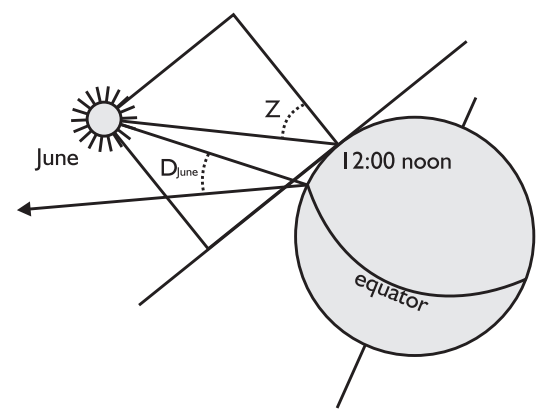

b)

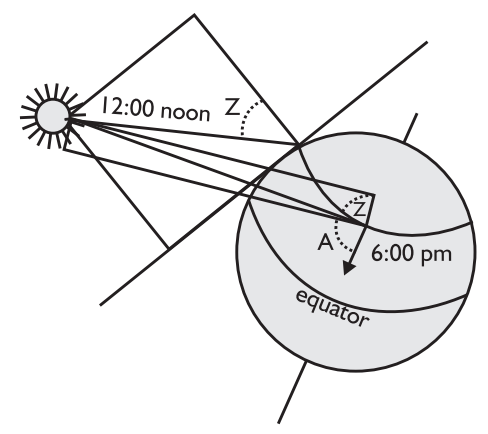

d)



Figure 2.15: Illustration of the three components of radiation (Pierce 2004).

Diffuse and reflected radiation are difficult to quantify (Dubayah and Rich 1995) [34]. These components tend to minimize spatial differences in radiation. Under clear sky conditions, the largest share of radiation is direct-beam. This condition provides the maximum contrasts in radiation load between sites with differences in topographic orientations. As the radiation shifts from direct to diffuse, sites are affected similarly and the relative differences between sites are reduced. 


\subsubsection{Radiation Sources}

Slope and aspect are easily measured and therefore, often employed to estimate the potential relative radiation. Both of these factors have been employed as radiation proxies in several studies.

Some of the earliest gradient analysis studies carried out by Whittaker (1956) [154] categorized topographic aspects as factors along a moisture continuum. Another study by Frank and Lee (1996) [42] standardized the relationships between relative radiation and slopes and aspect in tables that account for latitudinal differences.

Aspect is represented as a continuous quantity by reorienting the variable along a specified axis. This requires a particular designed orientation, such as a northsouth axis. One common approach is to use "absolute aspect", computed as ABS (180-aspect), which solves the circularity problem while aligning the index on a northsouth axis. Beers et al. (1996) [7] transformed aspect data along an axis running from northeast to southwest in order to reflect the combined influence of bright illumination with warm afternoon temperatures affecting southwest-facing slopes of the Northern Hemisphere.

Slope influences radiation by affecting the solar illumination angle. Transformation of the sine and cosine of the local slope angle are used as a substitute measure. For example, the transformation of a cosine of local slopes provides maximum insolation at zero slope and decreases insolation with increasing slope. This is correct for slopes facing away from the sun, but for slopes facing the sun the isolation should increase only until the slopes angles equals the solar zenith angle, at which time the sun is normal to the slopes (Pierce 2004) [120].

The radiation levels vary with time in many ways. For instance, a higher radiation load during the morning hours is observed on east-facing slopes, whereas on the westfacing slopes higher radiation is experienced in late afternoon hours. Annually, the solar period changes in accordance to the change of the solar inclination (Pierce 2004) [120]. Hence, the incorporation of daily and annual solar paths is essential when comparisons of solar exposure between two sites are carried out. Obstructions to direct beam radiation can result not only from self-shading by the slope itself, but also from shading by nearby ridges. 


\subsubsection{Radiation Models}

Quantitative estimations of radiation must include the sum of three components: direct, diffuse, and reflected radiation. Direct-beam radiation $\left(R_{b}\right)$ to a spot on the horizontal plane of the earth can be estimated as

$$
R_{b}=\cos (Z) R_{a e} \exp ^{(-t / \cos (Z))}
$$

where extra atmospheric radiation $\left(R_{a e}\right)$ is attenuated by atmospheric transmittance $(t)$ and the cosine of the solar Zenith angle $(Z)$ is the angle between a vector directed at the sun and normal to the horizontal surface of the earth (Dubayah 1994) [33].

Transmittance is largely a function of the optical depth of the atmosphere and air pressure. The solar zenith angle is:

$$
\cos (Z)=\sin (L) * \sin (D)+\cos (D) * \cos (15(T-12))
$$

where $L$ is latitude, $T$ is the time of days in hours, and the coefficient 15 represents the degree of longitude the earth rotates each hour. Solar declination $(D)$, the angle between the sun and a position directly above the equator at noon, accounts for the inclination of the earth. It depends only on time (Julian day $J$ ) and can be estimated for each day of the year as:

$$
\sin (D)=0.3978 \sin [279.0+0.9856 J+1.9165 \sin (356.6+0.9856 J)]
$$

The radiation calculations described above belong to a flat plain on the earth's surface. Radiation is modified by local topography using tilt factors and view angles. Directbeam radiation is attenuated by tilt factors based on the solar azimuth $(A)$ and local topography. The solar azimuth, the angle between a vector directed towards the equator and a vector directed towards the suns's current position in horizontal coordinates is calculated by

$$
A=\arcsin [(\cos (D) * \sin (15(t-12)) / \cos (90-Z)]
$$

The solar azimuth $(A)$, local slope $(\mathrm{S})$, and local azimuth $(a)$ are incorporated into the Hillshade function described in the chapter 3, section 3.4. 


\subsubsection{Digital Elevation Model (DEM)}

A digital elevation model (DEM) is a computer representation of the earth's surface, and as such, provides a base data set from which topographic parameters can be digitally generated (Burrough and McDonell 1998) [18]. Thus, the DEM represents a sector of the earth's surface by numerical values and provides a base data set from which topographic parameters can be generated. In general, this representation is a simplification of the geometry of the earth's surface. A DEM consists of numerous singularities (points) of which the coordinates are known and that refer to a system of bi-dimensional coordinates with assigned values of elevation. In other words, the DEM is a group of values representing points of the three-dimensional surface of a terrain (Hildebrandt 1996) [67]. Hence, topography is defined numerically by the coordinates $X$ and $Y$ to which the elevation value $Z$ is assigned.

Use of a Digital elevation model: One of the uses of the DEM is to determine the attributes of terrain, such as elevation at any point, slope, and aspect. Therefore, models to estimate the potential insolation can be obtained from a DEM. Direction and solar incidence angle were simulated using Geographical Information Systems and digital elevation models, in order to characterize the local or microclimate environmental conditions (insolation and solar radiation) of the study area.

The influence of topography on vegetation patterns is well documented (Franklin 1995, Pierce 2004) [43, 120] therefore the use of topographic attributes such as elevation and slope derived from a Digital Elevation Model (DEM) are among the most common variables employed in vegetation modelling studies (e.g. Gallegos 1997, Osborne 2001, Pardo 2000) [53, 114]. The terrain attributes from a DEM refer to elevation, aspect and slope and compound attributes such as potential solar radiation, soil properties as well as temperature (Vogiatzakis 2003) [150]. The importance of topographic parameters such as slope, aspect and elevation in determining vegetation composition and distribution has been highlighted by ecological and silvicultural studies (Franklin 1995) [43]. Therefore, primary terrain attributes derived from DEMs have been used extensively in predict vegetation mapping studies (Chang 2004, Pardo 2000) $[22,114]$, as well as predictive maps of wildlife habitats Gurnell et al. 2002 [64]. 


\section{Chapter 3}

\section{Material and Methods}

\subsection{General Description of the Research Area}

The investigation was carried out in the Ecological Park Chipinque (PECH), which is part of the National Park "Cumbres de Monterrey" in the northern part of the mountain range "Sierra Madre Oriental" in northeast Mexico. The Sierra Madre Oriental runs about 1000 kilometres from north to south and includes eleven states: Coahuila, Nuevo León, Tamaulipas, San Luis Potosí, Guanajuato, Queretaro, Hidalgo, small parts of Mexico, Tlaxcala, Puebla and Veracruz (General Libraries 2003) [56].

The High Sierra stretches southwards from Monterrey (Nuevo León) to near Jalapa (Veracruz). The northern part of the High Sierra consists of closely folded limestone ridges forming canoe shaped anticlines with very steep sides. A good example for the impressiveness of this landscape is the "Huasteca Canyon" near Monterrey (General Libraries 2003) [56]. Potosí (3,625 m above sea level) and Peña Nevada (3,480 m above sea level) in the state Nuevo León are the tallest peaks of the Sierra Madre Oriental (Jímenez et al. 1997) [77].

The PECH is located in the State Nuevo León near the state's capital Monterrey (ca. 3 millions inhabitants, INEGI 2004 [72]). About 200 kilometres south of the border to Texas. The park extends over a territorial area of 1624 hectares $\left(25^{\circ} 34^{\circ}\right.$ to $25^{\circ} 38^{\circ} \mathrm{N}$ and $100^{\circ} 18^{\circ}$ to $100^{\circ} 24^{\circ} \mathrm{W}$ ) between $650 \mathrm{~m}$ and $1800 \mathrm{~m}$ above sea level (Alanís 1995) [3] (Figure 3.1). 


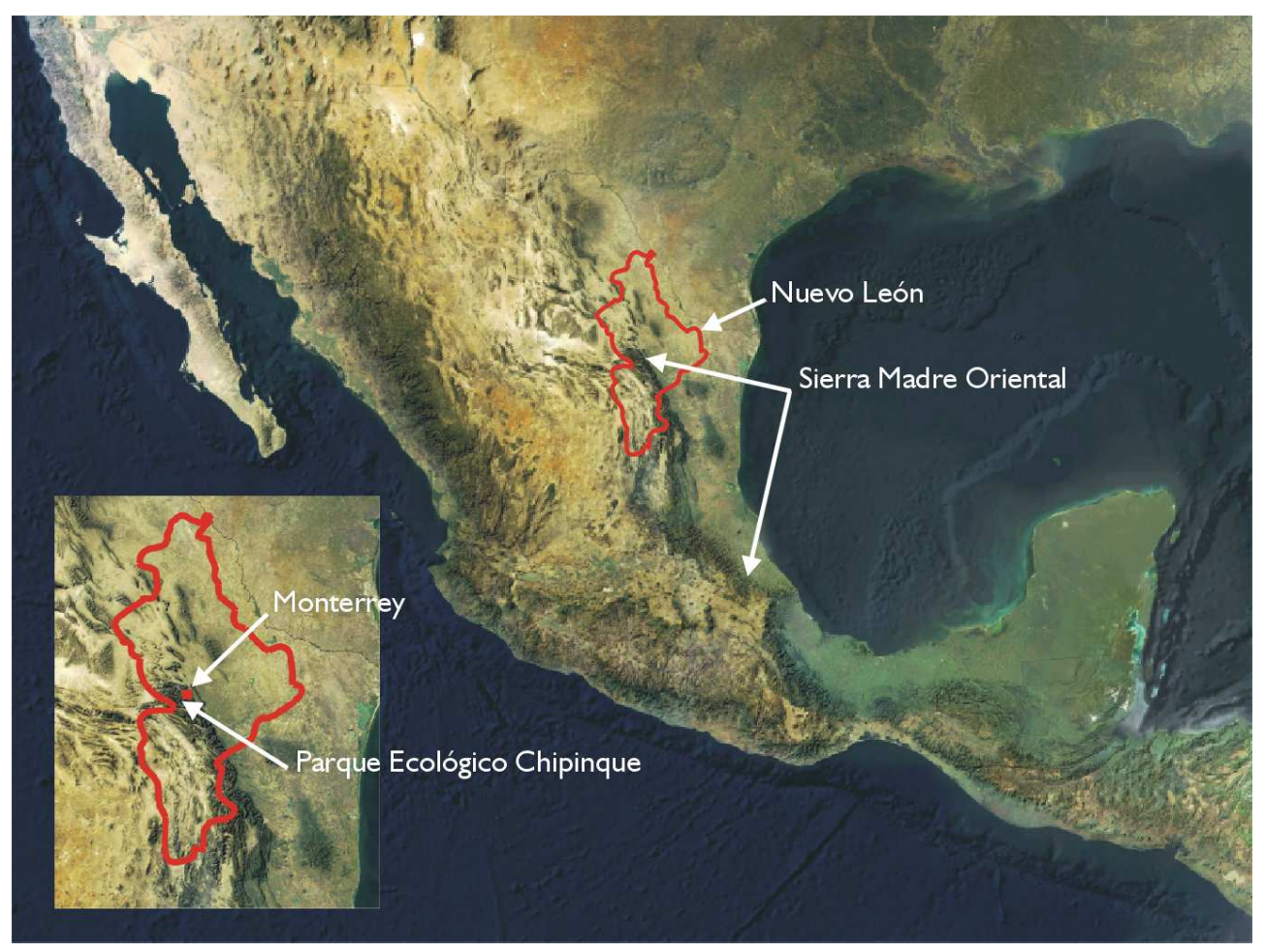

Figure 3.1: Satellite image of Mexico, including Nuevo León, its capital (Monterrey), and the location of the PECH.

\subsubsection{Topography and Soils}

The Sierra Madre Oriental consists of cretaceous and jurassic sediments, mostly limestone. The whole mountain range is folded into anticlines and synclines forming evenly sculptured elongated ridges (General Libraries 2003) [56]. Four sections are distinguished: the Northern Section, the High Sierra, the Cross Ranges, and the Lower Ranges (General Libraries 2003) [56].

The northern range of the Sierra Madre Oriental, as part of the trans-Mexicanvolcanic-belt, is irregular, due to considerable volcanism, and connects the Sierra Madre Oriental with the Sierra Madre Occidental. Abrupt topography, numerous valleys, deep canyons, and ravines run through the mountains and give the landscape spectacular scenery.

The most widespread and most common soil types in the National Park "Cumbres de Monterrey" including the PECH, are litosoles (PNCM 2003) [113]. 


\subsubsection{Climate}

The research area is located in a high pressure, subtropical zone. The local climate is influenced by maritime and continental air masses, as well as superior circulations that cause a wide amplitude of temperature that is characteristic for the subtropical region (PNCM 2003) [113].

According to Köppen's (1918) [86] classification, the climate in the north and southwest of Nuevo León is defined as steppe climate with an average annual temperature over $18^{\circ} \mathrm{C}$ and a dry season winter (BShw). The climate in the eastern part of the research area is defined as a middle latitude rainy climate with mild winters and a small amount of rainfall in all months, with a maximum in autumn $\left(\mathrm{Cx}^{6} \mathrm{w}^{6}\right)$ (General Libraries 2003) [56].

In the winter time, the subtropical zone of high pressure moves towards the south and the climate is predominately influenced by the cyclonic air masses from the west that are typical for the middle latitudes (PNCM, 2003) [113]. These air masses (or winds) are considerably less humid and the cool season is, therefore, mainly arid. In this period, an invasion of polar air masses from the north (USA and Canada) is possible and the temperature can fall below $0^{\circ} \mathrm{C}$. Extraordinary minimum temperatures were measured in December 1983 with an absolute minimum of $-8.0^{\circ} \mathrm{C}$.

During the summer season, the climate is influenced by humid air masses coming from the Mexican Gulf in the Northeast (caused by the anticyclonic centre "BermudaAzores" over the Mexican Gulf) that collide with the mountain range "Sierra Madre Oriental", where the air masses rise up, cool off, and the humidity in the air falls as precipitation. This is an important reason why the northeast side of the mountain range is humid and the windless southwest side more arid (PNCM 2003) [113].

There was no weather station in the PECH until the year 2001/02, but the general climatic conditions in the PECH are considered to be similar to those of Monterrey. Therefore, climatic data to describe the research area are taken from the station "San Nicolas de los Garza" in Monterrey $\left(25^{\circ} 44^{\prime} 01^{\prime \prime}\right.$ ' N and $100^{\circ} 18^{\prime} 17^{\prime \prime}$ ' W, $515 \mathrm{~m}$ above sea level).

In general, the climate is determined by two seasons: the hot summer from May to October and the cool winter circulation (or season) from November to April. The mean annual temperature is $22.3^{\circ} \mathrm{C}$ (calculated from 1977 to 2001) and the mean 
annual total precipitation is $602 \mathrm{~mm}$ (calculated from 1958 to 2001) (CNA 2004 internet) [23]. The variation and distribution of the mean monthly temperature and the mean monthly total precipitation are shown in Figure 3.2.

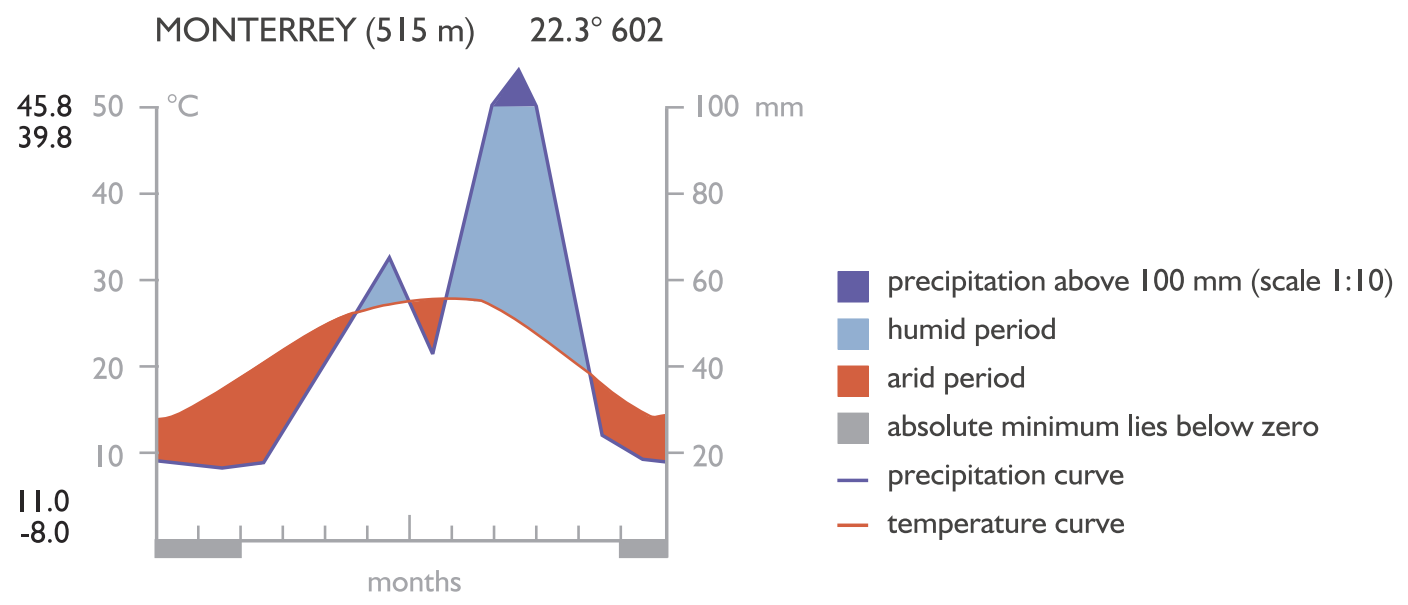

Figure 3.2: Climatic diagram for Monterrey (computed from INEGI, 2004 [72]; based on Walter and Lieth, 1967) [151].

Since the PECH is located on the northeast side of the Sierra Madre Oriental, the precipitation rate is relatively high. The name "Chipinque" or "chichipini" has its origin in the indigenous language Náhuatl and can be translated as "caer gota a gota" in Spanish or "falling drops" in English (CONABIO 2002, México desconocido No. 232 / junio 1996) [24, 96].

The highest temperatures and solar radiation occur during the summer season. In the hottest month, July, a mean daily temperature of $28.5^{\circ} \mathrm{C}$ is reached (CNA 2004 internet) [23]. A mean daily maximum of $30.7^{\circ} \mathrm{C}$ was recorded in June 1998 and an absolute maximum of $45.8^{\circ} \mathrm{C}$ in May 1998 , which are the hottest values in the period from 1977 to 2001 . With increasing precipitation, the temperatures start to fall at the end of August to a minimum mean daily temperature of $14.1^{\circ} \mathrm{C}$ in January (CNA 2004 - internet) [23].

The absolute of $11.0^{\circ} \mathrm{C}$ was recorded in January 1985 for the period from 1977 to 2001 (CNA 2004 - internet) [23]. Only minimal precipitations (frontal type precipitations) occurs during the cold season; it is caused by the accumulation and collision of several cold fronts. February is the driest month with a mean daily total of $16.3 \mathrm{~mm}$ of precipitation (CNA 2004 - internet, PNCM 2003) [23, 113]. Since the main precipitation occurs during the hot months, when the monthly evaporation is extremely 
high, (232.90 mm mean evaporation in July and $216.58 \mathrm{~mm}$ mean evaporation in August calculated from 1982 to 2001), water is a limititing factor for the vegetation in the PECH.

\subsubsection{Vegetation}

Due to the topographical diversity and the different altitudes of the Sierra Madre Oriental, three main vegetation types could develop: the "matorral submontano" in the lower parts, the oak forests in the middle altitudes, and the pine-oak forests in the higher parts of the mountain range. The most important species of flora present in the research area are mentioned in the Table 3.1.

Table 3.1: Important species of flora present in the Park (Alanis 1996) [3].

\begin{tabular}{llll}
\hline Oak & mixed-forest & Submontane matorral & Other species \\
\hline Q. rhizophylla & P. pseudostrobus & Acacia rigidula & A. xalapensis \\
Q. canby & P. teocote & Pithecellobium pallens & Juglans mollis \\
Q. laceyi & J. flaccida & Zanthoxylum fragara & Carya illionensis \\
Q. polymorpha & & Sophora secundifolia & Cornus florida \\
Q. laeta & Ehretia anacua & Prunus serotina \\
Q. virginiana & & Cordia boissieri & Cercis canadensis \\
& & Acacia berlandieri & Ungnadia speciosa \\
\hline
\end{tabular}

$\mathrm{A} .=$ Arbutus, $\mathrm{J} .=$ Juniperus, $\mathrm{P} .=$ Pinus, $\mathrm{Q}=$ Quercus 


\subsection{Stand Inventory and Plot characteristics}

\subsubsection{Identification of Burned Areas}

Scientific and statistical literature was studied intensively to evaluate if forest fires had occurred in the study area in the PECH. However, there was no detailed information available, in historical documents, journal accounts, or in general land office survey notes about wildland fire occurrences within the PECH. Also, the comparison of historic photographs with their contemporary equivalents did not result in viable indications. Thus, there was no detailed recorded information about forest fire events in the research area, except the extraordinary wildland fire in the year 1998. Hence, postfire cohorts had to be identified in the pine-oak forests in order to reconstruct the fire history of the PECH and to analyze the reafforestation and succession after forest fires. Even-aged forest stands were a precondition for this research. Personal reconnaissance field surveys were carried out to detect and identify homogenous and even aged pineoak stands that might be post-fire cohorts. To start, homogeneous pine-oak stands had to be identified in the PECH, in order to narrow down possible formerly burnt forest stands. These pine-oak stands covered a range of different age classes, from young recently burnt stands to mature forests that were disturbed by a forest fire a long time ago (Fig. 3.3). Forest stands of different age classes were required for the planned investigation of changes in plant diversity and natural succession after forest fires.

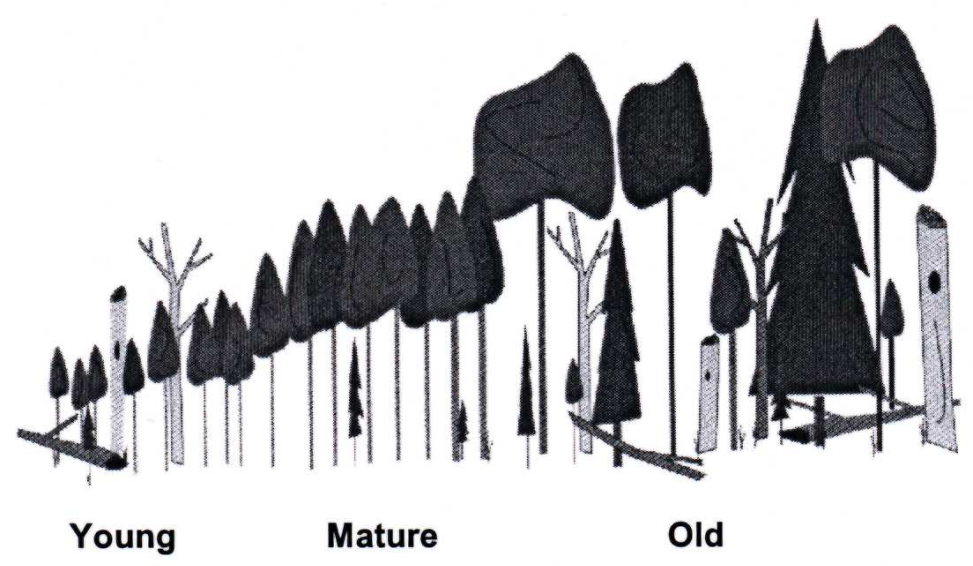

Figure 3.3: Schematic representation of stand structure as a function of the stand age (Schneider 2001) [128]. 
This method, also known as "Chronological community ordination" and used for the initial identification of formerly burnt areas, is employed internationally. For example, Gill (1999) [59] determined the changes in plant diversity after wildland fires in Australia by employing chronological community ordination in several investigations.

Nine stands were randomly selected within the PECH, five on north-northeast exposed slopes and four on south-southwest facing slopes. Next, the nine homogeneous stands were searched for signs of past forest fires like bole scars or charcoal in the surface soil, in order to identify them as post-fire cohorts. Detailed information about the location of all stands in the PECH is showed in the following map (Fig. 3.4). 


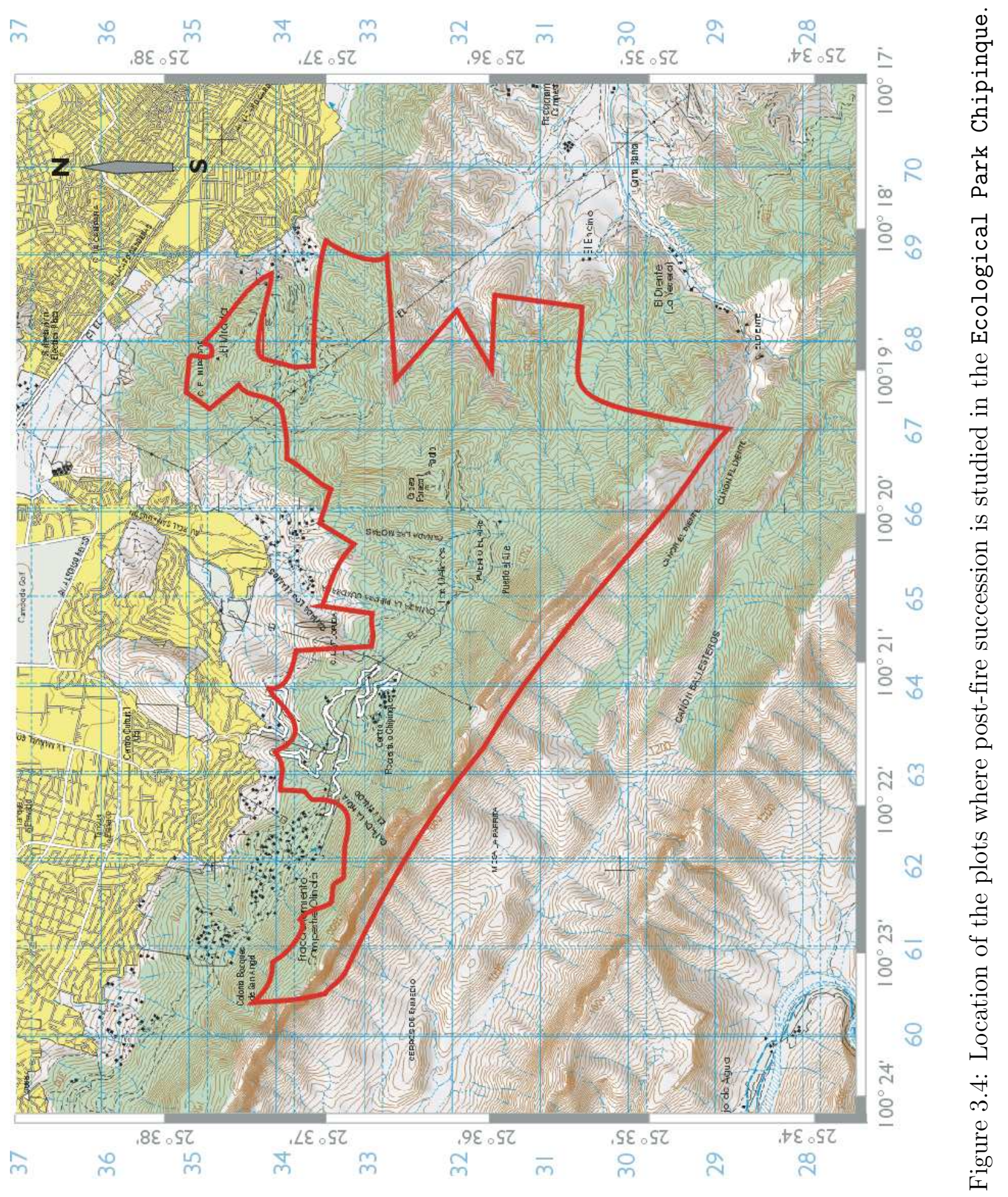


The next step was to determinate the approximate size of the burned area. To do this, bole scars were systematically searched in each identified homogeneous forest stand. The search began at a randomly chosen point in an edge of the prevailing stand. From this point on, a straight trail (T1) was followed and all the trees within a range of $15 \mathrm{~m}$ on each side of the trail were checked for bole scars (Fig. 3.5). The biggest and oldest trees showing bole scares were marked with a tape. The end of the burned area was reached when there were no scarred trees found anymore. At this point, a second trail (T2) was then followed and checked, at a distance of $30 \mathrm{~m}$ and parallel to the first one. This procedure was continued until no more bole scars could be found and the formerly burnt area was defined definitively.

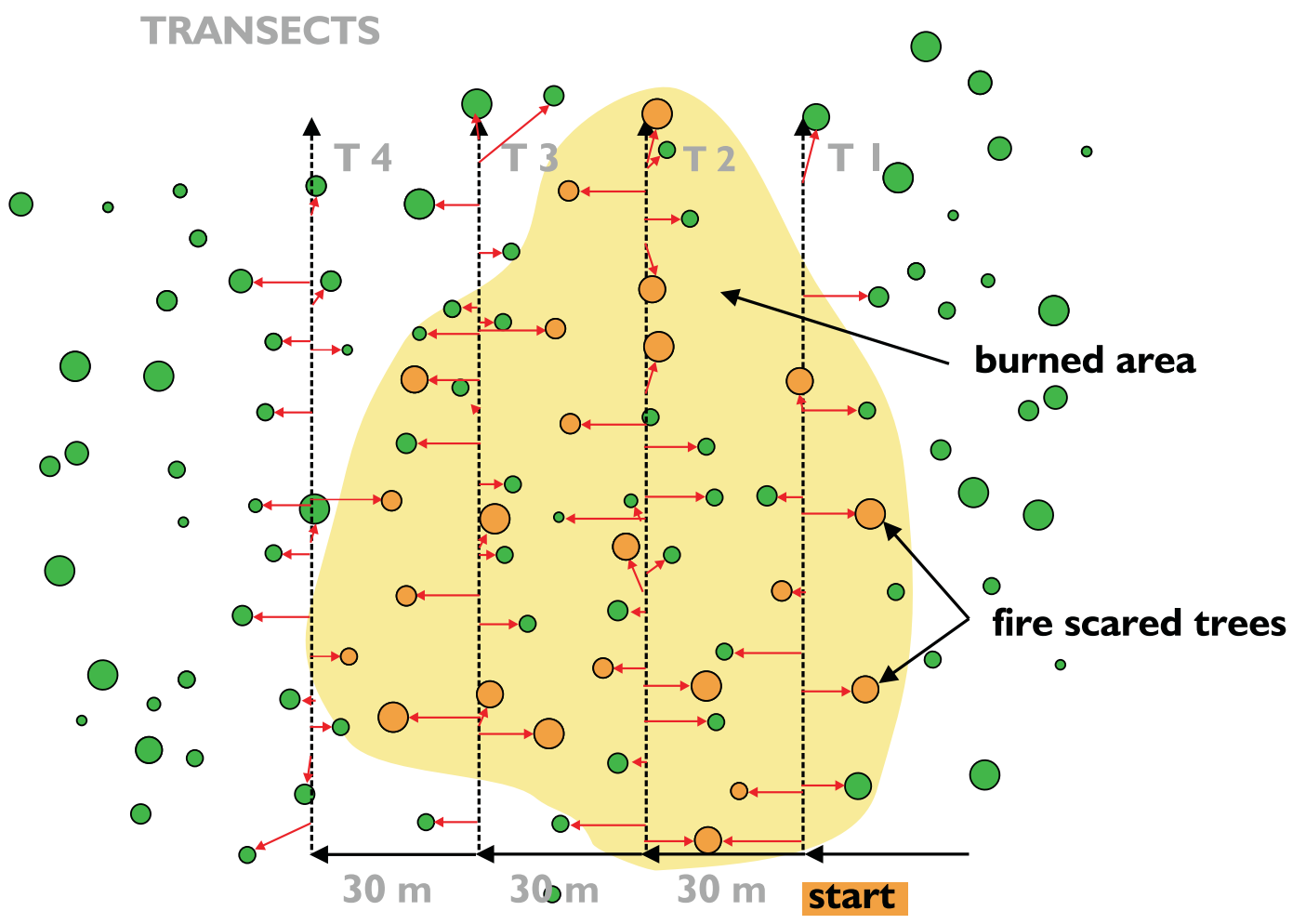

Figure 3.5: Transects in the delimited burned area. Traces of fire were marked and core samples were obtained from the oldest individuals of Pinus teocote and Pinus pseudotrobus.

Cores from 64 living trees of $P$. teocote and P. pseudostrobus were taken between October 2002 and April 2003 (Table 3.2). Two core samples where taken: at breast height $(1.3 \mathrm{~m})$ and $20 \mathrm{~cm}$ above the ground, where possible. The cores were taken using a SUUNTO® increment borer. Tree rings of all samples were analyzed in the 
tree ring laboratory of the Institute of Silviculture at the Forestry Faculty (UANL) in Linares, N.L., Mexico. First, core samples were dried and glued in a grooved wooden stick. The surface of the cores was sanded and polished in order to improve the distinctiveness of fire scars under the Digitalpositiomer.

In the Table 3.2 the stand characteristics of all nine post-fire cohorts found on north- and south-facing slopes in the PECH are summarized.

Table 3.2: Characteristics of five fire history sites in the PECH.

\begin{tabular}{llllllll}
\hline $\begin{array}{l}\text { Fire } \\
\text { year }\end{array}$ & $\begin{array}{l}\text { Stand } \\
\text { age }\end{array}$ & Site name & Aspect & Elevation & Slope & Forest type & $\begin{array}{l}\text { samples } \\
\text { cored }\end{array}$ \\
\hline 1998 & 4 & PECH-098 & NE & $1125 \mathrm{~m}$ & $23^{\circ}$ & pioneer species & 0 \\
& & & SE & $1220 \mathrm{~m}$ & $36^{\circ}$ & pioneer species & 0 \\
1984 & 18 & PECH-084 & $\mathrm{N}$ & $1300 \mathrm{~m}$ & $36^{\circ}$ & oak & 5 \\
& & & $\mathrm{~S}$ & $1332 \mathrm{~m}$ & $30^{\circ}$ & oak & 6 \\
1972 & 30 & PECH-072 & $\mathrm{N}$ & $1380 \mathrm{~m}$ & $23^{\circ}$ & oak-pine & 11 \\
& & & $\mathrm{~S}$ & $1370 \mathrm{~m}$ & $22^{\circ}$ & oak-pine & 4 \\
1940 & 62 & PECH-040 & $\mathrm{NE}$ & $1300 \mathrm{~m}$ & $27^{\circ}$ & pine-oak & 4 \\
& & & $\mathrm{~S}$ & $1206 \mathrm{~m}$ & $26^{\circ}$ & pine-oak & 4 \\
1868 & 134 & PECH-868 & $\mathrm{N}$ & $1195 \mathrm{~m}$ & $28^{\circ}$ & pine & 30 \\
\hline
\end{tabular}

\subsubsection{Plot Layout}

One important objective of this research was to describe and understand forest succession after forest fire events in pine-oak forests.

There are different ways to document succession:

- observation of several stages in one area and repeated measurements on one plot over time, or

- comparison of plant communities in different areas of comparable site factors, corresponding to different points in times since the succession's beginning, from which the sequence of communities is inferred (Holmes 2003) [71]. 
Since the ecological processes have not been observed and recorded over a long period of time, the temporal scale is much too long. Thus, succession in the pine-oak forests was documented by the comparison of forest stands at different successional stages. To record and understand the natural succession after forest fire events in pine-oak forests, these stands had to be described and compared by an inventory.

Due to the high costs and large investment of time demanded by an inventory of all individuals, a method of random sampling was carried out in order to collect the parametric data required for the description of the identified post-fire stands (Jiménez 2001)[76].

Once the burnt forest stands were identified, a systematic grid of $300 \times 300 \mathrm{~m}$ was laid over each stand. Oriented on the grid, sample plots of concentric circles were established in the stands starting at a random point (Fig. 3.6).

\section{COMPLETELY BURNED}

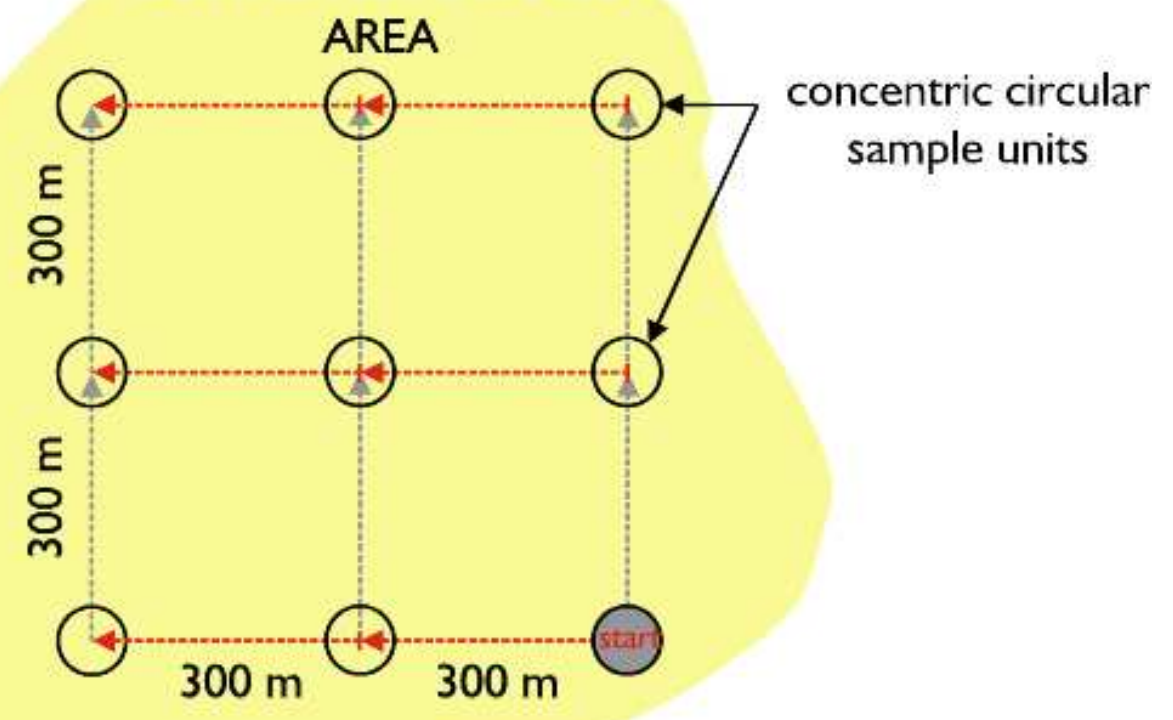

Figure 3.6: Plot layout for concentric circular sampling plots.

The concentric circular sample unit consisted of an $1000 \mathrm{~m}^{2}$ outer plot and a 500 $\mathrm{m}^{2}$ plot. The outer plot $\left(1000 \mathrm{~m}^{2}\right)$ was used to collect the parametric data such a height, diameter, azimuth for all species trees with a dbh $\geq 10 \mathrm{~cm}$. The inner subplot, 
with a radius from $12,62 \mathrm{~m}\left(500 \mathrm{~m}^{2}\right)$ it was used for measurements of tree species with a dbh $\leq 10 \mathrm{~cm}$ (Fig 3.7$)$.

\section{CONCENTRIC CIRCULAR SAMPLE AREA}

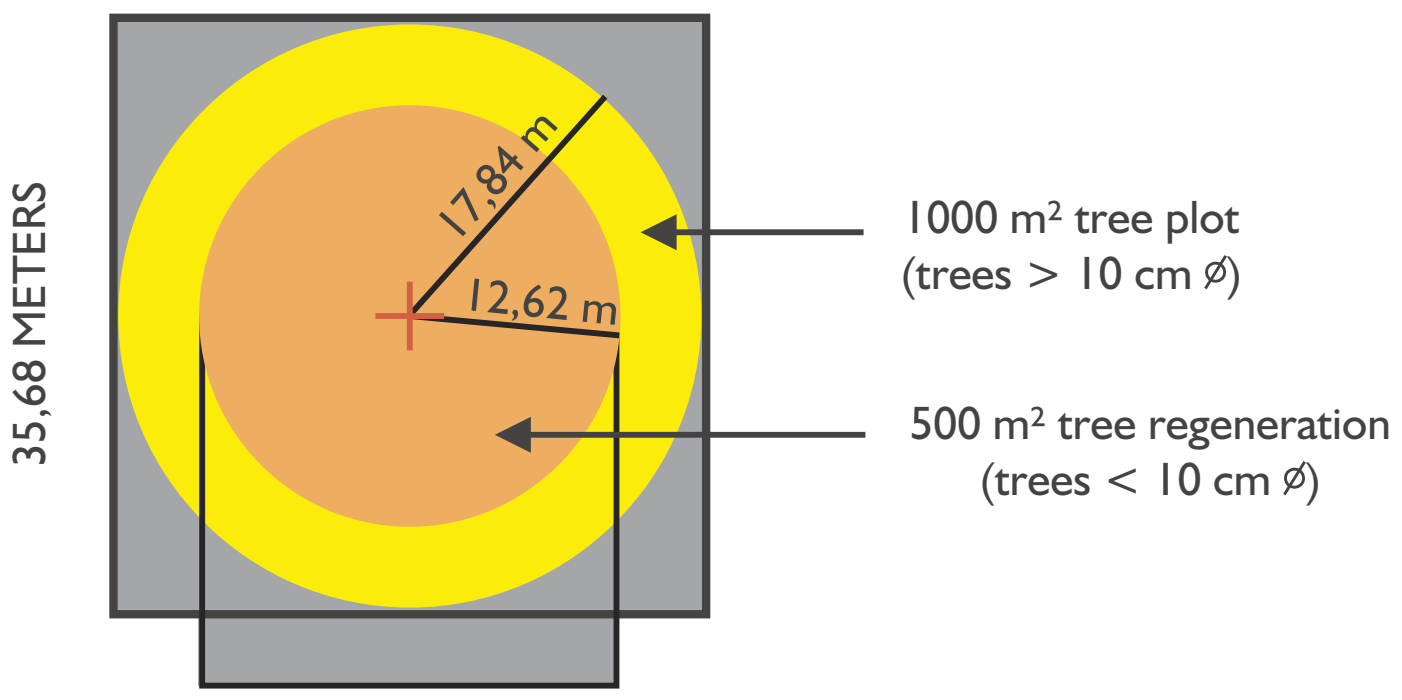

25,24 METERS

Figure 3.7: Concentric circular sample plots design.

To investigate structural characteristics of the stand in the study areas, the following parameters were measured and recorded in the concentric plots:

1. Species name: Determination of the botanical name using keys; unidentified specimens were taken to the herbarium of the faculty of Forestry Sciences in Linares (FCF, UANL) for identification.

2. Diameter at breast height $(\mathbf{d b h})$ : Measured with a diameter tape at $1.3 \mathrm{~m}$ above ground or in case of small trees, $0.30 \mathrm{~m}$ above the ground.

3. Tree height: Measured with a Haglöf laser Vertex hypsometer. In regeneration cohorts, the height was estimated using a measuring stick for heights up to $6 \mathrm{~m}$. 


\subsection{Forest Structure}

A forest stand is defined as an aggregation of trees occupying a specific area and sufficiently uniform in species composition, age, arrangement, and condition so that it is distinguishable from the adjacent forest areas. Stand structure in forestry is generally concerned with the different horizontal and vertical physical elements of the forest, such as basal area and volume, the diameter frequency distribution, and the height of stand. This quantitative information regarding a stand is related directly to silvicultural and management decisions (Aguirre 2003, Gadow 2003) [2, 50]

\subsubsection{Diameter Distribution}

Diameter and variation in diameter are often used for a first characterization of a stand. For a detailed stand analysis, it is necessary to have information on diameter structure. For many purposes in practice, however, the use of mean values is sufficient.

\section{Arithmetic Mean Diameter $(\bar{d})$}

Arithmetic mean diameter of a stand is calculated as

$$
\bar{d}=\sum_{i=1}^{N} \frac{d_{i}}{N}
$$

where $d_{i}$ is the diameter of the individual tree and $N$ the total number of trees in the stand.

Besides the mean diameter itself, the standard deviation is a very meaningful value. Equals to the square root of the variance. Standard deviation is a measure of the homogeneity of the diameter distribution. The variance $\left(\sigma_{x}^{2}\right)$ and standard deviation $\left(\sigma_{x}\right)$ of a population are calculated using the following equations

$$
\begin{gathered}
\sigma_{x}^{2}=\sum_{i=1}^{N} \frac{\left(x_{i}-\mu\right)^{2}}{N} \\
\sigma_{x}= \pm \sqrt{\sigma_{x}^{2}}
\end{gathered}
$$

To compare variance for values of different orders of magnitude, the coefficient of variation $\left(\sigma_{x} \%\right)$ is useful.

$$
\sigma_{x} \%=\frac{\sigma^{x}}{\mu_{x}} * 100
$$


The absolute distribution of the number of stems per diameter class gives a good perception of the stand structure (Gadow 2003) [50]. These values, which can be calculated from the compiled basic data, are usually depicted in a graphical form.

\subsubsection{Stand Height}

While it is relatively easy to measure the diameter of all the trees of a stand, the height measurement is technically more difficult and time consuming. Therefore, the heights for a representative sample of trees are usually measured. While, the dbh is a function of age and influenced by silvicultural treatments, the height is an indicator for the quality of the site (climate, soil, exposition) and is barely influenced by silvicultural treatments. On high quality sites, increased growth energy leads to differentiation into sociological tree classes (Loetsch et al. 1973) [90].

\subsubsection{Mean Height}

The mean height of a stand is calculated as

$$
\bar{h}=\sum_{i=1}^{N} \frac{h_{i}}{N}
$$

where $h_{i}$ is the height of the individual tree and $N$ is the total of number of trees in the stand.

\subsubsection{Stand Density}

The stand density expresses to which extent a given area is covered with trees. It is an indicator for the productivity of a stand and can be used to estimate the potential yield (Gadow 2003) [50]. Basal area and number of stems, these two parameters are commonly used to describe stand density.

\section{Stand basal area}

The stand density expresses the extent to which a given area is covered with trees. It is an indicator for the productivity of a stand and can be used to estimate the potential yield. Basal area and number of stems are two parameters, which are commonly used to describe stand density. 
Stand basal area $(G)$ is defined as the sum of the cross section of all trees of a stand, measured at $1.3 \mathrm{~m}$ height. It is usually expressed per hectare (Gadow 2003) $[50]$ :

$$
G=\sum_{i=1}^{N} g_{i}
$$

where

$$
g i=\frac{\pi}{4} * d_{i}^{2}
$$

and $g_{i}$ is the basal area of a single tree.

\subsubsection{Stand Volume}

Stand volume is the most important stand characteristic in stand inventories. It is a function of the number of trees, basal area, height, and form of the trees. The stand volume is usually estimated from the diameter and height of the mean tree (van Laar and Akça 1997) [147]. A higher precision is obtained when the stand volume is estimated as the sum of the volumes of the individual trees:

$$
V=\sum_{i=1}^{N} v_{i}
$$

where $V$ equals to the stand volume/ha, $v_{i}$ is volume of the individual tree, and $N$ is the number of trees per hectare.

The volume of individual standing trees is estimated from a function with dbh and height as predictor variables:

$$
v=g * h * f
$$

where $v$ is volume, $g$ is basal area, $h$ is height, and $f$ is a form factor. The form factor varies between different tree species and with tree age. For uneven-aged mixed stands, a form factor of 0.5 is commonly used (Gadow 2003) [50].

The stand volume for each post fire cohort in this study was estimated as

$$
V=\sum_{i=1}^{N} g_{i} * h_{i} * 0.5,
$$

where $V$ is the volume of above-ground wood and bark with a minimum diameter of $4 \mathrm{~cm}$. 


\subsubsection{Importance Value Index (IVI)}

At each post-fire cohort, the importance value index (IVI) of each species was calculated, based on all data from the measurement (including all woody species $\geq 5 \mathrm{~cm}$ ). IVI was used to describe the composition of each post-fire stand and was calculated as follows:

$$
I V I=\sum(R A+R D+R F)
$$

where RA is relative abundance (stem density of a species in a plot, expressed as percentage of all stems of all species in a plot), RD is relative dominance (basal area of a species in a plot), and RF is relative frequency, which is the occurrence or absence of a given species in a subplot (calculated as its percentage of the total of the absolute frequencies of all the species). This index permits a comparison of the ecological significance of species in a given forest type (Gadow 2003) [50].

When these relative values are combined (frequency, abundance, and dominance), we are able to get a better understanding and depict the horizontal structure of the species. Jiménez (2001) [76], describes a classification system with different possibilities of combinations of the species. According to the relative values of frequency, abundance, and dominance, four groups are differentiated.

Group 1 Both high abundances and high frequencies. This a characteristic where there is a regular horizontal distribution of species.

Group 2 High abundance and low frequency. The species found in this group have the tendency to form clusters. These species occur in widely separated, small and large groups.

Group 3 Low abundance and high frequency. Typical for this group are single trees in a dominant position, whose occurrence is uncommon but which are evenly distributed over extensive areas.

Group 4 Low abundance, low frequency, and low dominance. Rare casual species of no major ecological or economic significance occur in this combination. 


\subsection{Estimation of the Potential Solar Radiation}

To account for temporal variability in radiation, we developed potential solar radiation (PSR) as an integrative index which sums hourly estimates of radiation over the day and then sums daily values over the growing season. Each point estimate accounts for topographic shading by surrounding landscape features. The method can be summarized as follows:

1. Calculate solar inclination angle (the complement of solar zenith) and solar azimuth for daylight hours for the 15th day of a month in order to represent the entire year and growing season (equations 2.14 and 2.16).

2. Calculate hourly hillshade radiation grids using a Digital Elevation Model (DEM), solar azimuth and solar inclination (Arc/Info Hillshade function with Model Shadow and all option).

3. Obtain DEM of the study site (Governmental Agency INEGI ${ }^{1}$ ).

4. Sum hourly values to get daily totals which represent monthly averages.

5. Sum monthly averages to get seasonal values of Potential Solar Radiation.

There are many sources for finding solar azimuth and inclination for a specific location and time of the day. Since solar path changes continuously throughout the year, it is recommended to use a single day of the month to represents that period (Klein 1997) [85]. The program developed by Wittmann, from the Göttingen Observatory (Schulz 2003) [129]. This program was employed, in order to calculate the precise solar inclination for the $24 \mathrm{hrs}$ of the day and the azimuth for the coordinates $25^{\circ} 34^{\prime}$ North and $100^{\circ} 18^{\prime}$ West for the study area.

Special care was dedicated to the incorporation of enough surrounding area to properly capture topographic shading. The DEM was incorporated into Arc/Info and used the solar position information with the Hillshade function.

$$
H S=255[\cos (90-Z) \sin (s) \cos (\alpha-A)+\sin (90-Z) \cos (s)]
$$

\footnotetext{
${ }^{1}$ Instituto Nacional de Estadística Geografía e Informática
} 
where $Z$ is the solar zenith, $s$ is the local slope, $A$ is the solar azimuth, and $\alpha$ is the azimuth of the slope facet (ESRI 1994) [36]. The Hillshade function uses the solar inclination angle, which is the complement of solar zenith $(90-Z)$.

This function calculates relative insolation, based on surface orientation, solar position, and self-shading, by calculating the angle between the vector normal to the plane of the ground and the solar Position (ESRI 1994) [36]. Model shadow and all option. These operation were performed for each hour of daylight on the representative day of each month of the growing season. To calculate monthly radiation values, the sum over the hourly grids was made. To calculate relative seasonal radiation values, the sum of the monthly grids was used (Schulz 2003) [129].

\subsection{Measurement of Ecological Diversity}

\subsubsection{Alpha Diversity $(\alpha)$}

The indices are a means of gaining information for comparisons, particulary between different burned areas and slopes. The alpha diversity analysis was first calculated for both gradients, the north- and south- facing slopes, which were considered as two data sets. Afterwards, these indices were calculated for each post-fire cohort found in the nine post-fire stands. The listed indices for the analysis of the Alpha diversity are provided in Table 3.3.

Forest fire can have major effects on plant species diversity. These effects occur through changes which take places after a fire event. The way we measure diversity is important to the way in which the effect of forests fire are perceived. Variables that contribute to the measurement of diversity include the number of species present in an area itself and the number of individuals plants per species. Measures of diversity can be also expressed in the form of a relationship, for example, the number of species in areas or as indices (Gill 1999) [59]. Although there is much interest in the development of indicators or inventories of ecosystem function, species richness is still the most employed approach to distilling the available information. Species richness is simply systematic inventory of the number of species contained within an area. The $\alpha$ indices were calculated using the software $R$ statistical. The species accumulation curves were obtained from the $\mathrm{R}$ statistic program, vegan package, specacumm function. 
Table 3.3: The measures of alpha diversity $(\alpha)$ for the PECH and each post-fire cohort.

\begin{tabular}{lll}
\hline Indices & Formula & Equation \\
\hline Species richness indices & & \\
Margalef's index $\left(D_{M g}\right)$ & $D_{M g}=(S-1) \ln N$ & Eq. 2.1 \\
Evenness $(\mathrm{E})$ & $E(\%)=100 * H^{\prime} / \ln H_{\max }$ & Eq. 2.2
\end{tabular}

\section{Species abundance models}

The geometric series

$$
\begin{array}{ll}
n_{i}=N C_{k}(1-k)^{i-1} & \text { Eq. } 2.3 \\
\alpha x, \frac{\alpha x^{2}}{2}, \frac{\alpha x^{3}}{3} \ldots \frac{\alpha x^{n}}{n} & \text { Eq. } 2.4 \\
S(R)=S_{0} \exp \left(-a^{2} R^{2}\right) & \text { Eq. } 2.5 \\
S(n)=\frac{S(S-1)}{N} \frac{(1-n)}{N}^{(s-2)} & \text { Eq. 2.6 }
\end{array}
$$

The $\log$ series

The log normal distribution

The broken stick model

\section{Proportional abundance indices}

Simpson Index (D)

$D=\sum_{i}^{S_{o b s}} p_{i}^{2}$

Eq. 2.7

Shannon index $\left(\mathrm{H}^{\prime}\right)$

$H^{\prime}=-\sum p_{i} \ln p_{i}$

Variance of H'

$\operatorname{Var} H^{\prime}=\frac{\sum p_{i}\left(l n p_{i}\right)^{2}}{N}+\frac{S-1}{2 N^{2}}$

Eq. 2.10

Hutcheson ( $\mathrm{t}$ Test)

$t=\frac{H_{1}^{\prime}-H_{2}^{\prime}}{\left(\operatorname{Var} H_{1}^{\prime}+\operatorname{Var} H_{2}^{\prime}\right)^{1 / 2}}$

Eq. 2.11

Degree of freedom

$d f=\frac{\left(\operatorname{VarH}_{1}+\operatorname{VarH}_{2}\right)^{2}}{\left(\operatorname{VarH}_{1}\right)^{2} / N_{1}+\left(\operatorname{VarH}_{2}\right)^{2} / N_{2}}$

Eq. 2.12

$S=$ number of species, $N=$ Number of individuals, $n_{i}=$ the number of individuals in the $i$ th species, $C_{k}=\left[1-(1-k)^{s}\right]^{-1}, \alpha x=$ the number of species predicted to have one individual, $S(R)=$ the number of species in the $R$ th octave (class), $a=\left(2 \sigma^{2}\right)^{1 / 2}=$ the inverse width of the distribution, $S(n)=$ the number of species in the abundance class, $p_{i}$ equals the proportion of individuals in the $i$ th species, $N_{1}$ and $N_{2}$ are the total number of individuals in the two samples, respectively. 


\subsubsection{Beta Diversity $(\beta)$}

Several similarity coefficients were used to test the hypothesis that the north- and south-facing slopes of each burned area were random samples from identical species. The alternative hypothesis was that the number of species and abundance are not identical. The Whittaker's measure $\beta_{w}$ was used to compare the species composition of the north and south-facing slopes. Furthermore, indices such as the Jaccard and Sorensen's coefficient of similarity were calculated for each post-fire stands. Additionally, in order to considerate quantitative data, the Sorenson quantitative similarity index was calculated.

The $\beta_{w}$ was calculated for the two data sets with a formula proposed by Whittaker (1960) [154] using the software R statistic.

$$
\beta_{w}=(S-\alpha)-1
$$

where $\mathrm{S}$ is the total number of species recorded in every slope along the chronosequence and $\alpha$ is the average species richness in the two slopes. Particulary widely used are the Jaccard index (eq. 3.14) and the Sorensen index (eq. 3.15) (Magurran, 1988) [91].

$$
\begin{gathered}
C_{j}=\frac{j}{a+b-j}, \\
C_{s}=\frac{2 j}{a+b},
\end{gathered}
$$

where $j=$ the number of species found in both sites, $a=$ the number of species in Site $\mathrm{A}$, and $b$ the number of species in Site B.

These indices are designed to equal 1 in cases of complete dissimilarity (species in both data sets are not identical) and 0 if the sites are similar and have all species in common. For these indices, all species count equally in the equation irrespectively of whether they are abundant or rare. This consideration has led to similarity measures based on quantitative data. The most widely used is the version if the Sorensen index modified by Bray and Curtis in 1957 (Magurran 1988) [91].

$$
C_{N}=\frac{2_{j N}}{a N+b N}
$$

where $a N=$ the total number of individuals in site $\mathrm{A}, b N=$ the total number of individuals in the site $\mathrm{B}$, and $j N=$ the sum of the lower of the two abundances 
recorded for species found in both sites.

\section{Complexity Index (CI)}

Values of diversity were calculated for the north and south-facing slopes. The complexity of each post-fire stand had to be considered. In an extreme example, a stand with only two trees per hectare, where the trees belong to different species, would have the highest possible diversity $(D=0$ and $E=1$ ). To express the complexity of a stand the complexity Index (CI) is proposed, which is based on $1000 \mathrm{~m}^{2}$ sample plot surveys of all trees with a dbh $\geq 10 \mathrm{~cm}$. Lamprecht (1986) [87] made a modification to this because of the small sample sizes. This modification allowed one to extrapolate to the size of 1 ha. The modified Complexity Index for the sample size was calculated as follows.

$$
C I=10^{-4} * h * g * n * s
$$

where $\bar{h}=$ mean stand height $(\mathrm{m}), g=$ basal area of all trees $\left(m^{2}\right), \mathrm{n}=$ number of trees measured, and $s=$ number of species.

\section{Spanning Trees for Dissimilarities}

In order to find the connection between the post-fire cohorts on both slopes, the function disconnected (Connectedness and Minimum Spanning Tree for Dissimilarities) from the R statistic program was used. Function 'disconnected' finds subsets in dissimilarity matrices which can be related to each other. The function will produces a grouping vector that can be used for subsetting the data. If data are connected, the result vector will be all 1s. 


\subsection{Multivariate Analysis and Statistics}

\subsubsection{Multivariate Analysis}

Multivariate analysis serves to understand community ecology in the following ways: (1) it aids investigators in the discovery of structure in a data set and (2) provides relatively objective summarization of the data (Huag 1997) [145]. Both concepts help one understand the data and provide a mean for producing successful results. Jongman (1995) [80] review some differences between multivariate methods with statistical univariate and bivariate methods. Classical statistics is primarily concerned with the testing of hypotheses and is powerful when dealing with one or a few variants. Multivariate statistics begins with no specific hypotheses; the purpose is to elicit some internal structure from the data, from which hypotheses can be derived.

Three basic multivariate strategies are recognized: (1) classification, (2) ordination, and (3) direct gradient analysis (Pielou 1984) [119]. Classification results in the assignment of species and samples to classes (Pielou 1984) [119]. Ordination results in the arrangement of species and samples in a low dimensional space so that similar sets are close and dissimilar sets are separate (Gauch 1982) [54]. Direct gradient analysis portrays both abundances and environmental variables along recognized gradients.

\section{Classification}

The goal in community classification is to summarize data sets. Classification of data involves grouping similar entries together in cluster or classes (Gauch 1982) [54]. There are three techniques: table arrangement, non-hierarchical, and hierarchical classification (Gauch 1982) [54]. Table arrangement, which displays general features and details of data. Non-hierarchical classification assigns each entry to a cluster. This is a technique which effectively deals with redundancy, noise and outliers, but does not identify appropriate relationship analysis. Hierarchical classification on the other hand assigns each entry to a cluster, but in addition arranges the clusters into a hierarchy. The use of such a technique allows the analysis of any relationship in the data (Gauch 1982) [54].

Divisive classification begins with the entire data set, which is progressively divided into individuals. The major gradients in the data are used to construct the dendrogram or cluster. Agglomerative classification begins with separate entities which 
are successively combined until a single cluster is formed. Small distances between similar samples are the basis of the division (Gauch 1982) [54]. Divisive techniques are preferred for analysis because they avoid the fusion of individual atypical sets that can have a negative influence in progressive clustering (Gaush and Wittaker 1981, Pielou 1984) [55, 119].

In this study the $\mathrm{R}$ statistic program, Vegan package and hclust function were used (Orkasen 2004) [109]. Classification was completed using the post-fire cohorts strata of both the north and south-facing slopes, separately. These groups were described based on plot age or indicator species. One basic goal of the study was to evaluate the species abundance patterns and the predicted connection between the species abundances and the functional ways in which communities are organized.

Initially, each object was assigned to its own cluster. Then the algorithm proceeded iteratively, joining the two most similar clusters at each stage, until there was just a single cluster. At each stage, distances between clusters were recomputed by the Lance-Williams dissimilarity formula. A corresponding species classification was produced and, in combination with the sample classification, an arranged data matrix was the result. A dendrogram was built, using sequences of division as the average distance between samples in ordination space.

Discriminant analysis was then used to build a model that classifies the sampled species according to their abundance. The resulting model was used in conjunction with the environmental layers and geographical information system to estimate the distribution of plant communities.

\section{Ordination}

Ordination is a conceptual model in which samples or species can be arranged along environmental gradients (Gauch 1982) [54]. The ordination techniques are considered indirect gradient analysis, due to the fact that environmental gradients are not studied directly, but inferred. The Ordination technique used in this study was the Detrended Correspondence Analysis (DCA), which builds on the RA algorithm. The DCA is the most widely used indirect gradient analysis (Hill and Gauch 1980) [70]. Then, DCA was used to examine the major vegetation gradients in the data, using the R statistic program, Vegan package and decorana function (Orkasen 2004) [109]. New steps were added which take advantage of the extra data contained within the 
environmental variables (Gauch 1982) [54]. Graphic examination, correlation statistics, and regression analysis were then used to assess the importance of environmental factors in determining the major species on the DCA axes.

\section{Direct Gradient Analysis}

While the classification and ordination techniques organize community data by species abundance without considering environmental data (Haug 1997) [145], the direct gradient analysis portrays species and community variables along recognized environmental variables and gradients. Consequently, the analysis provides a direct relationship between species composition and measured environmental variables. In order to find out whether correlation exists between the species abundance and the environmental variables, a Mantel test was conducted. The Mantel test measures correlations and allows for spatial autocorrelation of the data (Oksanen 2004) [109].

$$
r=\left[\frac{n(n-1)}{2}\right] * \sum_{i} \sum_{j}\left[\frac{\left(x_{i j}-\bar{x}\right)}{S_{x}}\right] *\left[\frac{\left(y_{i j}-\bar{y}\right)}{S_{y}}\right]
$$

where, $n$ refers to the total number of sampling points, $S_{x}$ and $S_{y}$ are the standard deviations, $x$ and $y$ are any variables, and $\bar{x}$ and $\bar{y}$ are means.

The $\mathrm{R}$ statistic program, vegan package, and cca function were used to perform the correspondence analysis. Function cca is based on Legendre and Legendre's algorithm (Orkasen 2004) [109]. In cca, the Chi-square transformed data matrix is subjected to weighted linear regression on constraining variables and the fitted values are submitted to correspondence analysis performed via singular value decomposition (svd).

The statistical model underlying CCA is that a species abundance is a unimodal function of position along an environmental gradient (Pielou 1984) [119]. The initial analysis involves defining the axes or canonical variates in species and environmental space. Once the variates are defined, four structure matrices are generated, that are composed of intraset and interset correlation coefficients of species and environmental factors with their own and each-other's canonical variates (Jongman et al. 1995) [80]. Graphic examination, correlation statistics, and regression analysis were then used to assess the importance of environmental factors in determining the major species on the DCA axes. 


\section{Standardization of Environmental data}

The environmental variables (radiation, time since fire, tree density, slope, and exposition) for the direct gradient analysis had to be standardized. Topographic information derived from the terrestrial inventory includes slope (degrees), and aspect (degrees). Because aspect is a circular variable, it was transformed into one derived variable, which is referred to as southness.

$$
\text { southness }=180-\mid \text { Aspect }-180 \mid
$$

so that south would be 180 and north take the value of 0 .

The Jahmeadow is defined as the mean annual direct radiation, Vegmeadow is defined as the photosynthetically active radiation (eight months). In addition the variable stand age (years after disturbance), tree density, and slope were analyzed. Species abundance and environmental data were subject to relativization by species or variable maximum before CCA.

The environmental data or variables are represented by lines which are overlaid with the species and post-fire stands scores. The importance of an environmental variable (line) is indicated by its relative length. Also, the direction of a line indicates how the variable correlates with the axes, and the angle between lines infers correlations between variables. Thus, the location of species or site scores relative to the lines indicates the environmental preference of a species and the characteristics of a stand.

\subsubsection{Statistics}

\section{Abundance of Species}

The Chi - squared analysis was used to test the null hypothesis that a given species is equally likely to occur (or will occur in equal abundance) on north- versus southfacing slopes. The ANOVAs compared the means between categories, such as the mean number of species on the post-fire stands on the north-facing slope versus those found on the south-facing slope. These analyses were run with the software SAS and the $\mathrm{R}$ statistical program (GPL2). 


\section{Differences Between Post-fire Stands and Slopes}

A two sample t-test was used to determine whether there was a significant difference between the average values of measurement made on the north and south-facing slopes. Both measurements were made on each post-fire cohort and the test is based on the paired differences between these two slopes (Delgaard 2002, Dolić 2004) [29, 32].

Ranked signs test The Wilcoxon matched pairs test is a nonparametric alternative to the t-test for dependent (correlated) samples. This rank test does not require the assumption that the population is normally distributed. It often involves the use of matches pairs, for instance the north and south-facing slope, in which case it test for a median difference of zero. The procedure assumes that the variables under consideration were measured on a scale that allows the rank ordering of observations based on each variable, and that allows rank ordering of the differences between variables. The Kruskal-Wallis Test is also a non-parametric test used to compare three or more samples. It is used to test the null hypothesis that all populations have identical distribution functions against the alternative hypothesis that at lest two of the samples differ only with respect to the median (Dolić 2004, Müllenberg 1993)[100, 32]. It is the analogue to the F-test used in analysis of variance. While analysis of variance test depend on the assumption that all populations under consideration are normally distributed, the Kruskal-Wallis test places no such restriction on the comparison (Hartung 2002, Maidonald 2004) [65, 93]. 


\section{Chapter 4}

\section{Results}

\subsection{Fire Chronology Based on Fire Scars}

The collected cores were dated and used for the reconstruction of a fire chronosequence, which covers 134 years of fire history. As a result of this reconstruction, five forest fires events could be identified in the years from 1868 to 2002 . The forest fires which occurred from 1948 to 2002 were found in stands located on both north and south-facing slopes. The burned area of the forest fire in 1868 was situated completely on the north facing slope.

The fire occurrences were compiled into a general frame, resulting in a master fire chronology. The detailed fire history reconstructed for the PECH shows that the first forest fire observed in 1868 was followed by a large period without fire occurrence. After 1940 an increased occurrence of forest fires was observed with intervals ranging from 14 to 20 years (Fig 4.1).

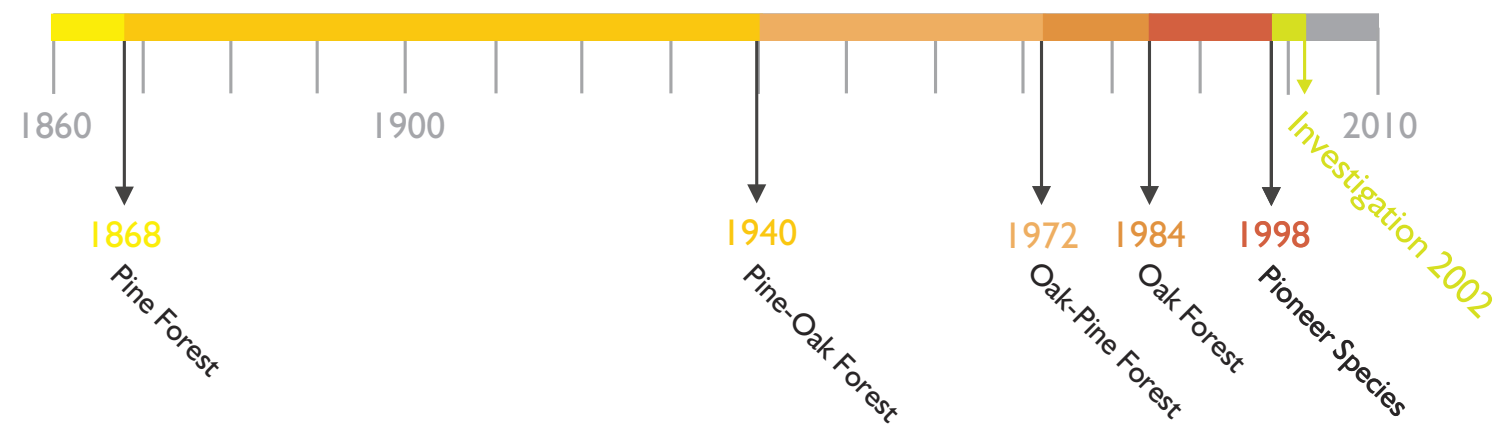

Figure 4.1: Reconstructed master fire chronology for the PECH from 1868 to 2002. 


\subsection{Fire Cohorts}

Although the fire intensity within and among different forest fires was variable, the forest fires, were responsible for destroying most above-ground vegetation in some areas within the PECH. The evidence of past fire occurrence and wildfire behavior was reflected in post-fire patches with characteristics such as tree recruitment patterns and different age structures in the PECH (Fig. 4.2).
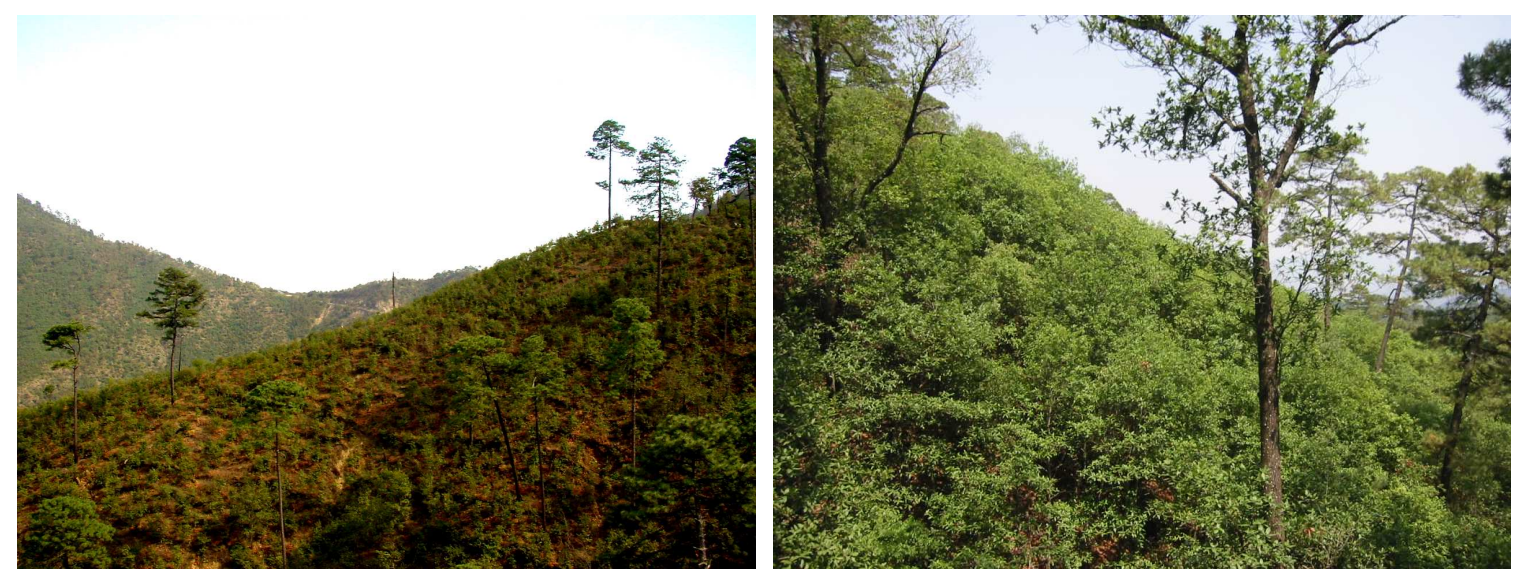

Figure 4.2: Two stands of the PECH, showing conditions after the forest fires in 1998 and 1984: the 4 years old stand on the left, the 18 years old stand on the right.

Therefore, ecological succession can be documented by comparison of stands at different successional stages. The following synthesis of forest succession in the mixedpine oak forest was derived from the post-fire cohorts. After a forest fire, the immediate effect is an increase in cover; the few species capable of immediate sprouting manage to cover the space in the initial stage after the disturbance. Pioneer species require full sunlight to germinate, while climax species can tolerate shade. Last mentioned species will begin to grow only in the shadow of pioneer species. However, this cover does not persist, because succession is influenced by a variety of local site characteristics (moisture regime, soil type, and seed availability, among others). 


\subsection{Forest Structure}

\subsubsection{Mean Diameter $(\bar{d})$}

Comparing the mean diameter of each post-fire cohort, by using the parametric ttest, significant differences were found on the PECH-098, PECH-084, and PECH-072. On two of these post-fire stands, the mean diameter were high on the south-facing slopes. No significant differences were observed in site PECH-040. The Kruskal-Wallis test (Signed-rank Test) showed significant differences with enclosed $95 \%$ of the probability between the north and south facing slopes. The total of mean diameter $\bar{d}$ values for each post-fire cohort of this study are shown in Table 4.1.

Table 4.1: The mean diameters $(\bar{d})$ in $\mathrm{cm}$ of the post-fire cohorts on both, north and south-facing slopes.

\begin{tabular}{lccccccc|c}
\hline & \multicolumn{3}{c}{ North } & \multicolumn{3}{c}{ South } & \multicolumn{2}{c}{ Test Statistics } \\
\cline { 2 - 8 } $\begin{array}{l}\text { Post-fire } \\
\text { cohort }\end{array}$ & $\bar{d}(\mathrm{~cm})$ & $\pm \sigma_{x}$ & $\mathrm{~N}$ & $\bar{d}(\mathrm{~cm})$ & $\pm \sigma_{x}$ & $\mathrm{~N}$ & t-Test & Rank Test \\
\hline PECH-098 & 3.0 & 1.3 & 1223 & 3.9 & 2.5 & 267 & + & \\
PECH-084 & 5.7 & 5.1 & 1304 & 5.3 & 3.0 & 437 & + & + \\
PECH-072 & 6.8 & 3.9 & 383 & 7.5 & 5.1 & 921 & + & \\
PECH-040 & 16.3 & 13.6 & 353 & 15.8 & 13.3 & 142 & - & \\
\hline PECH-868 & 14.6 & 8.2 & 879 & $\mathrm{x}$ & $\mathrm{x}$ & $\mathrm{x}$ & $\mathrm{x}$ & $\mathrm{x}$ \\
\hline
\end{tabular}

+ significant, - not significant at $p<0.05 \%, \mathrm{x}=$ not included in analysis

The north-facing part of the post-fire stand PECH-098, had the smallest variation coefficient $\left(\sigma_{x} \%\right)$ of $46.7 \%$, followed by PECH-868 and PECH-072 with $56.1 \%$ and $57.3 \%$ respectively. The highest variation coefficients were found in PECH-084 (89.5\%) and PECH-040, with a variation coefficient of $83.4 \%$. Among the south-facing slopes, the smallest variation coefficient was found in PECH-084 (56.6\%), followed by PECH-098 and PECH-072 with a coefficient of variation of 63.3 and $68.0 \%$ respectively. The highest variation was found in the post-fire stand PECH-040 with $84.1 \%$. These values are high on both, the north and south-facing slopes, indicating a high variability of diameters in all post-fire stands. 
For a more detailed analysis of the stand structure, the diameter distribution of each post-fire stands was compared in form of a histogram with the estimated density ${ }^{1}$. The density stands overlay the histogram with diameters distribution of each post-fire stand, and a boxplot representing the median and the confidence interval are shown in Figure 4.3.

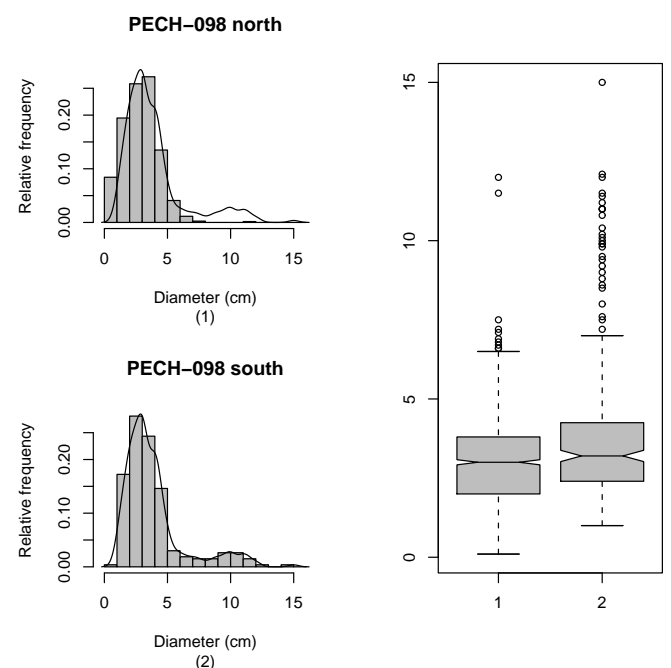

(a)

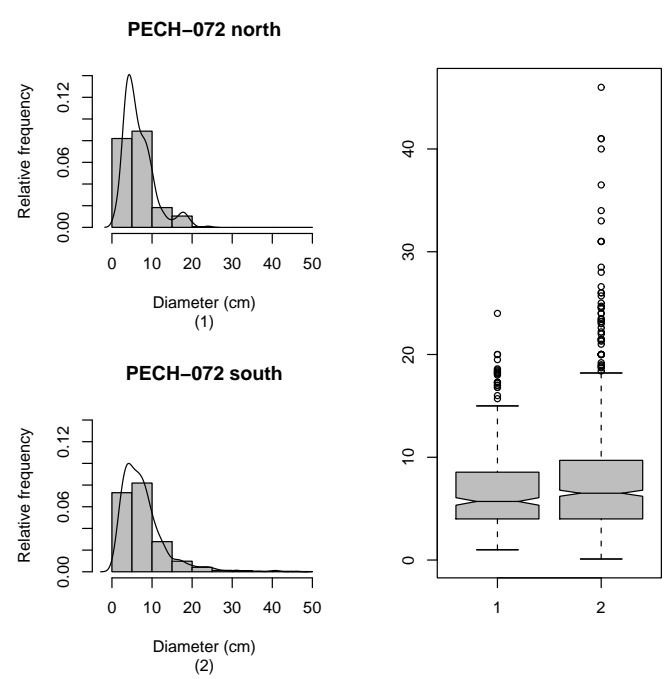

(c)

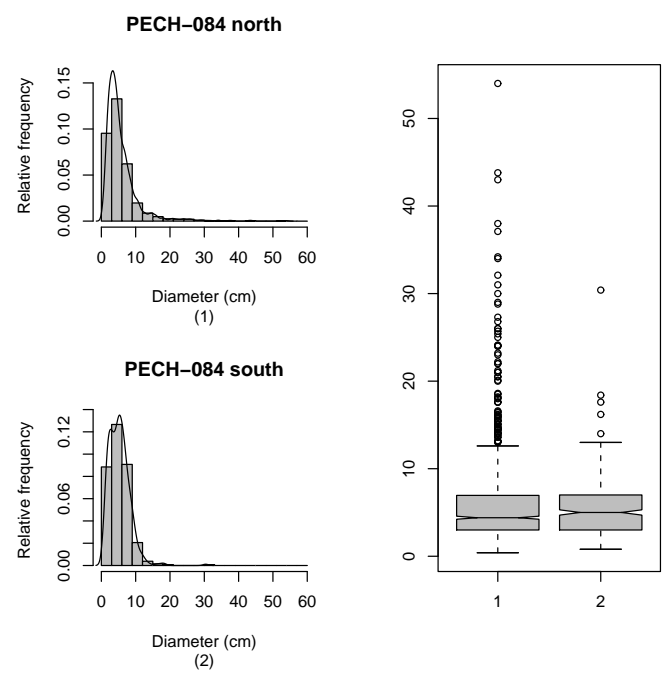

(b)

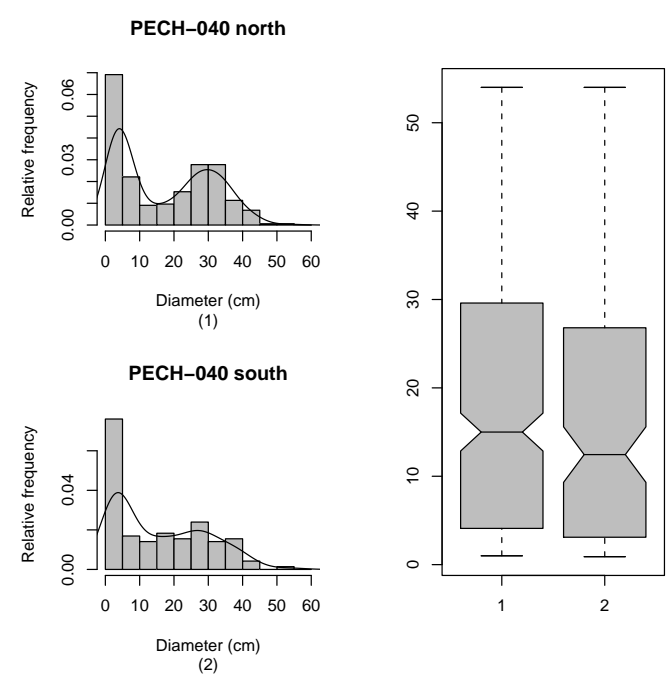

(d)

Figure 4.3: Diameters histograms for each post-fire cohorts on both slopes sides.

\footnotetext{
${ }^{1}$ For discrete distributions, the term density is used for the probability of getting exactly the value $x$
} 


\subsubsection{Mean Height $(\bar{h})$}

The values for the mean height $\bar{h}$ of the post-fire cohorts were contrasted and significant differences in height were found among the post-fire stands and between the facing slopes by calculating with the t-test and the Kruskal-Wallis test (Table 4.2).

Table 4.2: The mean height $(\bar{h})$ of the post-fire cohorts on both north and southfacing slopes.

\begin{tabular}{lccccccc|c}
\hline & \multicolumn{3}{c}{ North } & \multicolumn{3}{c}{ South } & \multicolumn{3}{c}{ Test Statistics } \\
\cline { 2 - 9 } Post-fire cohort & $\bar{h}(\mathrm{~m})$ & $\pm \sigma_{x}$ & $\mathrm{~N}$ & $\bar{h}(\mathrm{~m})$ & $\pm \sigma_{x}$ & $\mathrm{~N}$ & $\mathrm{t}$-Test & Rank Test \\
\hline PECH-098 & 2.1 & 0.7 & 1223 & 2.7 & 1.2 & 267 & + & \\
PECH-084 & 5.0 & 2.4 & 1304 & 4.2 & 1.9 & 437 & + & + \\
PECH-072 & 6.1 & 2.1 & 383 & 5.7 & 2.6 & 921 & + & \\
PECH-040 & 10.3 & 6.7 & 353 & 6.7 & 4.8 & 142 & + & \\
\hline PECH-868 & 14.6 & 8.2 & 879 & $\mathrm{x}$ & $\mathrm{x}$ & $\mathrm{x}$ & $\mathrm{x}$ & $\mathrm{x}$ \\
\hline
\end{tabular}

+ significant, - not significant at $p<0.05 \%, \mathrm{x}=$ not included in analysis

The height distribution of each post-fire stand was compared in form of a histogram showing the estimated density (Fig. 4.4 and 4.5).

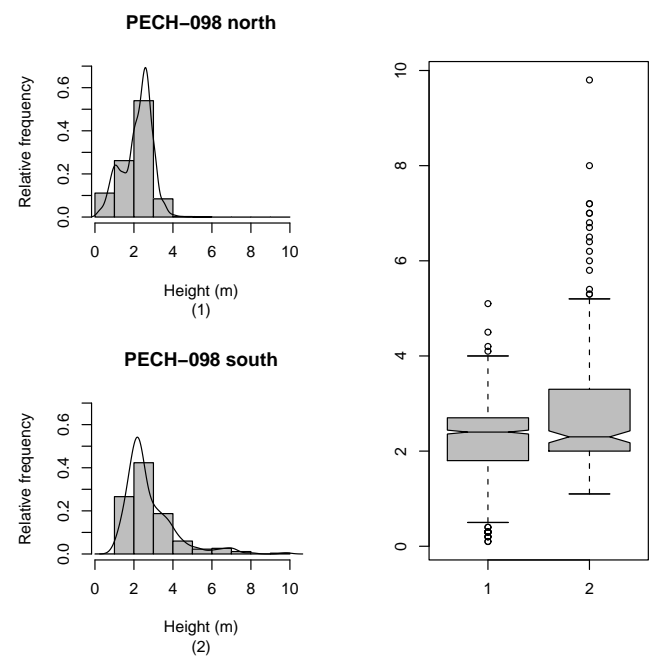

(a)

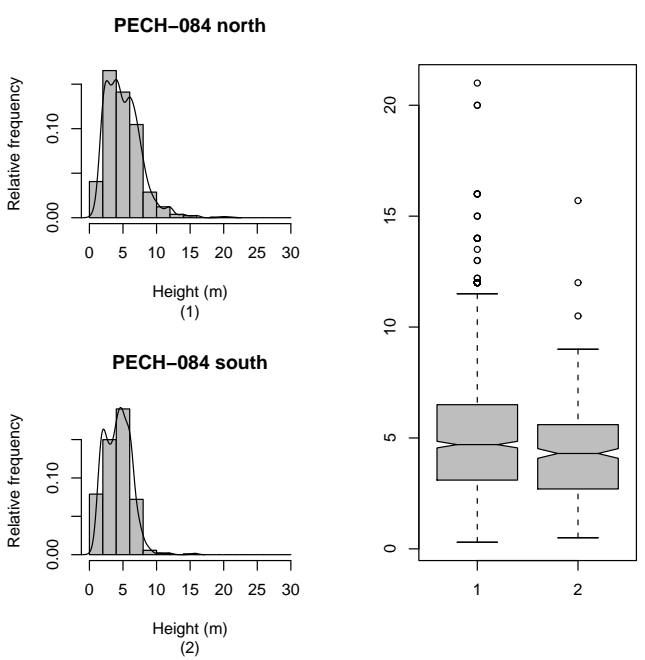

(b)

Figure 4.4: Height histograms for the post-fire stands PECH-098 and PECH-084. 


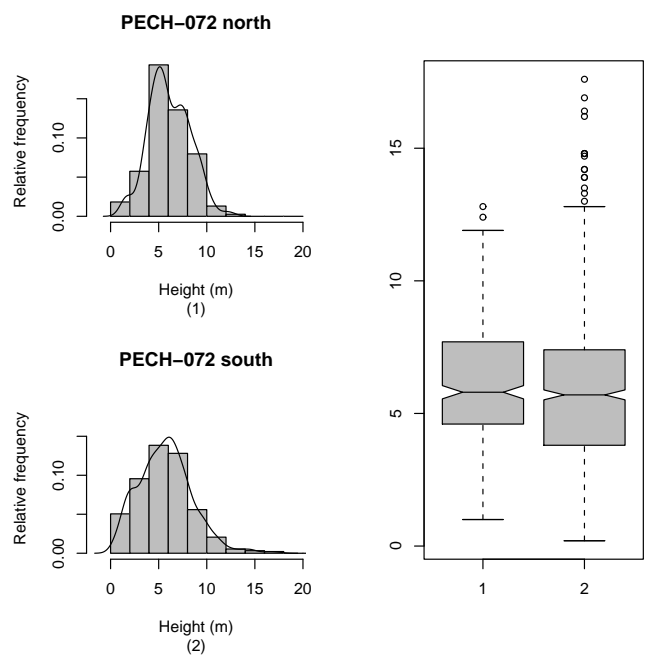

(a)

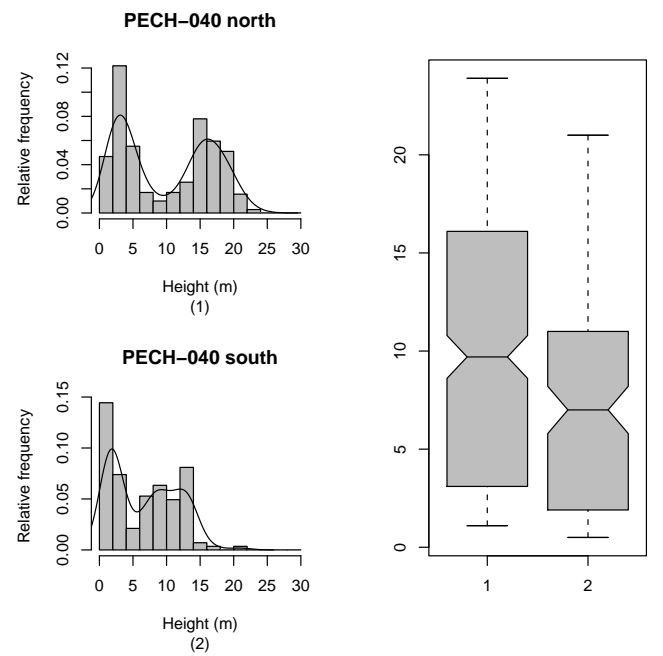

(b)

Figure 4.5: Height histograms for the post-fire stands PECH-072 and PECH-040.

On the north-facing slopes, the variation coefficient $\sigma_{x} \%$ for the post-fire stands PECH-098, PECH-084, and PECH-072 was 33.3\%, 48.0\%, and 34.4\% respectively. The highest variation coefficient was found on the two oldest post-fire stands PECH-040 and PECH-868 (65.0\% and 56.1\%). In contrast, on the south-facing slope of PECH-098, PECH-084, and PECH-072 the variation coefficient were all around 45.0\%. The highest variation was found in the oldest post-fire stand PECH-040 with a value of $71.6 \%$.

\subsubsection{Stand Density and Volume}

\section{Stand basal area}

On the north-facing slopes, the total tree density in the PECH mixed pine-oak forest was reduced by about $75 \%$ in time of 134 years after the disturbance effect. The tree density decreased from 4,000 trees/ha (PECH-098) to 1,059 trees/ha (PECH-868). In comparison, on the south-facing slope side the tree density was higher in the intermediate stands than in the youngest stand. In the oldest stand 1,420 trees/ha were registered.

In the youngest stands the comparison of north- and south facing parts produced differences concerning the number of individuals on the north-facing slopes was higher than on the south-facing slopes. This trend changed in the oldest stands, where the 
density was highest on the south-facing slopes (Table 4.3).

The basal area was increasing on the south-facing slope in time. On the northfacing slope of PECH-072 a decrease was observed. Significative differences regarding the basal area were found on three post-fire stands: PECH-098, PECH-084, and PECH-072. In PECH-040 no significative differences were observed. Along the northand south-facing slopes significant differences were detected according to the Rank signs tests.

\section{Stand Volume}

The trees with a souther exposure showed a greater diameter than those on the northfacing slope in most of the post-fire cohorts. However, the volume growth per hectare was grater in those stands whose the number of individuals was distinctly greater than in the others. The post-fire stand volume results are shown in Table 4.3.

The stand volume, on the post-fire cohorts PECH-084 and PECH-040 resulted significantly higher on the north-facing slopes. Whereas in the post-fire cohorts PECH-072 and PECH-098 the stand volume was significantly higher on the south-facing slopes. However, no significant differences were found between the north- and south-facing slopes, using the Rank sign test.

Table 4.3: Basal area and tree number per hectare in post-fire cohorts.

\begin{tabular}{cccccccccc|c}
\hline & \multicolumn{3}{c}{ North } & \multicolumn{3}{c}{ South } & \multicolumn{2}{c}{ t-Test } & \multicolumn{2}{c}{ Rank test } \\
\cline { 2 - 10 } & $N_{h a}$ & $G_{h a}$ & $V_{h a} m^{3}$ & $N_{h a}$ & $G_{h a}$ & $V_{h a} m^{3}$ & $G_{h a}$ & $V_{h a}$ & $G_{h a}$ & $V_{h a}$ \\
\hline PECH-098 & 4097 & 3.3 & 4.4 & 1335 & 2.2 & 4.6 & + & + & & \\
PECH-084 & 4347 & 19.5 & 48.5 & 2185 & 6.3 & 18.6 & + & + & & \\
PECH-072 & 1915 & 9.2 & 30.7 & 2303 & 16.8 & 76.7 & + & + & & \\
PECH-040 & 1177 & 44.7 & 363.4 & 1420 & 47.3 & 259.5 & - & + & & \\
\hline PECH-868 & 1059 & 28.1 & 137.7 & $\mathrm{x}$ & $\mathrm{x}$ & $\mathrm{x}$ & $\mathrm{x}$ & & & \\
\hline
\end{tabular}

+ significant - not significant at $p<0.05 \% \mathrm{x}=$ not included in analysis 


\subsubsection{Importance Value Index (IVI)}

The importance value index (IVI), can be used to demonstrate changes in vegetation dynamics through succession. The IVI for all species present on the north and southfacing slopes in the PECH are shown in Table 4.4 and 4.5 .

The vegetation of PECH-098 was dominated by sprouts of Quercus rysophylla, Quercus canbyi, and Quercus virginiana which had represented with IVI values of $141.4 \%, 46.1 \%$, and $32.5 \%$, respectively on the north-facing slope. Quercus rysophylla was the species which showed a maximum abundance and dominance in the early successional stages. On the south-facing slopes, Q. rysophylla, Q. virginiana and $Q$. canbyi were the species with the highest IVI value. Q. rysophylla had an IVI value of $107.2 \%$ and was present in most of the plots. Comparing the first rank species on both slope sides, it was observed that the abundance of $Q$. rysophylla was higher on north-facing slope than on the south-facing part of PECH-098.

Table 4.4: Calculated Importance value indices (IVI) for north-facing slopes.

\begin{tabular}{lccrrr}
\hline North-facing slope & \multicolumn{5}{c}{ IVI } \\
\cline { 2 - 6 } Species & 1998 & 1984 & 1972 & 1940 & 1868 \\
\hline Arbutus xalepensis & 15.4 & 11.5 & 11.9 & $\boldsymbol{x}$ & 9.9 \\
Ceanothus coeruleus & 18.4 & $\boldsymbol{x}$ & $\boldsymbol{x}$ & $\boldsymbol{x}$ & $\boldsymbol{x}$ \\
Cercis canadensis & 4.9 & 5.2 & $\boldsymbol{x}$ & $\boldsymbol{x}$ & 11.9 \\
Unidentified 1 & 11.9 & $\boldsymbol{x}$ & $\boldsymbol{x}$ & $\boldsymbol{x}$ & $\boldsymbol{x}$ \\
Unidentified 2 & 9.5 & $\boldsymbol{x}$ & $\boldsymbol{x}$ & $\boldsymbol{x}$ & $\boldsymbol{x}$ \\
Juglans mollis & $\boldsymbol{x}$ & 11.1 & 15.2 & $\boldsymbol{x}$ & 9.4 \\
Juniperus flaccida & $\boldsymbol{x}$ & 5.1 & 6.8 & $\boldsymbol{x}$ & $\boldsymbol{x}$ \\
Ligustrum japonicum & $\boldsymbol{x}$ & $\boldsymbol{x}$ & $\boldsymbol{x}$ & $\boldsymbol{x}$ & 9.4 \\
Pinus pseudotrobus & $\boldsymbol{x}$ & 20.6 & 26.1 & 31.9 & 91.2 \\
Pinus teocote & $\boldsymbol{x}$ & 68.3 & 43.9 & 160.0 & 20.7 \\
Pronus serotina & $\boldsymbol{x}$ & $\boldsymbol{x}$ & 13.1 & $\boldsymbol{x}$ & $\boldsymbol{x}$ \\
Prosopis glandulosa & 4.4 & $\boldsymbol{x}$ & $\boldsymbol{x}$ & $\boldsymbol{x}$ & $\boldsymbol{x}$ \\
Quercus canbyi & 46.1 & 18.1 & 18.9 & 42.6 & 56.0 \\
Quercus laceyi & 10.3 & 5.1 & $\boldsymbol{x}$ & $\boldsymbol{x}$ & 10.9 \\
Quercus laeta & 4.3 & $\boldsymbol{x}$ & $\boldsymbol{x}$ & $\boldsymbol{x}$ & $\boldsymbol{x}$ \\
Quercus polymorpha & $\boldsymbol{x}$ & $\boldsymbol{x}$ & 5.9 & $\boldsymbol{x}$ & 11.0 \\
Quercus rysophylla & 141.4 & 119.7 & 119.8 & 56.0 & 59.6 \\
Quercus virginiana & 32.5 & 35.2 & 37.9 & 9.3 & 9.3 \\
\hline $\boldsymbol{x}$ not found & & & & & \\
\hline
\end{tabular}


Pinus teocote and Pinus pseudostrobus, the only two conifers species registered in the park, appeared on both slope sides in PECH-084 18 years after a wildfire. On the north slope, the species was ranked as the most important species after $Q$. rysophylla (119.6\%), followed by P. teocote (68.3\%). On the southern side the species P. teocote had an IVI value of $34.2 \%$ and is ranked as number four in PECH-084.

On north facing-slope, for the post-fire cohort PECH-072 for the species Q. rysophylla, P. teocote, and Q. virginiana the highest IVI value was produced. Nevertheless, $P$. teocote had a lower IVI value $(43.9 \%)$ than registered in the younger stand (68.3\%). Compared with the younger cohort PECH-084, P. pseudostrobus showed greater density and dominance in $\mathrm{PECH}-072$. The same is true for P. teocote. On south-facing slope, Q. rysophylla occurred with the highest IVI value (99.5\%).

Table 4.5: Calculated Importance value indices (IVI) for south-facing slopes.

\begin{tabular}{lcccc}
\hline South-facing slope & \multicolumn{4}{c}{ IVI } \\
\cline { 2 - 5 } Species & 1998 & 1984 & 1972 & 1940 \\
\hline Arbutus xalepensis & 26.0 & 9.3 & 8.7 & $\boldsymbol{x}$ \\
Ceanothus coeruleus & 13.3 & $\boldsymbol{x}$ & $\boldsymbol{x}$ & $\boldsymbol{x}$ \\
Cercis canadensis & $\boldsymbol{x}$ & $\boldsymbol{x}$ & $\boldsymbol{x}$ & 16.0 \\
Juglans mollis & $\boldsymbol{x}$ & $\boldsymbol{x}$ & 4.4 & $\boldsymbol{x}$ \\
Juniperus flaccida & $\boldsymbol{x}$ & $\boldsymbol{x}$ & $\boldsymbol{x}$ & 15.2 \\
Pinus pseudotrobus & $\boldsymbol{x}$ & 13.9 & 10.0 & $\boldsymbol{x}$ \\
Pinus teocote & $\boldsymbol{x}$ & 34.2 & 70.1 & 128.1 \\
Quercus canbyi & 63.9 & 122.4 & 55.3 & 71.8 \\
Quercus laceyi & $\boldsymbol{x}$ & $\boldsymbol{x}$ & 4.5 & $\boldsymbol{x}$ \\
Quercus laeta & 11.1 & 44.2 & 36.7 & 25.1 \\
Quercus polymorpha & $\boldsymbol{x}$ & 12.0 & 10.7 & $\boldsymbol{x}$ \\
Quercus rysophylla & 107.3 & 55.4 & 99.5 & 26.0 \\
Quercus virginiana & 78.5 & 8.6 & $\boldsymbol{x}$ & 17.9 \\
\hline $\boldsymbol{x}$ not found & & & & \\
\hline
\end{tabular}

The north-faced post-fire cohort PECH-040 was characterized as a mixed pine-oak forest. Here Pinus teocote was the species with the highest IVI value (160\%), followed by $Q$. rysophylla and Q. canbyi with IVI values of $56.0 \%$ and $42.6 \%$ respectively. The species Q. virginiana had the lowest IVI value of $9.3 \%$. The species Juniperus flaccida 
appeared on the south-facing slope of PECH-040.

Site PECH-868, was situated only on a north-facing slope. For this site, Pinus pseudstrobus was the species with the highest IVI value (91.2\%) followed by Q. rysophylla (59.6\%) and Q. canby (56\%). In this stand the dominance of Pinus pseudstrobus is remarkable, whose had replacing the species Pinus teocote (20.7\%). P. teocote showed a continuous increase up to stand $\mathrm{PECH}-040$, but declined in the oldest stand. The IVI value of the species Pinus pseudostrobus increased continuously over the five north-sided post-fire cohorts. This species had an ecological value of $20.6 \%$ when emerged 18 years after fire disturbance and ended with a value of $91.2 \%$ in the oldest plot (PECH-868).

$P$. teocote reached the highest index values $(128.1 \%)$ in all post-fire cohorts on both, north and south-facing slopes. Comparing the abundance of $Q$. canbyi on the south-facing slopes in time (1940-1972), a grate (71.1\%) increment of the IVI value was found. While Q. rysophylla which was always found with a high dominance in young post-fire cohorts, was almost completely absent in PECH-040. Mentioned occurred although species with a relatively high density but lower dominance in the 62 years old stand, which explains its IVI value (26.0\%).

The horizontal distribution and classification based on the characteristics mentioned in section 3.3.6 are shown in Table 4.6. 


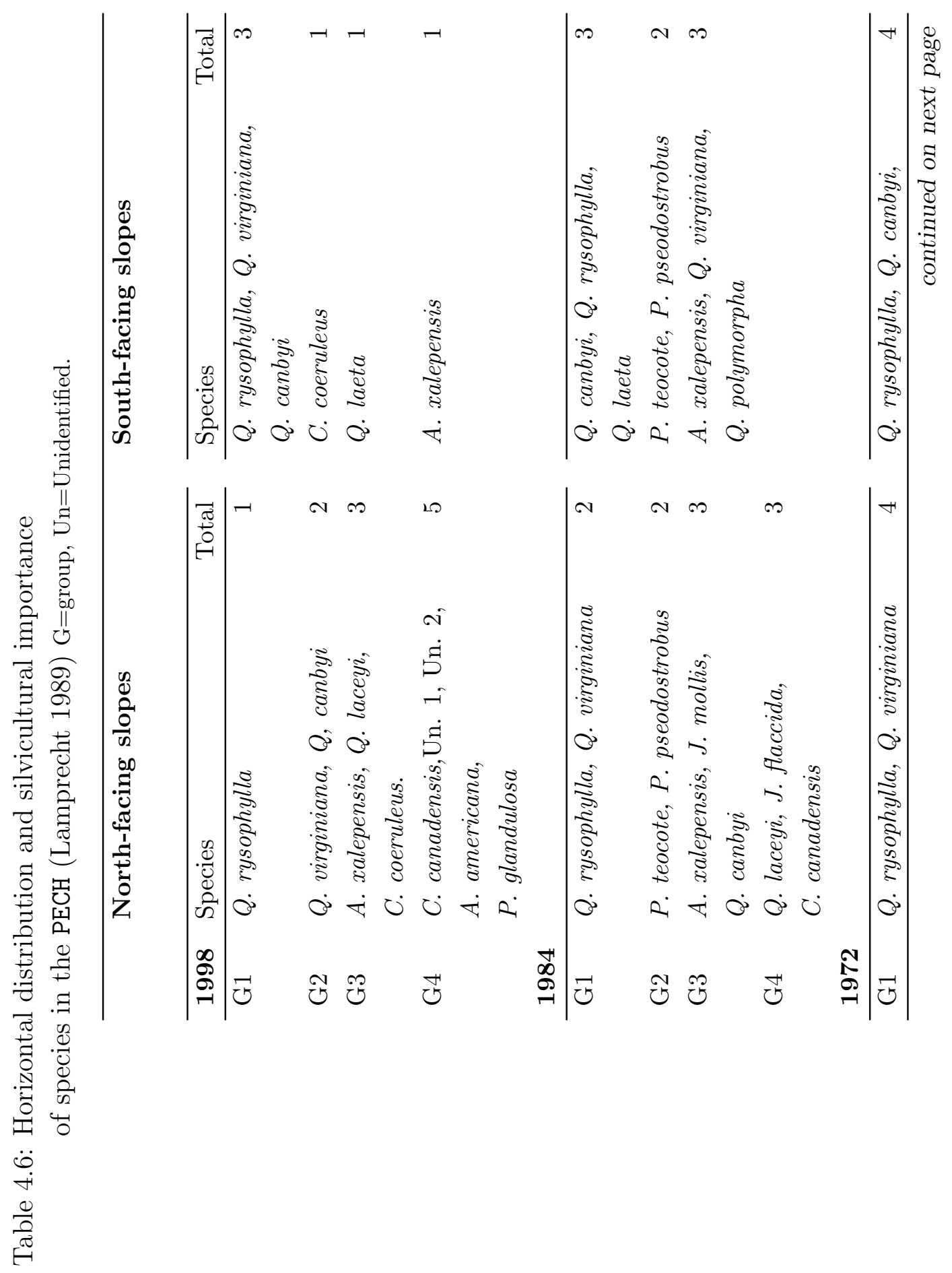




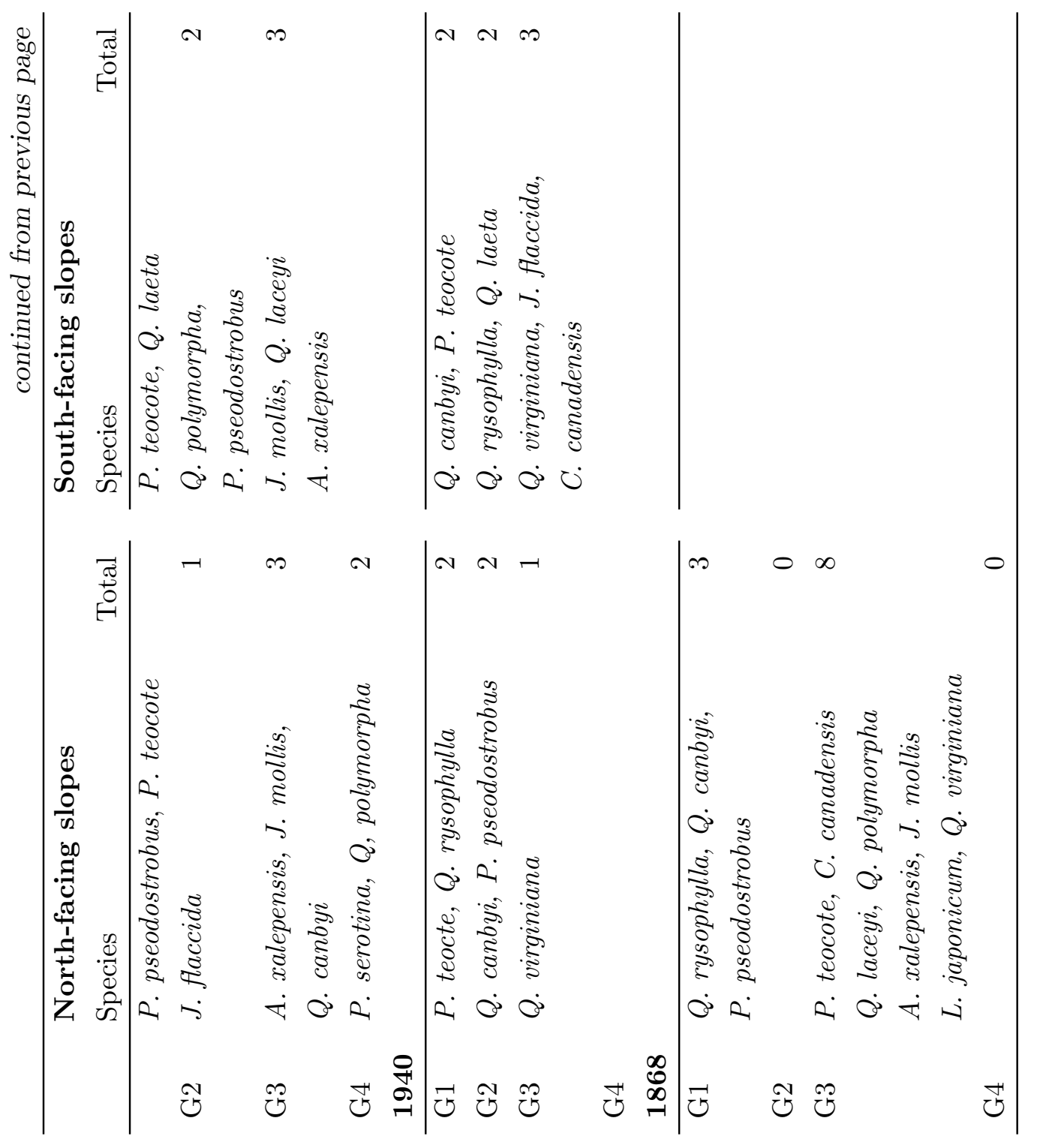


According to Lamprech's classification the importance of individual tree species, is obtained from the combination of frequency, abundance and dominance. Table 4.6 shows that most of the stands located on the north-facing slopes were dominated in the horizontal strata by the following species: Q. rysophylla, P. teocote, and P. pseudostrobus. These species occurred in Group 1 and are depicted along the chronosequence in Figure 4.6a page 76. The species classified in Group G2 are Q. virginiana and $Q$. canbyi, which had a tendency to appear as clusters in the understory strata. Species in Group 3 are A. xalepensis, Q. laceyi, Q. laeta, J. mollis. These species have the characteristic to occur in dominant positions and as a single trees. Group G4 (low abundance and low frequency) represented rare species in the post-fire cohorts, such as Juniperus flaccida, Prunus serotina, Cercis canadensis and Juglans mollis.

In the post-fire cohorts located on south facing slopes, Q. rysophylla was one of the species found to be dominant in the horizontal strata in the early stages of the succession. However, this species was replaced in later successional stages by the species Q. canby and Pinus teocote, which showed a continuous increase (Fig.4.6b). Species with a tendency to appear in cluster included: Ceanothus coeruleus and Juglans mollis. Arbutus xalepensis and Q. laceyi were rare species which were found only on the south-facing slopes. 


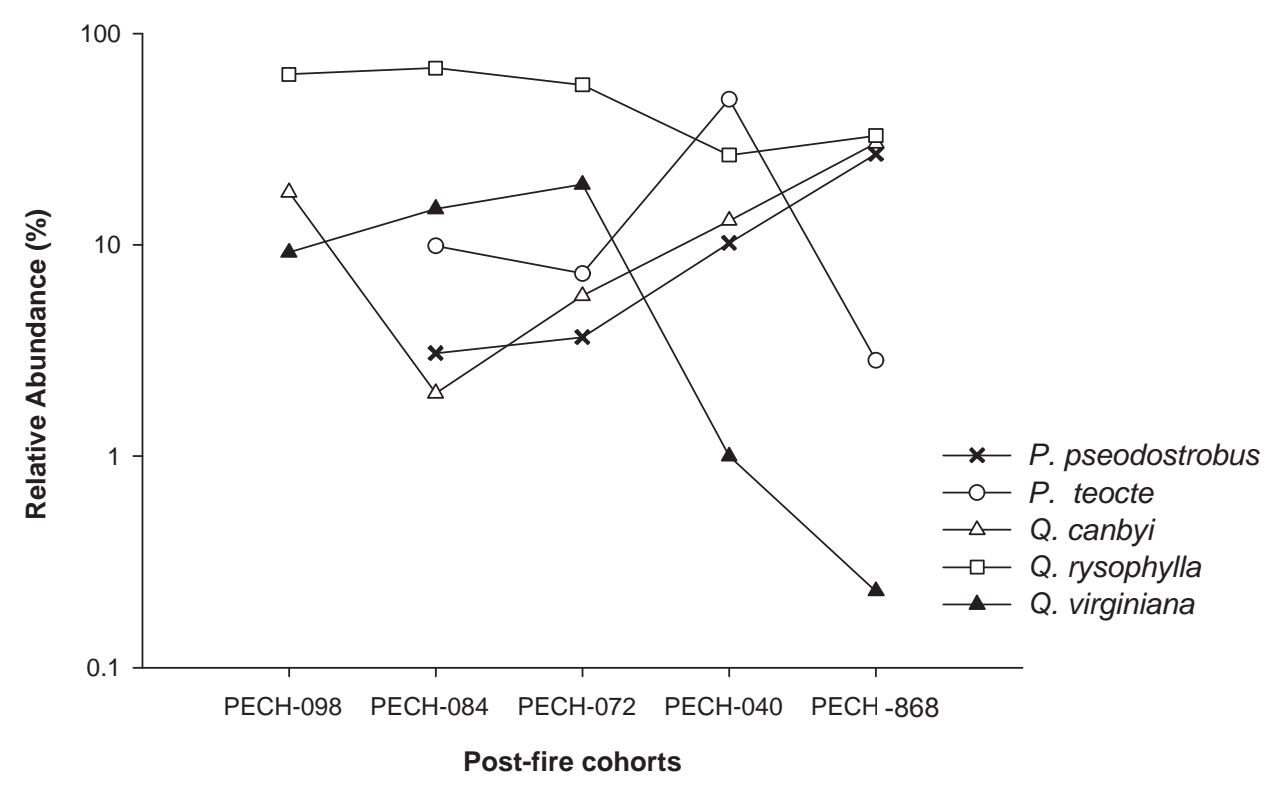

(a)

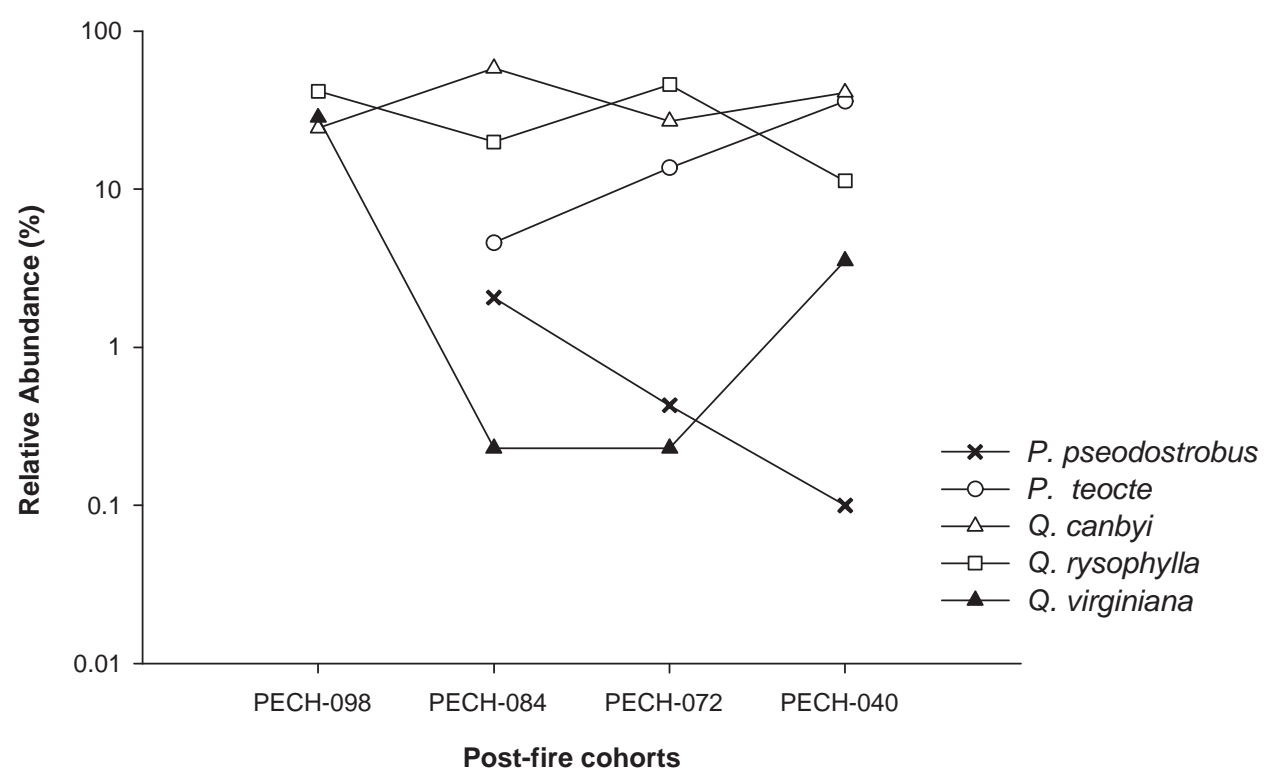

(b)

Figure 4.6: Changes in abundance of selected species in time after a forest fire. All five species are present within the groups G1 and G2. (a) north and (b) south-facing slopes. 


\subsection{Potential Solar Radiation}

Forest succession is influenced by various site characteristics. Topography is one of the most important factors, operating at both local and landscape scales. Table 4.7 shows that Potential solar radiation values for all four variables are not significant differences at $\mathrm{p}<0.05 \%$.

Table 4.7: Potential solar radiation (latitude $25^{\circ}$ ) in the $\mathrm{PECH}$.

\begin{tabular}{lcccc}
\hline \multicolumn{5}{c}{ North-facing slopes } \\
& Vegmeadow & Vegmeaall & Jahmeadow & Jahmeaall \\
\cline { 2 - 5 } PECH-098 & 72.3 & 11453.0 & 111.8 & 16785.8 \\
PECH-084 & 77.3 & 12517.3 & 117.5 & 16951.2 \\
PECH-072 & 76.1 & 12213.2 & 115.6 & 16298.1 \\
PECH-048 & 78.0 & 12730.6 & 121.7 & 19305.5 \\
PECH-868 & 82.0 & 12090.0 & 124.1 & 15767.7 \\
South-facing slopes & & & \\
\hline & Vegmeadow & Vegmeaall & Jahmeadow & Jahmeaall \\
\cline { 2 - 5 } PECH-098 & 79.2 & 12687.7 & 117.8 & 17188.6 \\
PECH-084 & 73.5 & 11097.2 & 113.0 & 15275.0 \\
PECH-072 & 73.9 & 12196.8 & 116.6 & 18084.7 \\
PECH-048 & 80.2 & 13313.4 & 124.2 & 20909.5 \\
\hline Jah= year, Veg=Vegetation period, Mea=mean & \\
Dow= option shadow, All=option all & &
\end{tabular}

Groups with similar slopes and aspects are commonly grouped in order to infer the variation of radiation in the landscape. In the northern hemisphere it is generally assumed that south-facing slopes receive more radiation than north-facing slopes, while the opposite is assumed in the southern hemisphere. The south-facing slopes showed higher median radiation than north-facing slopes, during the whole year and the vegetation period (Fig. 4.7). The boxplot graphic shows that in the Vegetation period using the option shadow, the north-facing slopes received more radiation than south-facing slopes. However, according to the t-test and Kruskal-Wallis test, no significant differences were found. 


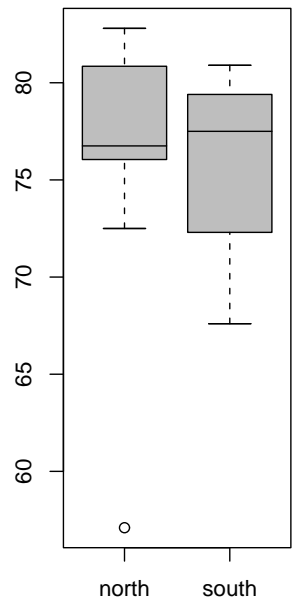

Vegmeadow

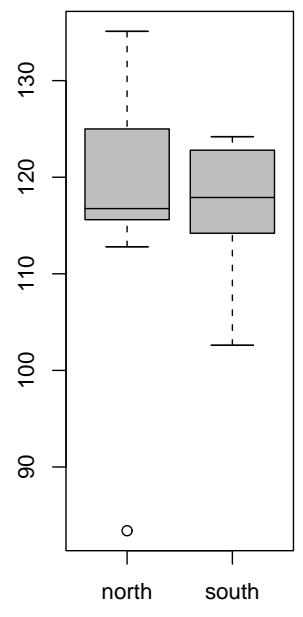

Jahmeadow

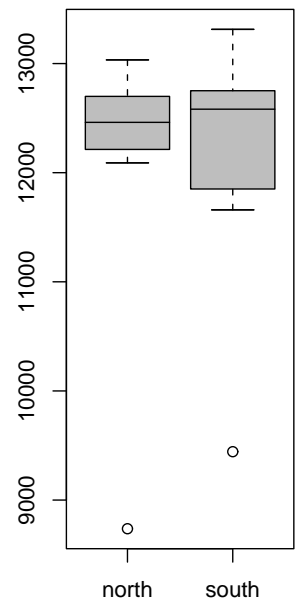

Vegmeaall

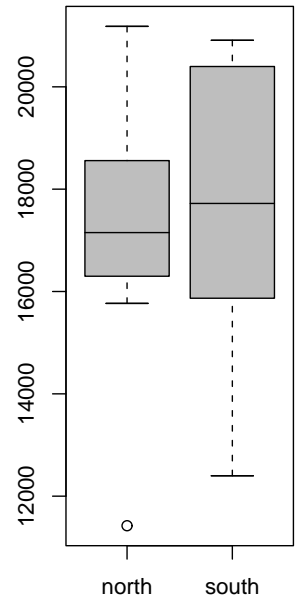

Jahmeaall

Figure 4.7: Variations of potential solar radiation over the year and the vegetation period. Using the options "shadow" and "all" on the north- and southfacing slopes.

\section{Spatial Radiation Patterns}

Maps of potential solar radiation for the whole year and for the vegetation period (eight months from April to November) are shown in Fig. 4.8. Among the distinct patterns, that can be noticed in the annual direct radiation map (Fig4.8a), the radiation on the north-facing slopes was lower compared with the one on south-facing slopes. Furthermore, high shading areas (lower radiations levels) were close to high sky obstruction along the suntrack in landscape (i.e. mountains toward the south, east or west). The variation of radiation values resulted primarily as a function of the slope (higher slope causing lower values or darker gray shade). 


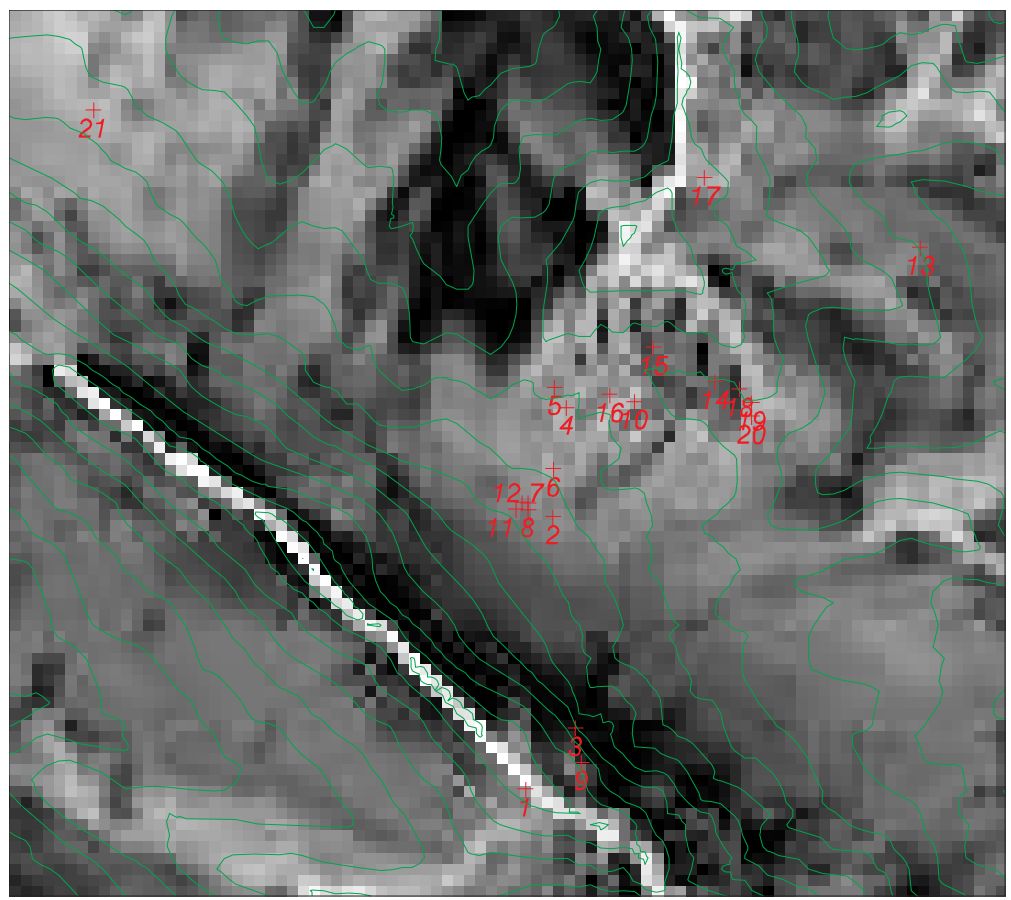

(a)

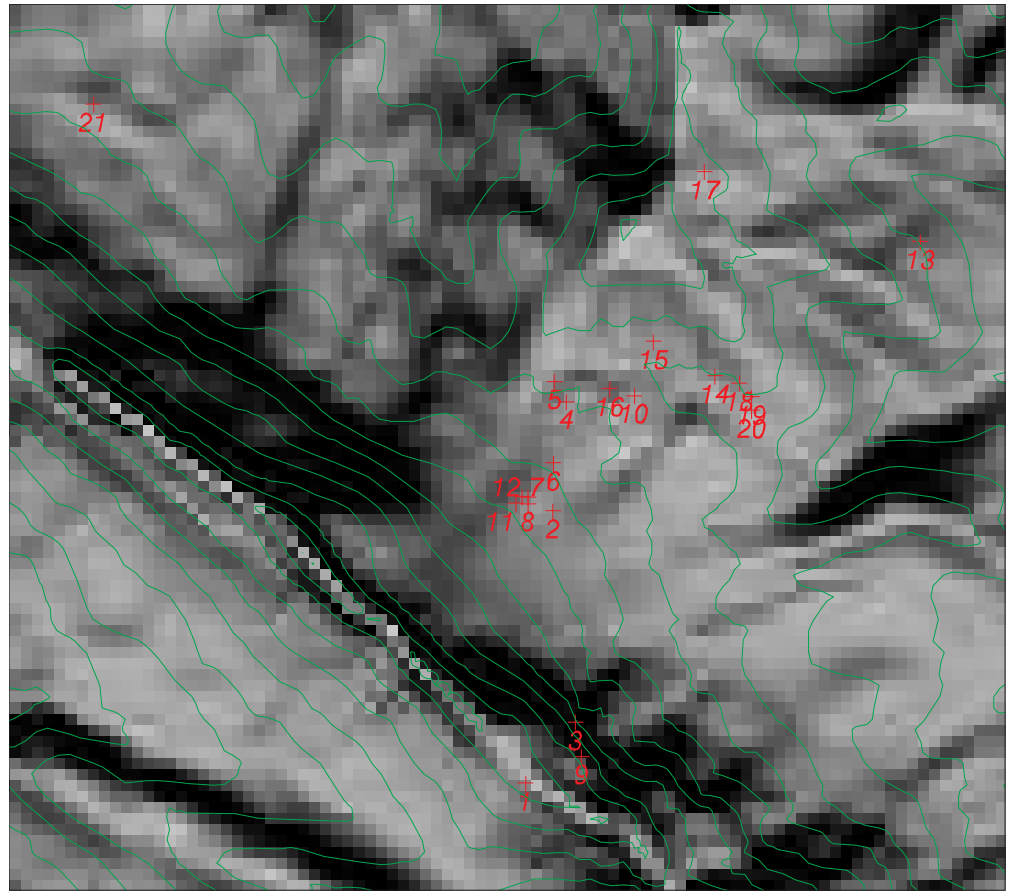

(b)

Figure 4.8: Maps of potential solar radiation: (a) Distribution of the integrated annual direct radiation calculated from a digital elevation data, and (b) map of the distribution from direct radiation calculated for the vegetation period, scale 1:40,000 cm. 


\subsection{Changes in Species Diversity}

Two data sets, north and south-facing slopes, contained a total of 19 species. The experimental design for the PECH incorporated five post-fire stands. Whereas all postfire cohorts were covering north-facing slopes with 17 species and 4,141 individuals. Only four stands extended also over south-facing slopes with 13 species and 1,767 individuals (c.f Appendix A.1) .

\subsubsection{Alpha Diversity}

Several diversity indices were calculated for both, north- and south-facing slope data sets. These results are summarized in Table 4.8. Moreover, a Hutcheson t-test (Eq. 2.11) was performed to find significant differences in the diversity of each post-fire cohort on both slope sides. This t-test revealed that significant differences in terms of species diversity between the post-fire cohorts on the north and south-facing slopes. The north-facing slope had a higher species richness value $(S=17)$ than the southfacing slope $(S=13)$. The inspection of the data (Table 4.8) shows that the abundance $(N)$ in most of the north-facing stands was higher than in south-facing areas, with the exception for the PECH-040.

\section{Species richness on north and south-facing slope}

Changes in the richness of plants species $(S)$ that had taken place in the different post-fire cohorts were observed in time after the wildland fire ( $t$ in years). The north-facing exposition supported higher levels of species richness $(S)$. The highest species richness values were recorded in the post-fire cohorts PECH-098 and PECH-868 $(S=11)$, while the lowest value was produced in $\mathrm{PECH}-040(S=5)$. At the initial phase of succession for the sout-facing exposition, the species richness value was poor $(\mathrm{S}=6$ in $\mathrm{PECH}-098)$ and increased in time after a forest fire $(\mathrm{S}=)$ in $\mathrm{PECH}-072$ and $\mathrm{S}=7$ in PECH-040). The peak in species richness of post-fire cohorts occurred on the north-facing slopes four years after disturbance. On the south-facing slopes, the peak occurred 30 years after a forest fire (Table 4.8). 
Table 4.8: Diversity indices of the post-fire stands located on north- and south-facing slopes.

\begin{tabular}{|c|c|c|c|c|c|c|c|c|c|c|}
\hline & Slope & $\mathrm{S}$ & $\mathrm{N}$ & $\left(D_{m g}\right)$ & $\mathrm{D}$ & $1 / \mathrm{D}$ & $\mathrm{H}^{\prime}$ & $\mathrm{E}$ & Ratio $^{1}$ & $\begin{array}{l}\text { Hutcheson } \\
\text { t-Test }\end{array}$ \\
\hline \multirow[t]{2}{*}{1998} & North & 11 & 4096 & 1.2 & 0.5 & 1.9 & 1.2 & 0.5 & 2.7 & + \\
\hline & South & 6 & 1335 & 0.7 & 0.7 & 1.5 & 1.3 & 0.7 & 4.5 & \\
\hline \multirow[t]{2}{*}{1984} & North & 10 & 4347 & 1 & 0.5 & 2 & 1 & 0.4 & 2.3 & + \\
\hline & South & 8 & 2185 & 0.9 & 0.6 & 1.6 & 1.2 & 0.6 & 3.7 & \\
\hline \multirow[t]{2}{*}{1972} & North & 10 & 1915 & 1.2 & 0.6 & 1.6 & 1.4 & 0.6 & 5.2 & + \\
\hline & South & 9 & 1248 & 1 & 0.6 & 1.5 & 1.2 & 0.6 & 6.4 & \\
\hline \multirow[t]{2}{*}{1940} & North & 5 & 1177 & 0.6 & 0.7 & 1.4 & 1.2 & 0.8 & 4.2 & + \\
\hline & South & 7 & 1420 & 0.8 & 0.7 & 1.4 & 1.4 & 0.7 & 4.9 & \\
\hline 1868 & North & 11 & 879 & 1.5 & 0.7 & 1.4 & 1.5 & 0.6 & 12.5 & \\
\hline
\end{tabular}

\section{Post-fire cohort PECH-098}

In general, on the north-facing stand (four years after disturbance) had a lower evenness value $((E=0.5))$ than compared with the south-facing slope. Low evenness occurs when one or few species are dominant in cover and suppress or inhibit other species. When all species are relatively equal in cover and importance, evenness values are higher. In comparison on the south-facing slopes, a significatively high evenness component $(E=0.7)$ was estimated. The Margalef index $\left(D_{M g}\right)$ was higher on the north-facing slope $\left(D_{M g}=1.2\right)$ than on the south-facing slopes $\left(D_{M g}=0.7\right)$. This indicates that more individuals were registered on the north-facing slope.

As described in literature, an increased Simpson index $D$ is reflected in lower values. To avoid this phenomenon and ensure that the Simpson's Index value increases with an increasing diversity, the reciprocal form is adopted; hence, Simpson's index is expressed as $1 / D$. In this way, the reciprocal $1 / D$ value for north-facing slope $(1 / D=1.9)$ indicates a higher level of competition between the species in the ecosystem. Likewise, the dominance of some species contribute to the future supply 
of resources present in the system. On the north-facing slope a lower value for the Shannon index $\left(H^{\prime}=1.2\right)$ was estimated, due to the low evenness in the post-fire stand. On the south-facing slope the remarkable high evenness $(E=0.7)$ resulted in a higher value for the Shannon index $\left(H^{\prime}=1.3\right)$. In order to illustrate the variety of richness and evenness values in both north and south-facing slopes, dominancediversity graphs were constructed. Figure 4.9 is a rank abundance graph for the north and south-facing slopes in PECH-098 after forest fire.

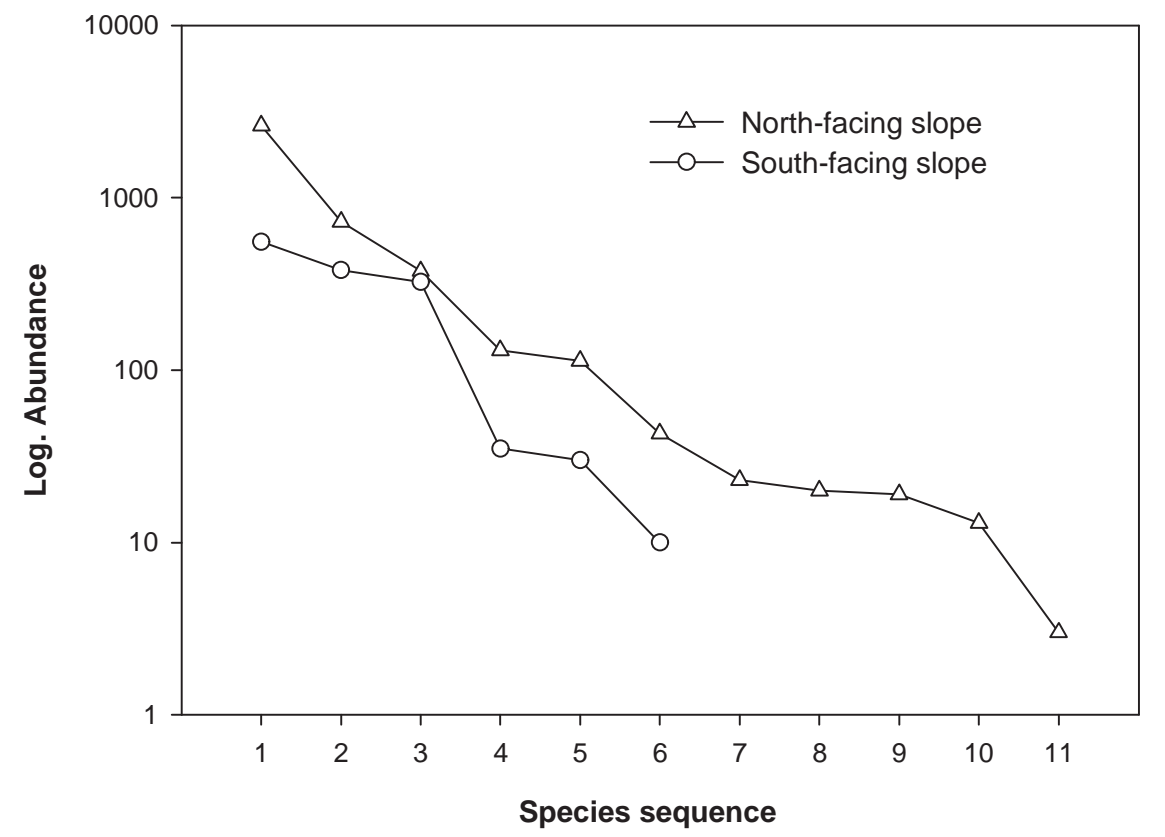

Figure 4.9: Species rank abundance curves for the north and south-facing slopes for the post-fire cohort PECH-098.

According to these diversity indices, the species richness and the number of individuals was the diverser on the north-facing slope. At the beginning, the rank abundance curve for the north slope, had a vertical orientation, which denotes a dominance factor of one or a few species. On the south-facing slope, three species were observed to be equally abundant. Despite of the differences in species and dominance values, both curves appear to follow the same underlying distribution. The distribution on both slopes was principally defined by the presence of many rare species (singletons) and a few abundant species. This young stands was characterized by the dominance of oak resprout. 


\section{Post-fire cohort PECH-084}

In PECH-084, the curves were more vertical than in PECH-098, although there was still one species which hold some dominance on both sides, the north- and south-facing slopes. In general, this post-fire cohort was less even than the four years old stand. In contrast to the previous fire-stand, just one species on the north- and one on the south-facing slope was observed to be the most abundant competitor in the stand (Fig. 4.10). The dominance of one species on the north-facing part can be translated in a low evenness $(E=0.4)$.

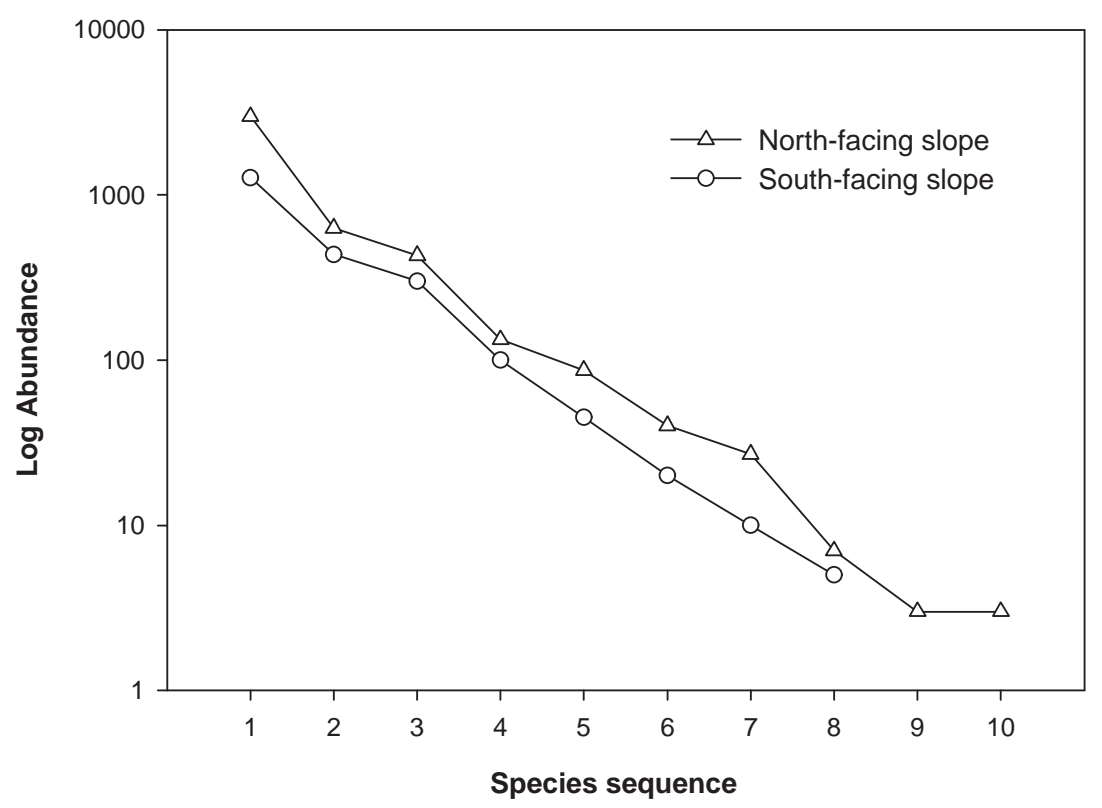

Figure 4.10: Species rank abundance curves for the north and south-facing slopes for the post-fire cohort PECH-084.

According to the Simpson inverse index $(1 / D=2)$, the north-facing slope was still with 10 species diverser than the south-facing one. On the south-facing slope, the inverse index (1/D) was 1.6 and eight species were observed. Nevertheless, the northfacing slope had a low value $\left(H^{\prime}=1\right)$ when comparing the Simpson index H'. This was because of the high number of individuals on the north-facing slope $(\mathrm{N}=4,347)$. The south-facing slope, with only $\mathrm{N}=2,185$, had a high value of evenness and a Simpson index of $H^{\prime}=1.2$. Three rare species were observed on the north facing slope, whereas on the south-facing slope only two observed species were considered to be singletons. 


\section{Post-fire cohort PECH-072}

In PECH-072, both slopes had the same evenness value $(E=0.6)$. On the north-facing slope, a higher number of species was still observed $(S=10)$, as opposed to $S=8$ on the south-facing slope. Dominance diversity curves for the north-facing slope are becoming more horizontal (Fig. 4.11). This is due to the low number of individuals observed $\mathrm{N}=1,915$ and $\mathrm{N}=1,248$ on the north- and south-facing slopes respectively. Consequently, the Margalef index on the north slope $\left(D_{M g}=1.2\right)$ was higher than on south slope $\left(D_{M g}=1.0\right)$. The curve did not decrease abruptly, when compared to the younger post-fire cohorts (PECH-098 and PECH-084).

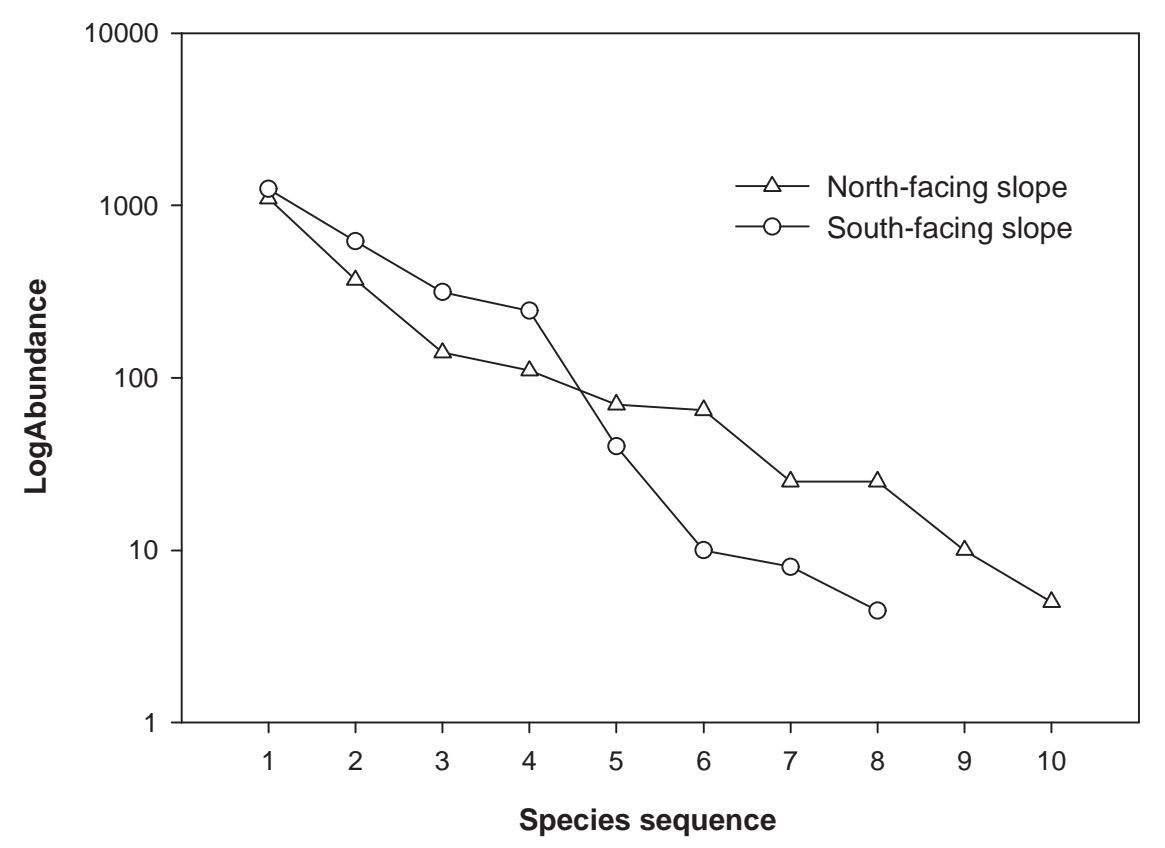

Figure 4.11: Species rank abundance curves for the north and south-facing slopes for the post-fire cohort PECH-072.

The inverse Simpson $(1 / D=1.6)$ and Shannon $\left(H^{\prime}=1.4\right)$ indices showed a high diversity on the north slope, and $1 / D=1.5$ and $H^{\prime}=1.2$ on the south slope. On both, the north- and south-facing slopes, the number of rare species as well as the abundance of dominant species was less in PECH-072. 


\section{Post-fire cohort PECH-040}

On the north-facing slope, four of the five observed species had very high abundance, the fifth species showed an abrupt decrease in number of individuals. The species located at the end of the species sequence curve had the lowest number of individuals and are therefore considered as rare species (Fig. 4.12). High values of evenness were calculated $(E=0.8)$ for the north slope as well as for the south-facing slopes was calculated $(E=0.7)$.

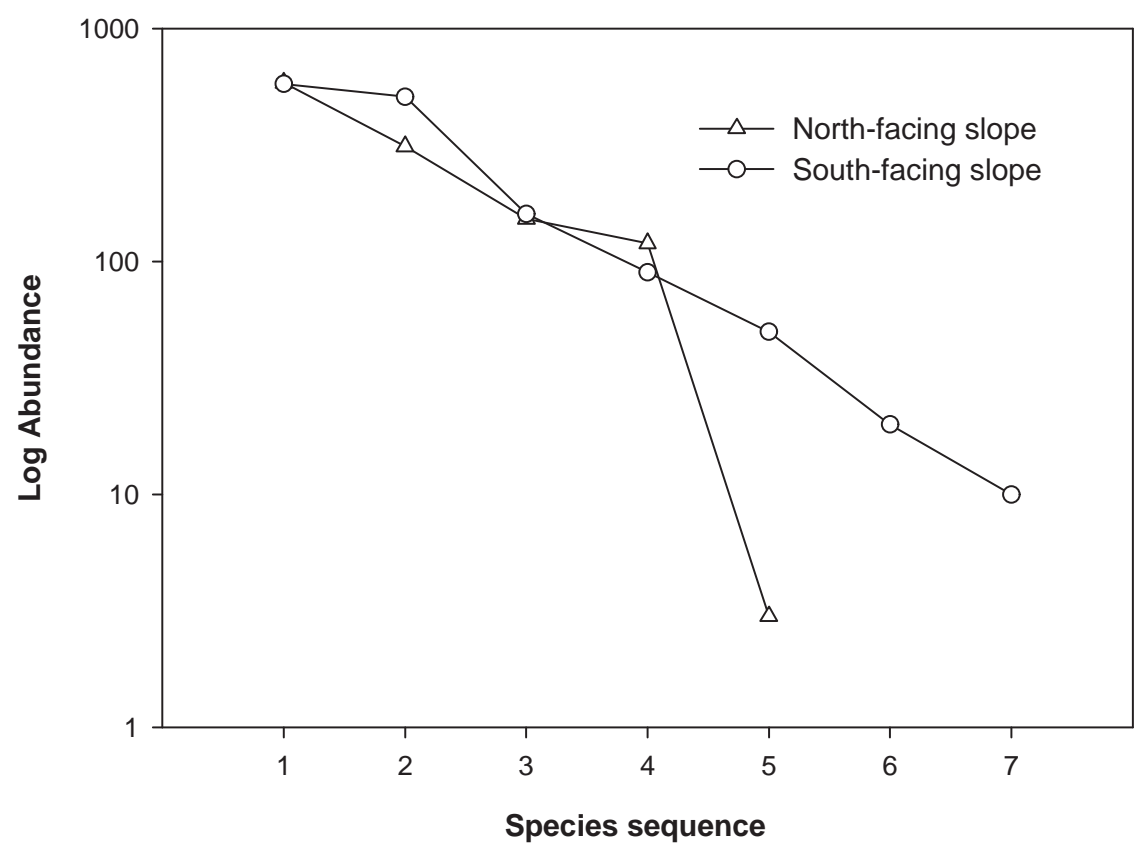

Figure 4.12: Species rank abundance curves for the north and south-facing slopes for the post-fire cohort PECH-040.

On the north-facing slope, two species were the most abundant. Hence dominance diversity curve shows a high decrease of the abundance of the rest of the species. The number of individuals was higher on the south-slope $\left(D_{M g}=0.8\right)$, than the northfacing slope $\left(D_{M g}=0.6\right)$ as depicted by the Margalef index. The inverse Simposn index indicated the same diversity for both slopes $(1 / \mathrm{D}=1.4)$. The major difference between the north and south-facing slopes is the higher species richness on the southfacing slope. 


\section{Post-fire cohort PECH-868}

For this stand, the number of species observed was $S=11$ with a number of individuals of $\mathrm{N}=879$. From this relationship the Margalef index was calculated $\left(D_{M g}=1.5\right)$. The species sequence curve shows three abundant species and four species singletons with a low number of individuals (Fig. 4.13).

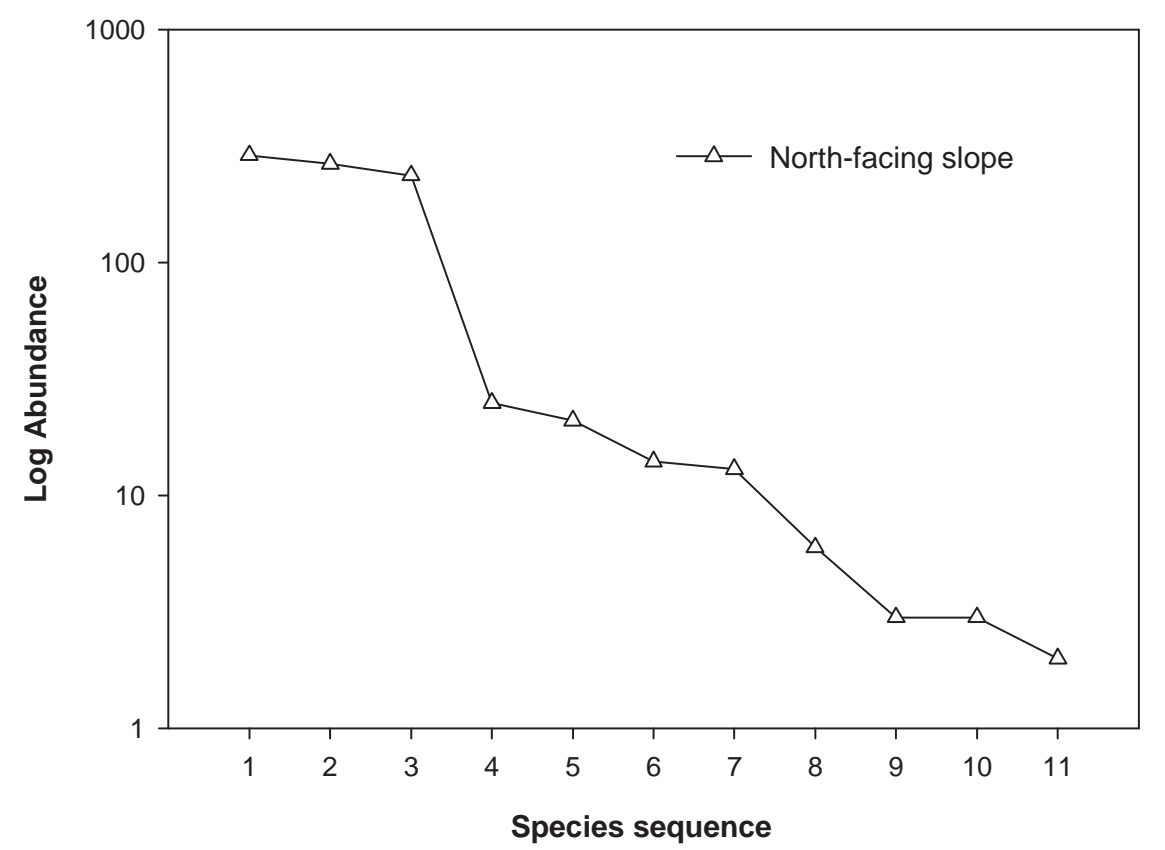

Figure 4.13: Species rank abundance curves for the north -facing slope for the postfire PECH-868.

High abundance of three species on the north-facing slope were observed. Three species were observed at the end of the curve. According to the Shannon index $\left(H^{\prime}=1.5\right)$ this stand had the highest diversity when compared to the previously postfire cohorts. 


\subsubsection{Species Abundance Models}

One of the questions to be answered was whether most of the species in the tail of rank-abundance curves can be found in high abundance at the homologous postfire cohorts within their respective geographical ranges. By analyzing the full species abundance distribution, it is possible to get a better understanding of the relationship between species richness and evenness, which describe the relative abundances of the species present in the area.

Four models have been proposed in this study to account for different species abundance patterns along the post-fire stands, in order to detect the habitat disturbance or grade of succession for each post-fire cohort. From these four models it is possible to trace a sequence from the geometric series. This model reflects a situation in which one or few species are dominant and the rest are rare. Furthermore, the log series, log normal, and the broken stick model. The broken stick model represent the greatest equality in species abundance.

The species abundance distributions in most of the post-fire stands located on both slopes, showed that most species were rare and a few species were abundant. Plotting the number of species against the number of individuals of each species (as in a probability distribution) yields a characteristic hollow curve called a species abundance distribution. This curves has been adjusted to the four described models.

\section{Goodness of fit test}

The Chi-squared test provided a way to evaluate which model best fits and describes patterns of abundance throughout geographical ranges for wood species of the mixed pine-oak forest. The ability to model the data made it possible to determine how close the abundance models fitted the data and whether one post-fire cohort differed from another. The probability threshold of $0.05 \%$ was used. A threshold value was used to create values from the mean probability images. When the probability was greater than the threshold, the species abundance model was accepted; when it was less than the threshold, the species abundance model was rejected. In Table 4.9, the fit of each post-fire cohort to each model are shown. Along the chronosequence, non of the post-fire cohorts fit the geometric series. 
Table 4.9: Fit of four abundance models in the post-fire cohorts for both north and southfacing slopes. The critical value in the $x i^{2}$ is $P>0.05$.

\begin{tabular}{|c|c|c|c|c|c|}
\hline Post-fire cohort & & Geometric series & Log series & Log normal & Broken stick \\
\hline \multirow[t]{2}{*}{ PECH-098 } & North & $x$ & $\checkmark$ & $\checkmark$ & $x$ \\
\hline & South & $x$ & $\checkmark$ & $\checkmark$ & $\checkmark$ \\
\hline \multirow[t]{2}{*}{ PECH-084 } & North & $x$ & $\checkmark$ & $\checkmark$ & $x$ \\
\hline & South & $x$ & $\checkmark$ & $\checkmark$ & $\checkmark$ \\
\hline \multirow[t]{2}{*}{ PECH-072 } & North & $x$ & $\checkmark$ & $\checkmark$ & $\checkmark$ \\
\hline & South & $x$ & $\checkmark$ & $\checkmark$ & $\checkmark$ \\
\hline \multirow[t]{2}{*}{ PECH-040 } & North & $x$ & $\checkmark$ & $\checkmark$ & $x$ \\
\hline & South & $x$ & $\checkmark$ & $\checkmark$ & $\checkmark$ \\
\hline PECH-868 & North & $x$ & $\checkmark$ & $\checkmark$ & $x$ \\
\hline
\end{tabular}

\section{Post-Fire Cohort PECH-098}

Between the both north- and south-facing exposition, the abundance data of the postfire cohort were appropriately described by the Log series and Log normal distribution. The broken stick model had been only fitted for the south-facing slope. On the north-facing slope, three oak species appeared as the most abundant, The species included were, Quercus rysophylla, Q. canbyi, and Q. virginiana. As singletons, five species were identified at the end of the curve: Arbutus xalepensis, unidentified2, Agave americana, Q. laceyi, and Cercis canadensis (Fig. 4.14). The species Q. rysophylla, Q. virginiana and $Q$. canbyi were abundant on the south-facing slope. Three singletons were found on the south slope; of these, two species were found on both slopes. These species were Ceanothus coeruleus and Arbutus xalepensis. The species Q. laeta appeared as singleton and was found only on the south-facing slope.

\section{Post-Fire Cohort PECH-084}

The distribution for the abundance data of the post-fire cohorts along the chronosequence, for the both north and south-facing exposition, were best described by the models Log series and Log normal (Fig. 4.15). 


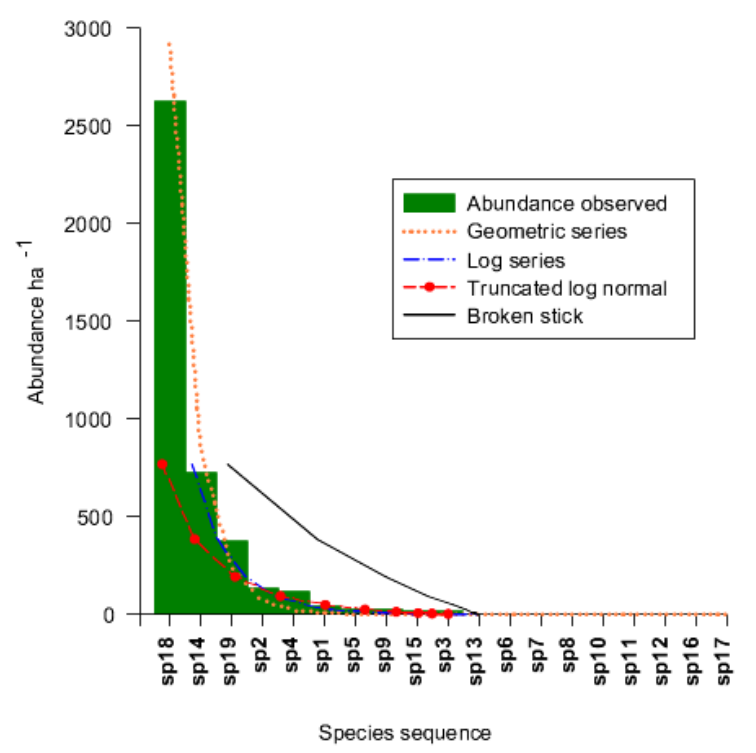

(a) North-facing slope PECH-098

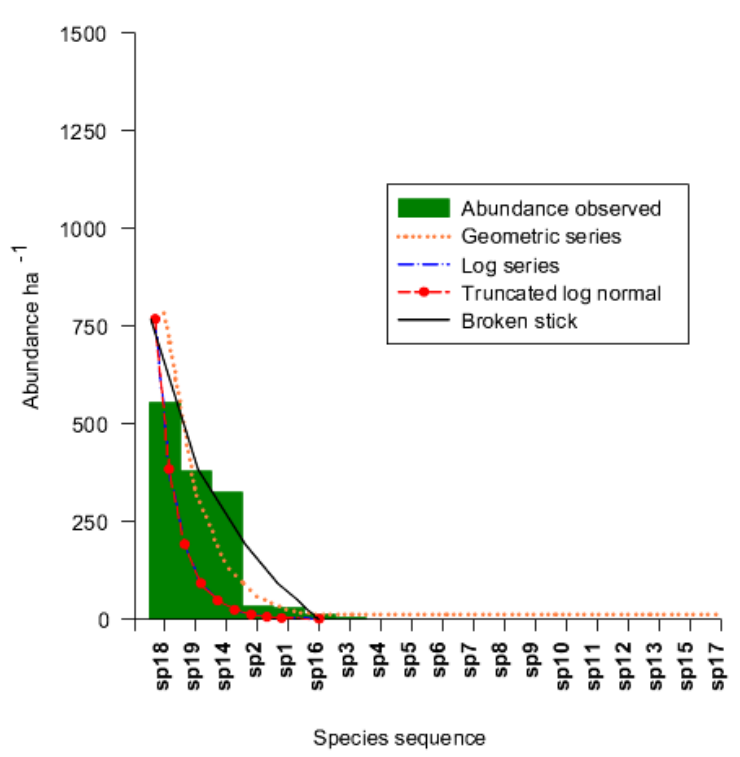

(b) South-facing slope PECH-098

Figure 4.14: Species abundance at the post-fire cohort PECH-098 and the shape of the four abundance models. For abbreviations c.f. Table A.2

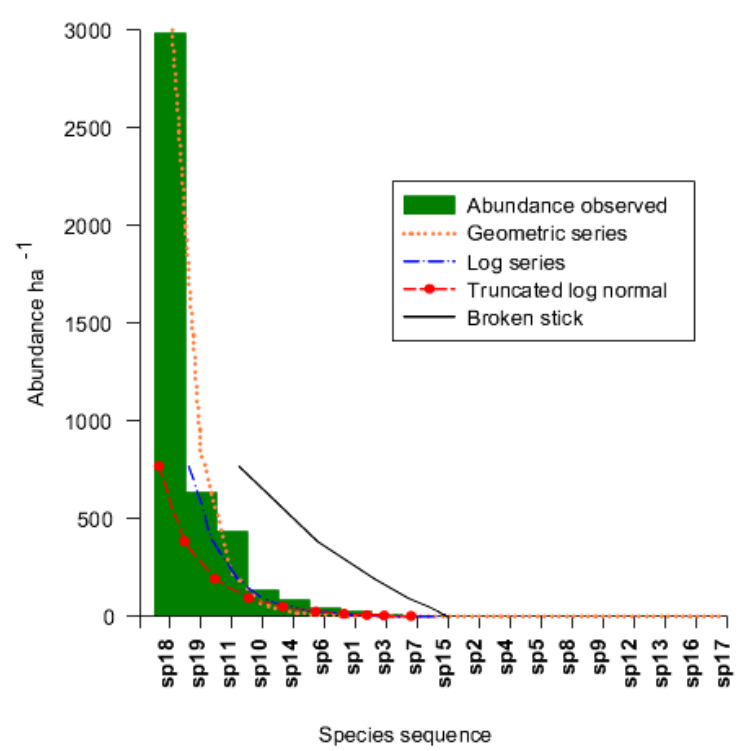

(a) North-facing slope PECH-084

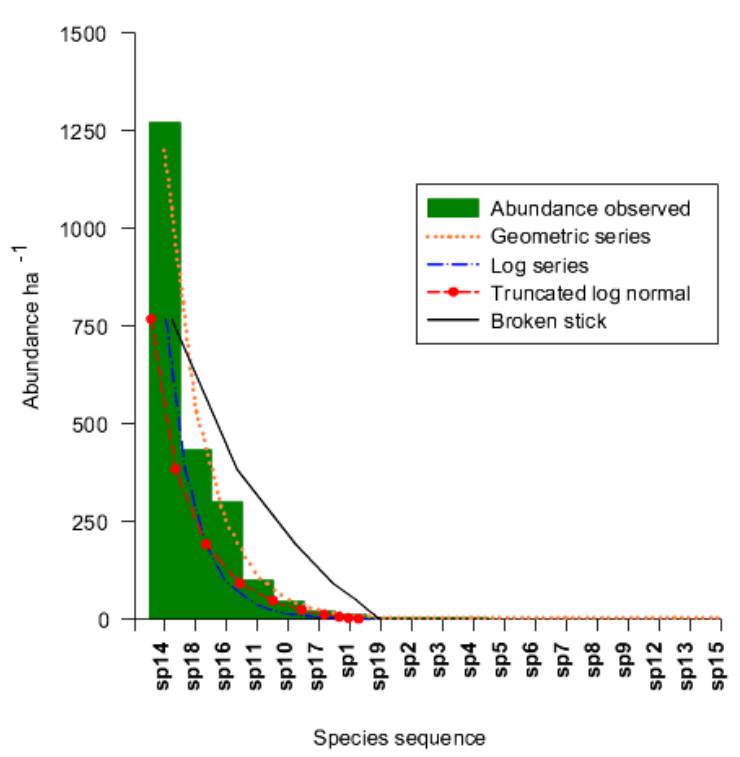

(b) South-facing slope PECH-084

Figure 4.15: Species abundance at the post-fire cohort PECH-084. and the shape of the four abundance models. For abbreviations c.f. Table A.2 
The most abundant species on the north-facing slope were Quercus rysophylla, $Q$. virginiana, and Pinus teocote. The appearance with low abundance of the species $P$. pseodostrobus in this cohort was remarkable. Three species were observed as rare: Juglans mollis, Arbutus xalepensis, and Cercis canadensis. Q. canbyi, which in the youngest post-fire stand appeared among the three most abundant species, decreased in abundance. In contrast, on the south-facing slope, $Q$. canbyi was observed to be the most abundant species, followed by Q. rysophylla and Q. laeta. Both species of Pinus in this stand were observed as singletons. Also appeared as singletons $Q$. polymorpha, Arbutus xalepensis, and Q. virginiana.

\section{Post-Fire Cohort PECH-072}

In the post- fire cohort 30 years after fire disturbance, three species abundance models were fitted for the north- and south-facing slopes. These models were the Log series, Log normal, and the Broken stick model.

On the north facing slope, Quercus rysophylla was still the most abundant species. The following species were also observed: Q. virginiana, Pinus teocote, Q. canbyi, Pinus pseodostrobus, and Juglans mollis. The species Juniperus flaccida, Prunus serotina, and Arbutus xalepensis were observed as rare (Fig. 4.16).

On the south-facing slope, the species Q. rysophylla was the most abundant species, followed by Q. canbyi, Pinus teocote, and Q. laeta. The species Q. polymorpha, P. pseudostrobus, and Arbutus xalepensis appeared as singletons.

\section{Post-Fire Cohort PECH-040}

The Log series and the Log normal distributions were fitted for the north facing slope. Additionally the Broken stick model was fitted for the south-facing slope.

On the north-facing slope, the abundance of Quercus rysophylla was exceeded by Pinus teocote, which at this post-fire stand was the most abundant species. Furthermore, the species Q. canbyi and P. pseudostrobus were also abundant. A single rare species was observed; this is the case for the species Q. virginiana (Fig. 4.17).

The oaks were still the most abundant species on the south-facing slope. In this post-fire stand, the species Q. canbyi was most abundant, followed by P. teocote. Among the most abundant species were also Q. rysophylla, Q. laeta, and Q. virginiana. As rare species, Cercis canadensis and Juniperus flaccida were found. 


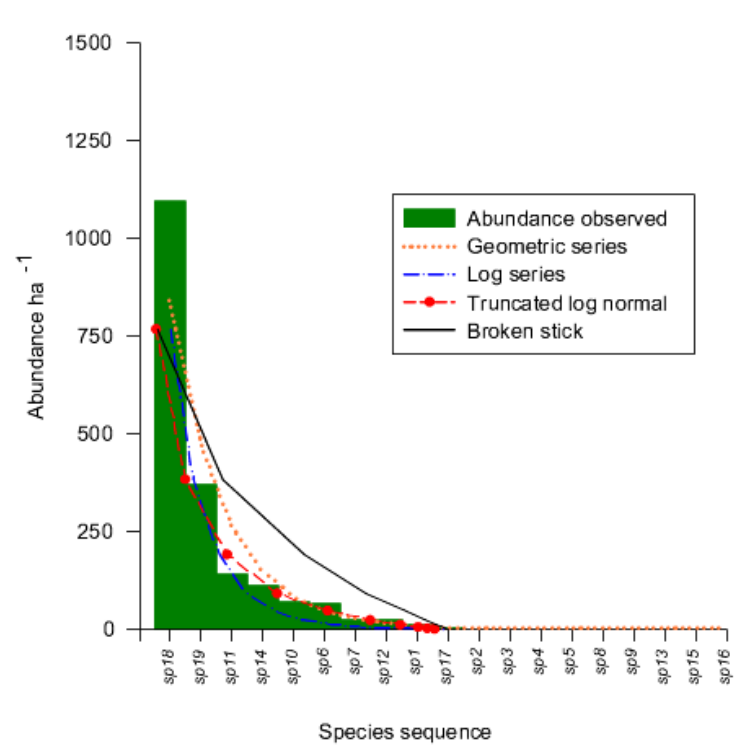

(a) North-facing slope

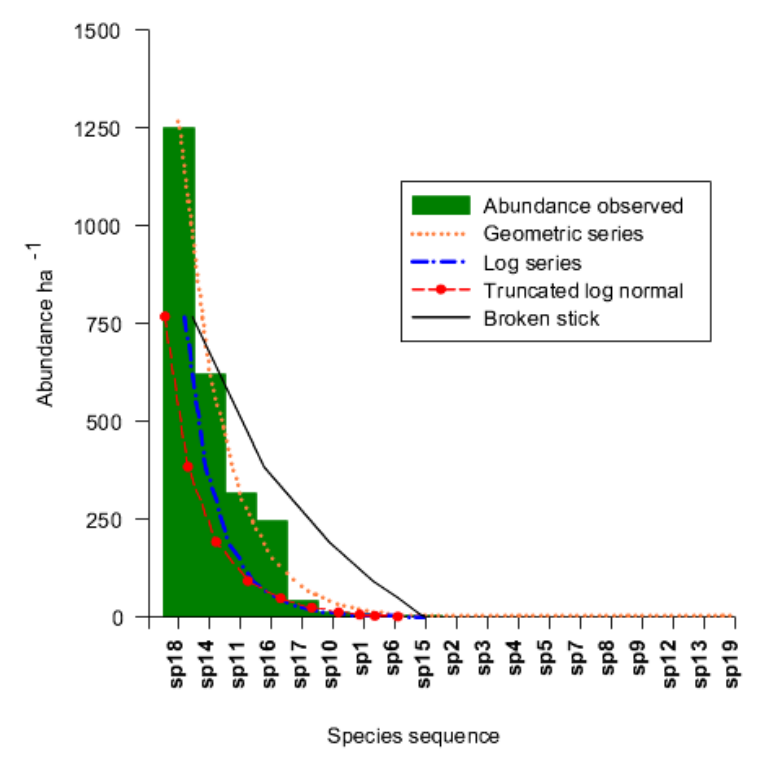

(b) South-facing slope

Figure 4.16: Species abundance at the post-fire cohort PECH-072 and the shape of the four abundance models. For abbreviations c.f. Table A.2

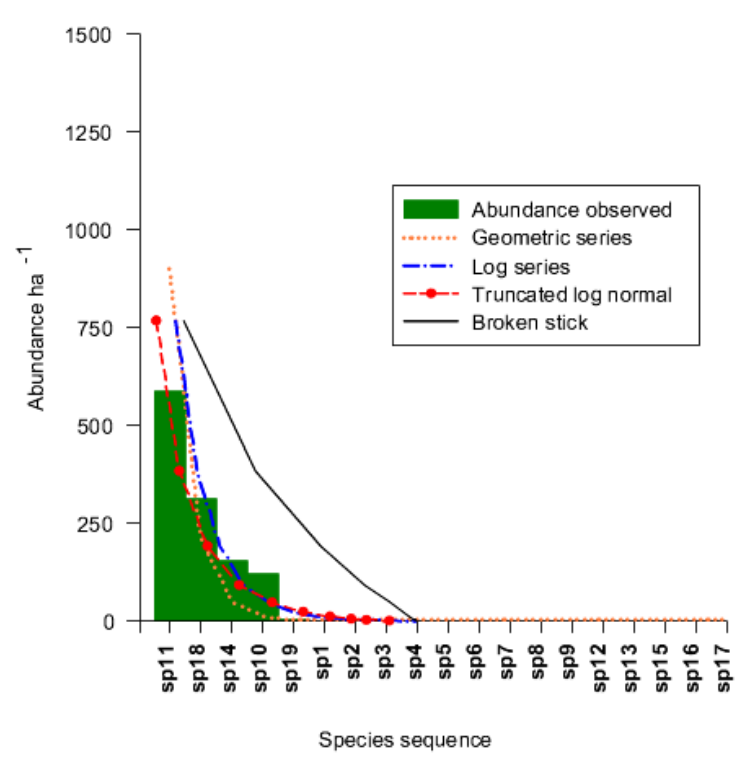

(a) North-facing slope

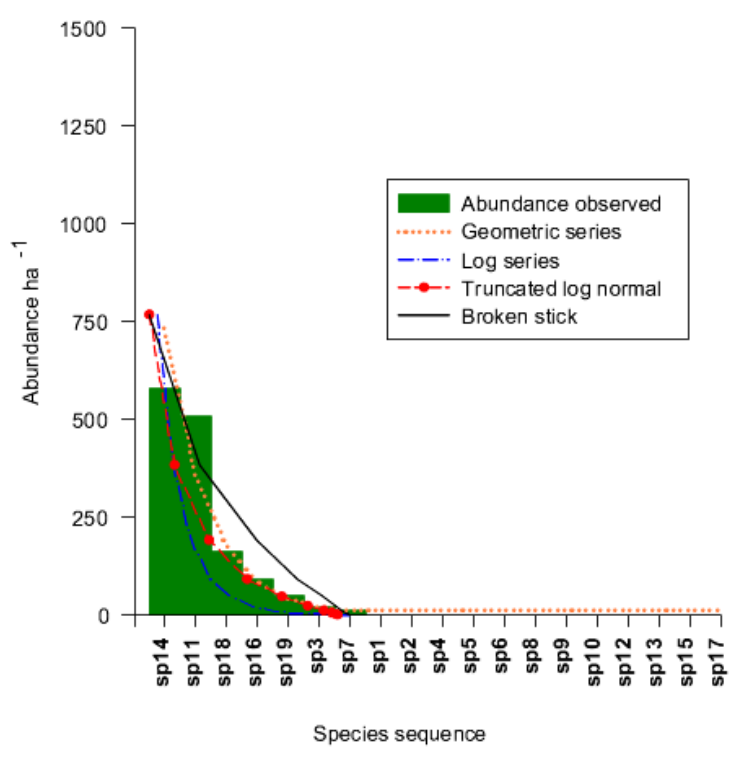

(b) South-facing slope

Figure 4.17: Species abundance at the post-fire cohort PECH-040 and the shape of the four abundance models. For abbreviations c.f. Table A.2 


\section{Post-Fire Cohort PECH-868}

The observed species and number of individuals data were fitted to the Log normal and Log series distributions. In this post-fire stand, 11 species were observed. Out of these, three species, Quercus rysophylla, Q. canbyi, and Pinus pseodostrobus, were registered as most abundant. Since its appearance in the post-fire stands the species $P$. teocte, was always among the most abundant species and had a higher number of individuals than P. pseodostrobus. In this case, however P. teocote, was observed as a rare species. In addition, Cercis canadensis, Q. laceyi, Q. polymorpha, Arbutus xalepensis, Juglans mollis, Ligustrum japonicum, and Q. virginiana, were all present in this post-fire stand as a singletons or rare species (Fig. 4.18).

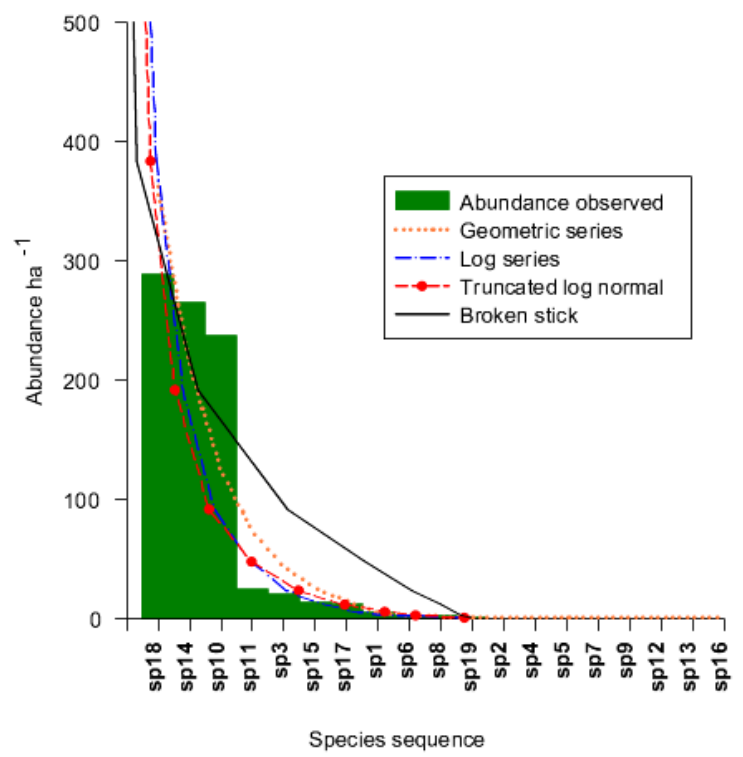

Figure 4.18: Species abundance at the post-fire cohort PECH-868 and the shape of the four abundance models. For abbreviations c.f. Table A.2

\subsubsection{Beta Diversity}

Beta diversity is also called differentiation diversity $(\beta)$. This index was essentially used to measure differences between the post-fire cohorts on both the north and south-facing slopes. 


\section{Whittaker's Beta Diversity $\left(\beta_{w}\right)$}

In order to compare the south- to the north-facing slopes, only the gradients from PECH-098 to PECH-040 were included on the calculation. Frequent changes in species over time cause higher beta diversity values. Thus, the diversity values obtained for the north-facing slope was $\beta_{w}=0.9$. For the south-facing slope the result was a value of $\beta_{w}=0.8$.

\section{Post-Fire Stand Complexity}

Complexity index (CI) values for both slopes, based on the height of the stem and the mean basal area, are compiled in Table 4.10 .

Table 4.10: Complexity index (CI) and it components in both north and south-facing slopes of the PECH.

\begin{tabular}{lccccc}
\hline North & $\bar{h}$ & $g_{i}$ & $\mathbf{N}$ & $\mathbf{S}$ & $\mathbf{C I}$ \\
\hline PECH-098 & 2.1 & 4.1 & 4097 & 11 & 38.8 \\
PECH-084 & 5.0 & 19.8 & 4347 & 10 & 430.4 \\
PECH-072 & 6.7 & 9.2 & 1915 & 10 & 118.0 \\
PECH-040 & 10.3 & 44.5 & 1177 & 5 & 270.0 \\
PECH-868 & 14.6 & 28.1 & 1059 & 11 & 477.9 \\
\hline South & & & & & \\
PECH-098 & 2.7 & 2.2 & 1335 & 6 & 4.8 \\
PECH-084 & 4.2 & 6.3 & 2185 & 8 & 46.3 \\
PECH-072 & 5.7 & 19.8 & 2303 & 9 & 233.9 \\
PECH-040 & 6.7 & 47.3 & 1420 & 7 & 315.0 \\
\hline $\bar{h}=$ mean height, $g_{i}=$ basal area, N=number trees/ha \\
S= number of species, CI = complexity index
\end{tabular}

On both slopes the CI value was much higher in the oldest cohorts, PECH-868 for north and PECH-040 for south-facing slope. The principal components that make the difference in the Complexity index of these plots were: ages play a important role, followed by the high species richness presented on the post-fire stands. On the north- 
facing slope, in the PECH-084 was also observed a high Complexity Index value. The high number of individuals and high diameters found made of this stand the second most complex stand on the north-facing slope. In contrast, on the south-facing slope, the complexity index increases with the time since fire disturbance.

\section{Species Similarity Between Post-Fire Stands}

The floristic comparison of the post-fire stands, was calculated using the Sorensen quantitative index. Coefficient of similarity for the post-fire cohorts are shown in Table 4.11 .

Table 4.11: Sorensen quantitative index, based on the number of species for both, north and south-facing slopes.

\begin{tabular}{lccccc}
\hline & \multicolumn{5}{c}{ Coefficient of similarity } \\
\cline { 2 - 6 } North & PECH-098 & PECH-084 & PECH-072 & PECH-040 & PECH-868 \\
\hline PECH-098 & $\boldsymbol{x}$ & $\boldsymbol{x}$ & $\boldsymbol{x}$ & $\boldsymbol{x}$ & $\boldsymbol{x}$ \\
PECH-084 & 0.97 & $\boldsymbol{x}$ & $\boldsymbol{x}$ & $\boldsymbol{x}$ & $\boldsymbol{x}$ \\
PECH-072 & 0.64 & 0.61 & $\boldsymbol{x}$ & $\boldsymbol{x}$ & $\boldsymbol{x}$ \\
PECH-040 & 0.45 & 0.43 & 0.76 & $\boldsymbol{x}$ & $\boldsymbol{x}$ \\
PECH-868 & 0.35 & 0.33 & 0.62 & 0.85 & $\boldsymbol{x}$ \\
South & & & & & \\
\hline PECH-098 & $\boldsymbol{x}$ & $\boldsymbol{x}$ & $\boldsymbol{x}$ & $\boldsymbol{x}$ & $\boldsymbol{x}$ \\
PECH-084 & 0.76 & $\boldsymbol{x}$ & $\boldsymbol{x}$ & $\boldsymbol{x}$ & $\boldsymbol{x}$ \\
PECH-072 & 0.98 & 0.74 & $\boldsymbol{x}$ & $\boldsymbol{x}$ & $\boldsymbol{x}$ \\
PECH-040 & 0.96 & 0.78 & 0.94 & $\boldsymbol{x}$ & $\boldsymbol{x}$ \\
\hline
\end{tabular}

When the post-fire cohorts on north facing slopes were compared with each other, the species similarity decreased with the time since forest fires. The highest degree of similarity (0.97) was observed between the PECH-098 and PECH-084. As could be expected, the lowest degree of similarity was found between the youngest post-fire cohort (PECH-098) and the oldest one (PECH-868). The post-fire cohort PECH-098 is a regeneration stand; the tree composition consists mostly of colonizer species with 
the ability to resprout (Quercus spp). On the south-facing slope, a relatively high similarity index was found among the different post-fire stands.

\section{Connectedness Among Post-Fire Stands}

The results of the connected data for the north- and south-facing slope are shown in (Fig. 4.19). The connectivity of distance matrix with threshold similarity of 0.4 , shows that most of the post-fire cohorts on the north-facing slopes were disconnected or sharing only $40 \%$ of the species registered. Furthermore the same trend was observed for the south-facing slopes. Although no strong connection was found for the north-facing slope, when the limit of dissimilarity was at 0.4 , there exists a close relationship between two post-fire cohorts. These plots were the post-fire cohorts PECH-084 and PECH-098. The same occurred on the south-facing slope, when the value of connection between post-fire cohorts was at 0.4 . Here, the post-fire cohorts which had a correlation were, PECH-072 and PECH-084 (Fig. 4.19a). In order to find out the threshold at which the post-fire stands were connected, two limits were calculated for each slope. The confident limit of 0.6 showed that all post-fire stands were connected (Fig. 4.19c). 

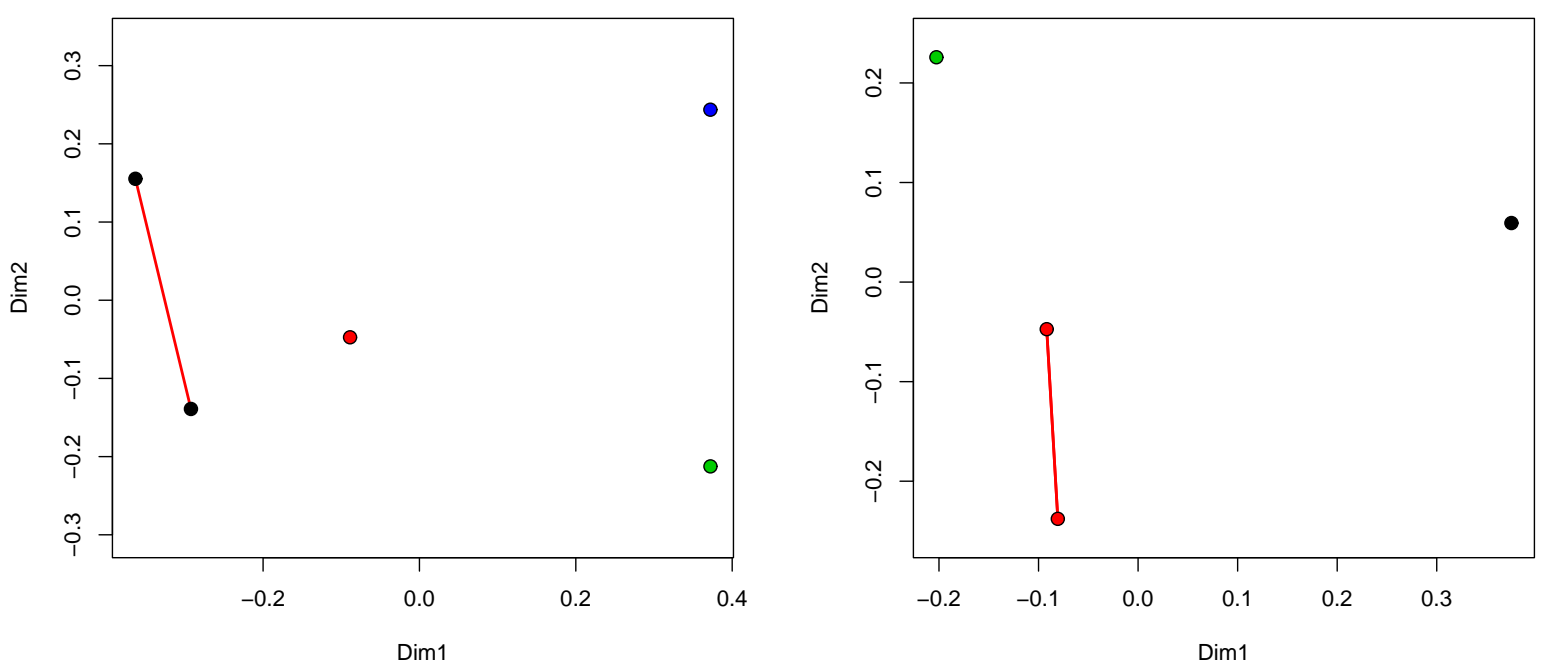

(a) Threshold value at 0.4 - Left for the north- Right; south-facing slopes
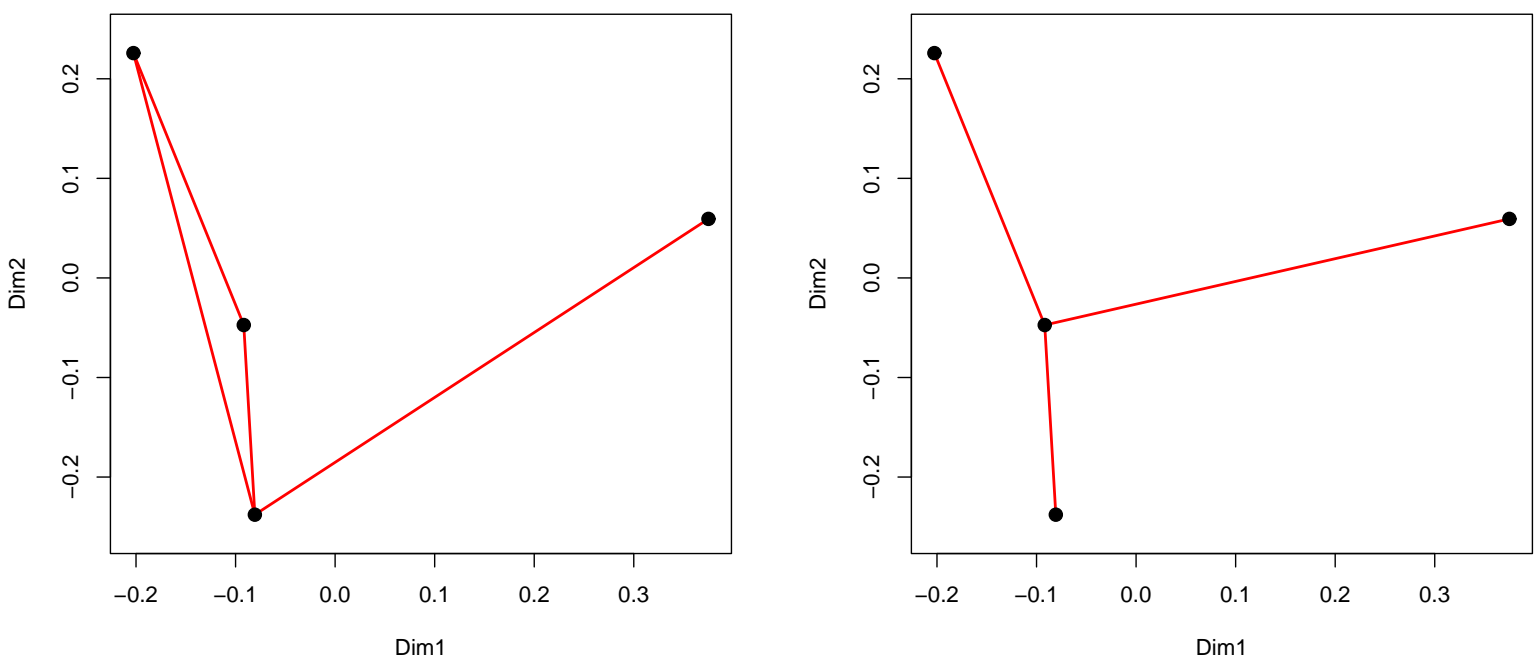

(c) Threshold value at 0.6 - Left for the north- Right; south-facing slopes

Figure 4.19: Connectedness and minimum spanning tree for similarities for both slopes and post-fire cohort, Threshold value at 0.4 and 0.6 . 


\subsection{Multivariate Analysis}

\subsubsection{Classification}

A hierarchical cluster analysis was conducted with the set of similarities obtained in the previous section 4.5.3. Classification by "hclust" (Orkasen 2004) [109] was completed using the post-fire cohorts for both the north- and south-facing slopes separately. A dendrogram for the post-fire cohort was recognized by the classification of the burn plots. These groups were described based on plot age and species were identified for each slope. A main goal of the study of pattern species abundance was to verify the presumed connection between species abundance and the functional ways in which communities are organized. For the north-facing slope, a Dendrogram with five groups were recognized; which seem to be based on plot age after disturbance (Figure 4.20, page 98). Group 1 is represented by the post-fire cohort PECH-098, four years after fire disturbance. This stand is also distinguished by the high cover or presence of Quercus rysophylla (c.f subsection 4.5.2). Group 2 includes the plots located in the cohort PECH-084 (18 years). In this plot, the most predominant species were Q. rysophylla. The incorporation of the species Q. virginiana was notable. Group 3 includes the cohort PECH-072 (30 years). This group includes those plots within the intermediate maturity forest stands and were distinguished by the high cover of four species $Q$. rysophylla, Q. virginiana. The genus Pinus becomes establish along the gradients. P. teocte and P. pseodostrobus were evident at this successional stage. It is also evident that this cohort was more related to those cohorts within mature forest stands. Group 4, is represented by the 62 years old cohort (PECH-040). At this successional stage, only two species appeared with both high abundance and frequency. The dominate species is now P. teocote, followed by $Q$. rysophylla. The last group (G5) includes Group PECH-868. The species P. pseodostrobus was at this point the most abundant and frequent. Due to the age of the cohort, some canopy gaps or disturbance were present. This can be confirmed by some of the species found in this cohort. The presence of the species Q. rysophylla and Q. canbyi, which occurred with a high number of individuals in the inferior diameter classes, indicates that regeneration is present at this stage. 


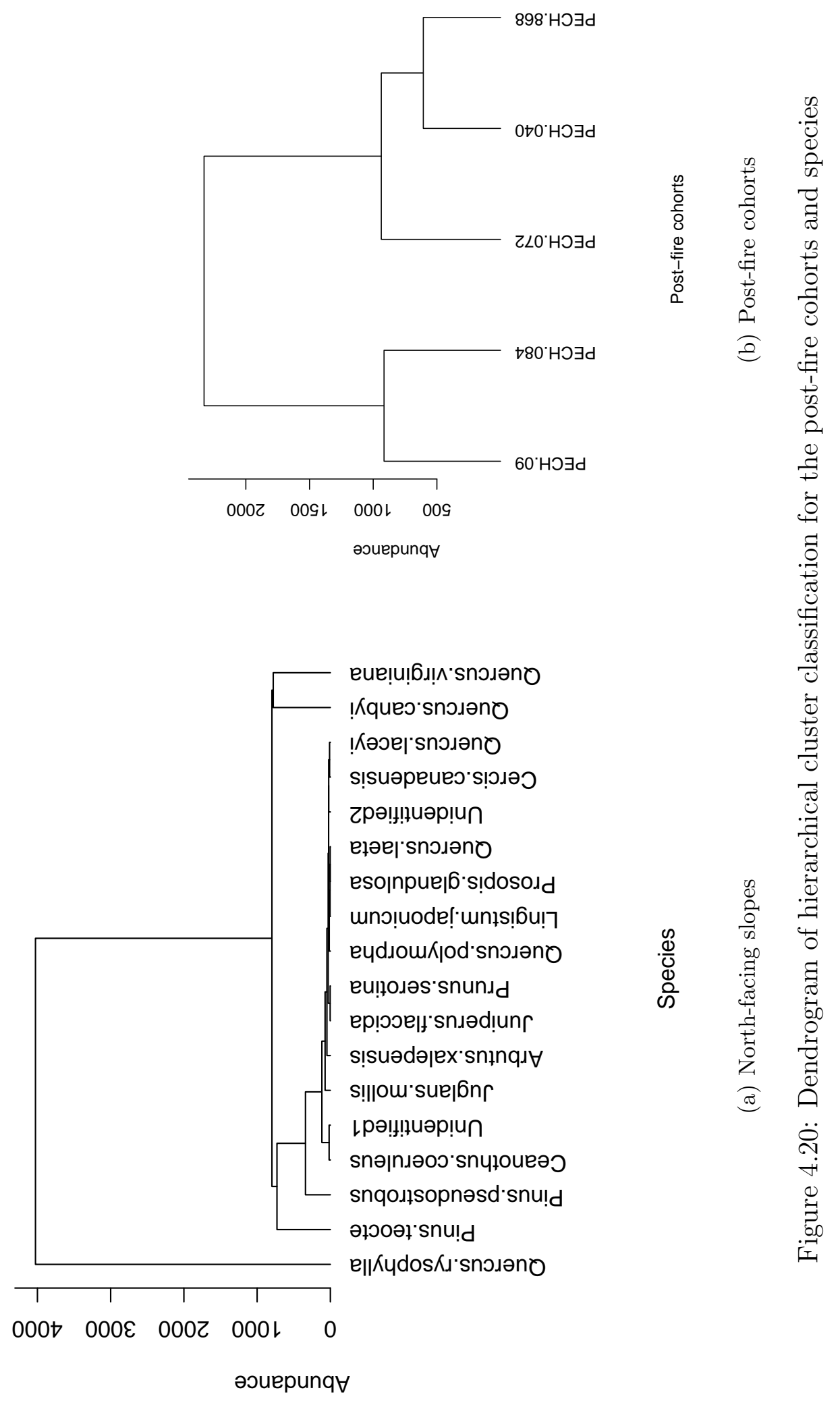




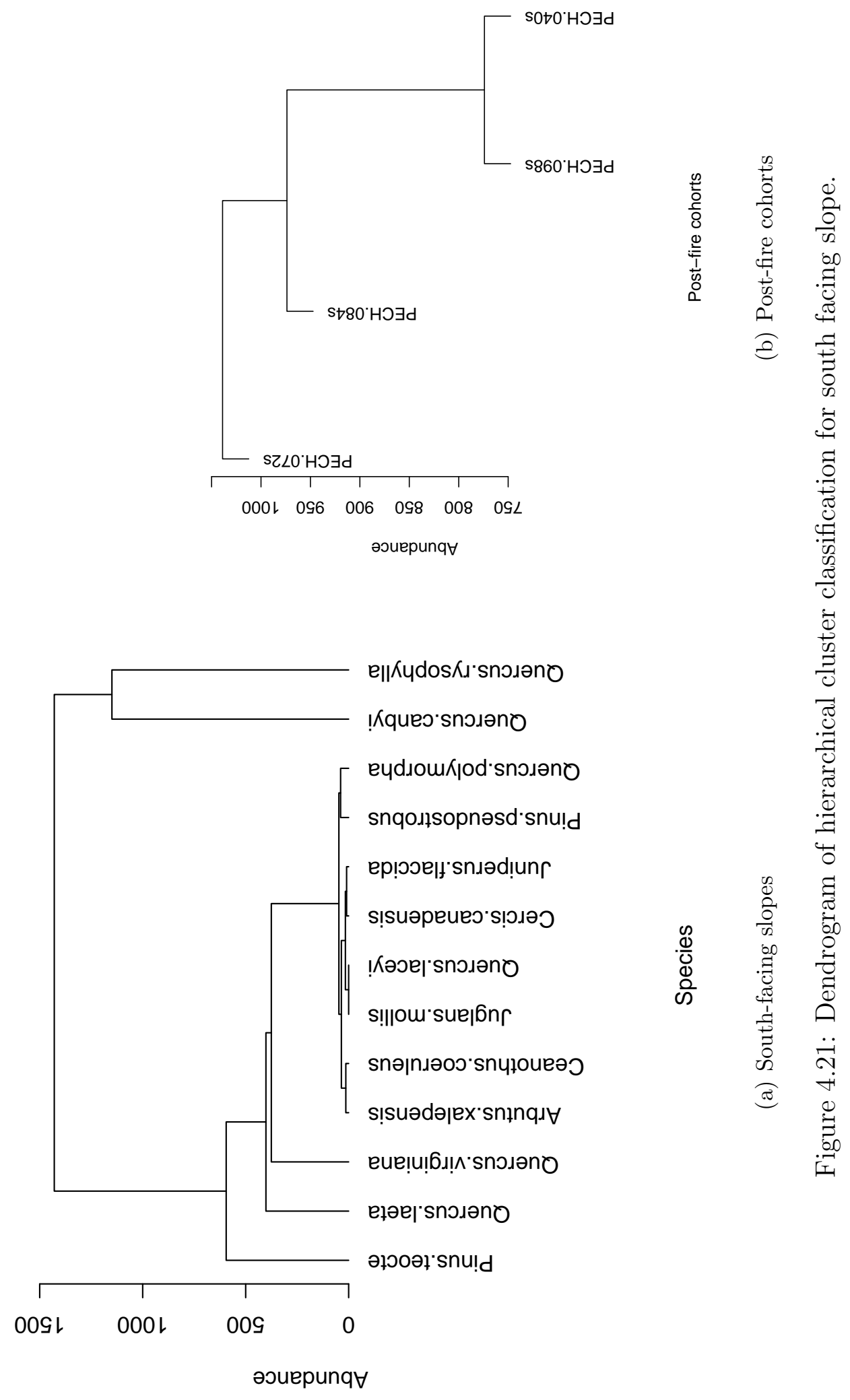


In the hierarchical cluster classification for the south-facing slope the following groups were identified (Figure 4.21, page 99). Group 1. This group consists of plots 30 years after disturbance (PECH-072). The occurrence of species of genus Quercus (Q. rysophylla and Q. canbyi), as well as Pinus teocote were notable. Group 2. The cohort sampled in this group represent the plots 18 years after fire (PECH-084). Again, a strong influence and dominance of genus Quercus was observed (Q. canbyi, $Q$. rysophylla, and $Q$. laeta), as well as P. teocote. Group 3. This group consists of the the youngest stand sampled (PECH-098), four years after forest fire. As in the previous cohorts, this one was characterized by individuals of oak, which became established due to the ability to resprout. The last identified group in the hierarchical cluster was Group 4, which correspond to the post-fire stand PECH-868. This plot was strongly dominated by the species $P$. teocote, closely followed by the species Q. canbyi. The dominance of oak species 62 years after a fire is notably less, and the apparition of new species, including Cercis canadensis and Juniperuss flaccida, is remarkable. All of these four groups identified by the hierarchical dendrogram in the south-facing slope suggest that the hierarchy was established with regard to the abundance and presence of species along the different gradients. This functional organization shows how species were related to another, as competitors through a range of other interactions.

Classification of the post-fire cohorts using abundance data emphasized the importance of age after disturbance as an indicator of species assemblages and turnover. Post-fire cohorts on the north-facing slope were classified into groups based on age; post-fire cohorts on the south-facing slope were classified into groups which were less related to stand ages. A classification including all post-fire cohorts further emphasized the differences between the north-and south-facing slopes. The post-fire cohorts on the south-facing slope were grouped with post-fire cohorts of older ages, solidifying the observation of increased similarity between the young post-fire cohorts on the south-facing and the mature post-fire cohorts on the north-facing slope. A classification including all post-fire cohorts is shown in Fig. 4.22. 


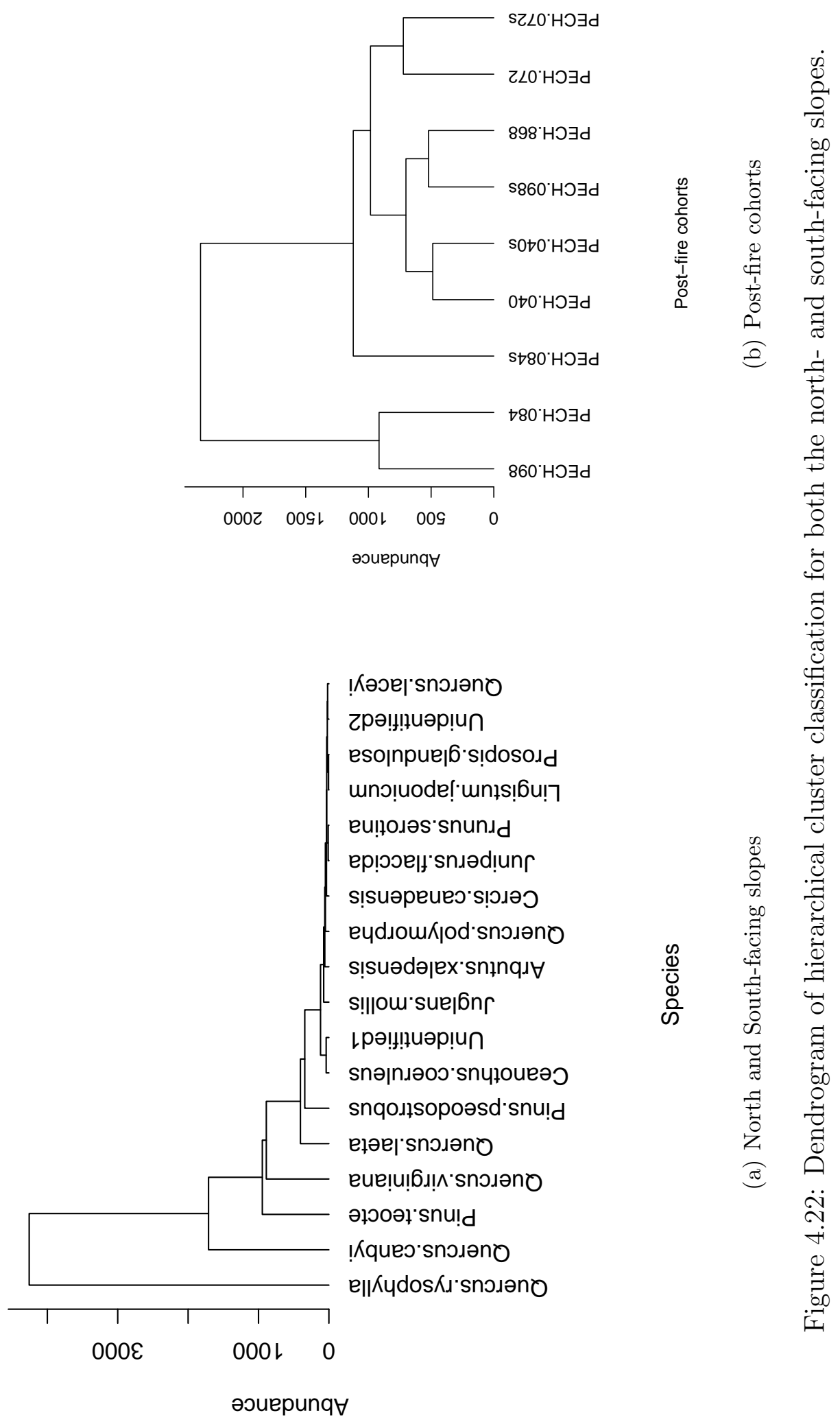




\subsubsection{Ordination}

The community data were summarized by producing a low-dimensional ordination space where similar individuals are close together and those which are dissimilar occur further apart. The species abundances were developed as a measure of how well this variable could explain the species data for the north-facing slope. The result for the detrended correspondence analysis (DCA) of the post-fire cohorts and species are shown in Table 4.12 .

Table 4.12: Eigenvalues defining the detrended correspondence analysis and correlations for the species and post-fire stands for the north-facing slope.

\begin{tabular}{lccccr}
\hline & DCA1 & DCA2 & DCA3 & DCA4 & Totals \\
\hline Eigenvalues & 0.2496 & 0.0551 & 0.0551 & 0.0550 & \\
Decorana values & 0.2609 & 0.0207 & 0.0011 & 0.0001 & \\
Axis lengths & 1.381 & 0.6501 & 0.6501 & 0.6501 & \\
\hline Species scores & & & & & \\
Arbuxale & -0.7816 & -0.0141 & -0.0141 & -0.0141 & 87 \\
Ceancoer & -2.0419 & 0.5443 & 0.5443 & 0.5443 & 130 \\
Cerccana & 1.0549 & -2.127 & -2.127 & -2.127 & 45 \\
UnidUnid.1 & -2.0419 & 0.5443 & 0.5443 & 0.5443 & 113 \\
UnidUnid.2 & -2.0419 & 0.5443 & 0.5443 & 0.5443 & 23 \\
Juglmoll & -0.1762 & 2.9541 & 2.9541 & 2.9541 & 109 \\
Juniflac & -0.4111 & 5.1172 & 5.1172 & 5.1172 & 28 \\
Lingjapo & 1.8446 & 0.5443 & 0.5443 & 0.5443 & 4 \\
Pinupseo & 1.632 & 0.7551 & 0.7551 & 0.7551 & 609 \\
Pinuteoc & 1.8141 & -0.9065 & -0.9065 & -0.9065 & 1187 \\
Prunsero & -0.4383 & 5.9296 & 5.9296 & 5.9296 & 25 \\
Prosglan & -2.0419 & 0.5443 & 0.5443 & 0.5443 & 3 \\
Quercanb & 0.579 & 0.9364 & 0.9364 & 0.9364 & 1397 \\
Querlace & 1.6387 & -2.0159 & -2.0159 & -2.0159 & 20 \\
Querlaet & -2.0419 & 0.5443 & 0.5443 & 0.5443 & 20 \\
Querpoly & 1.4986 & 1.9195 & 1.9195 & 1.9195 & 21 \\
Querryso & -0.3203 & -0.3766 & -0.3766 & -0.3766 & 7370 \\
Quervirg & -0.7345 & 1.0185 & 1.0185 & 1.0185 & 1382 \\
\hline & & & & &
\end{tabular}

For abbreviations c.f. Table A.2 
Taking the average of the abundance values for each stand is a good first indication of where a species occurred along the post-fire stands or gradients. This average (species score) is an estimate of the optimum number of individuals for the species. Applying the DCA for the north-facing slopes gives the first and the second eigenvalues, 0.25 and 0.05 , respectively. The third and higher numbered ordination axes did not contributed to explaining the variance. The DCA eigenvalues were not high, but the eigenvalue of axis DCA1 and DCA2 were considerably higher than those of axes 3 and 4, indicating that most of the extractable variance in species composition were accounted by the first two DCA axes. Hence, these first two ordination axes displayed trends which are biologically relevant; the variance explained by these eigenvalues was $29 \%$. The post-fire stands were plotted based on the stand scores and the species scores of one ordination axis against those of another (Fig. 4.23). The length of the first two axes representing the stands were estimated to have standard deviations of 1.4 and 0.6 , respectively. The length of the axis representing the species is about 2.0 with a standard deviation of 6.0 s.d. (Table 4.12 ).

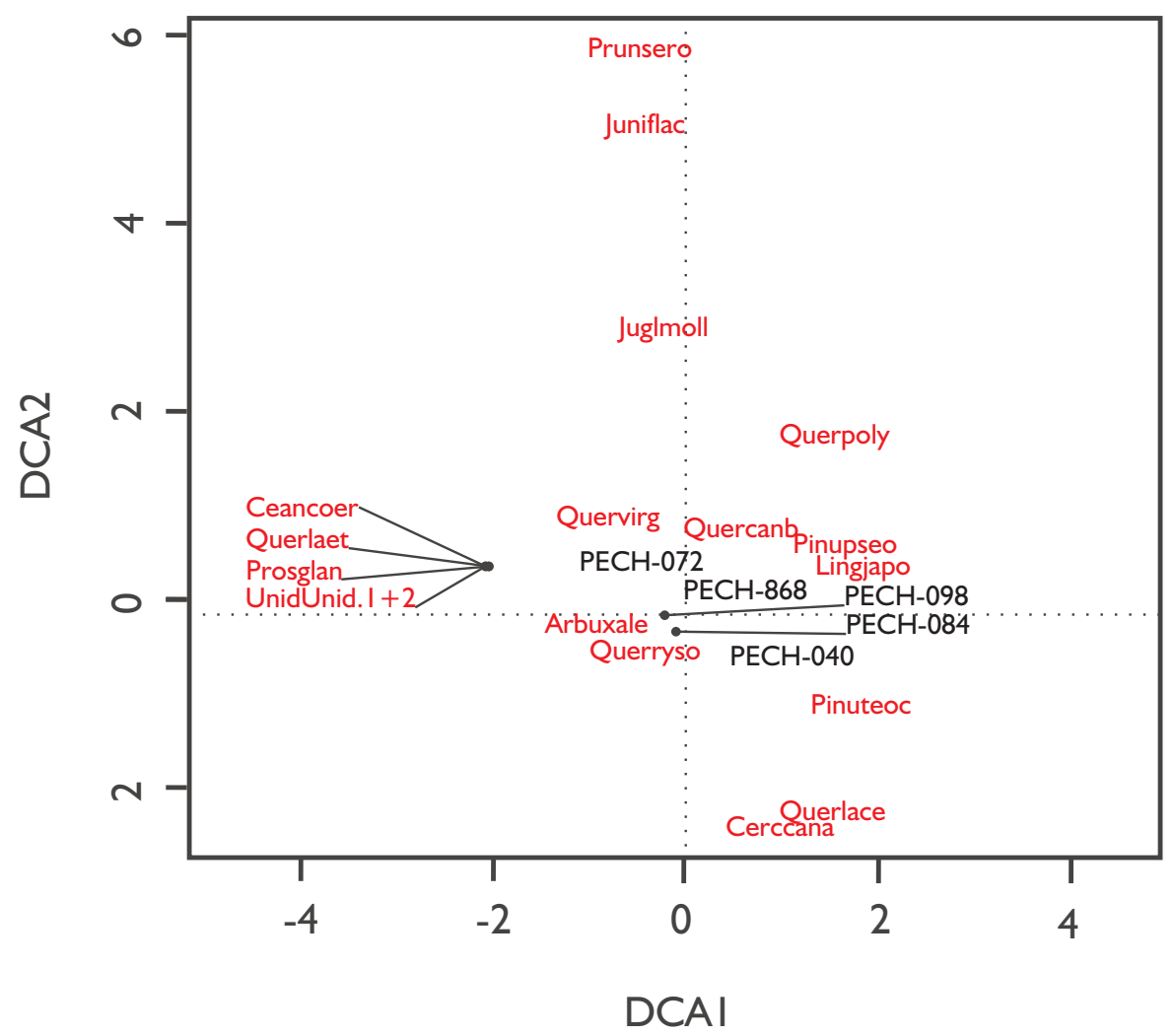

Figure 4.23: DCA ordination diagram for stands and species for the north-facing slopes. The scale refers to multiples of the s. d. For abbreviations c.f. Table A.2 
The first DCA1 axis had a length of about 2 standard deviations. The post-fire stands were closer, because they have one or more species in common, some of which were also observed as abundant species. For instance, the species Quercus rysophylla was observed with a high abundance with regard to the post-fire stands PECH-098 and PECH-084. This DCA prediction can be verified in Table 4.4.

The second DCA2 axis had a length of about 6 s.d. Therefore, the species that occur at the opposite end of the second axis have hardly any species in common and these species were observed as rare or singletons species. Species observed as rare were Prunus serotina, Juglans mollis, and Juniperus flaccida, which are displayed at the end of the second axis (Fig. 4.23).

For the south-facing slope, the result for the Detrended Correspondence Analysis (DCA) are shown in Table 4.13.

Table 4.13: Eigenvalues defining the detrended correspondence analysis and correlations for the species and post-fire stands for the south-facing slope.

\begin{tabular}{lccccr}
\hline & DCA1 & DCA2 & DCA3 & DCA4 & Totals \\
\hline Eigenvalues & 0.2648 & $3.51 \mathrm{E}-02$ & $2.25 \mathrm{E}-02$ & $1.69 \mathrm{E}-02$ & \\
Decorana values & 0.2957 & $2.22 \mathrm{E}-17$ & $5.81 \mathrm{E}-48$ & $2.33 \mathrm{E}-78$ & \\
Axis lengths & 1.5 & $4.00 \mathrm{E}-01$ & $3.47 \mathrm{E}-01$ & $3.13 \mathrm{E}-01$ & \\
\hline Species scores & & & & & \\
Arbuxale & 1.531 & 1.721 & 1.857 & 1.95 & 48 \\
Ceancoer & 2.236 & 1.730 & 1.856 & 1.94 & 35 \\
Cerccana & -2.127 & 1.751 & 1.903 & 2.009 & 20 \\
Juglmoll & -0.171 & 1.763 & 1.930 & 2.046 & 5 \\
Juniflac & -2.127 & 1.759 & 1.918 & 2.029 & 10 \\
Pinupseo & -1.068 & 1.723 & 1.903 & 2.032 & 55 \\
Pinuteoc & -1.372 & 1.035 & 0.967 & 0.943 & 925 \\
Quercanb & -0.346 & -0.666 & -0.624 & -0.603 & 2795 \\
Querlace & -0.171 & 1.763 & 1.930 & 2.046 & 5 \\
Querlaet & -0.860 & 1.254 & 1.484 & 1.685 & 645 \\
Querpoly & -0.543 & 1.719 & 1.9 & 2.03 & 60 \\
Querryso & 0.811 & -0.372 & -0.419 & -0.454 & 2398 \\
Quervirg & 1.955 & 1.322 & 1.030 & 0.776 & 435 \\
\hline
\end{tabular}

For abbreviations c.f. Table A.2 
The DCA applied for the south-facing slope gives an eigenvalue of 0.26 for the first and 0.003 for the second. The length of the first axis (1.5 s.d.) explained most of the biological variation (29\%) relevant for the south-facing slope data.

The separation between species is greater than on the north-facing slope. The species ordination indicates a preference of species for some of the post-fire stands. For instance, presence of Quercus canbyi is correlated to the post-fire stand PECH-084. Quercus rysophylla had a strong correlation with the stand PECH-072. Species such as Q. virginiana, Arbutus xalepensis, and Ceanothus coeruleus were related to the post-fire stand PECH-098.

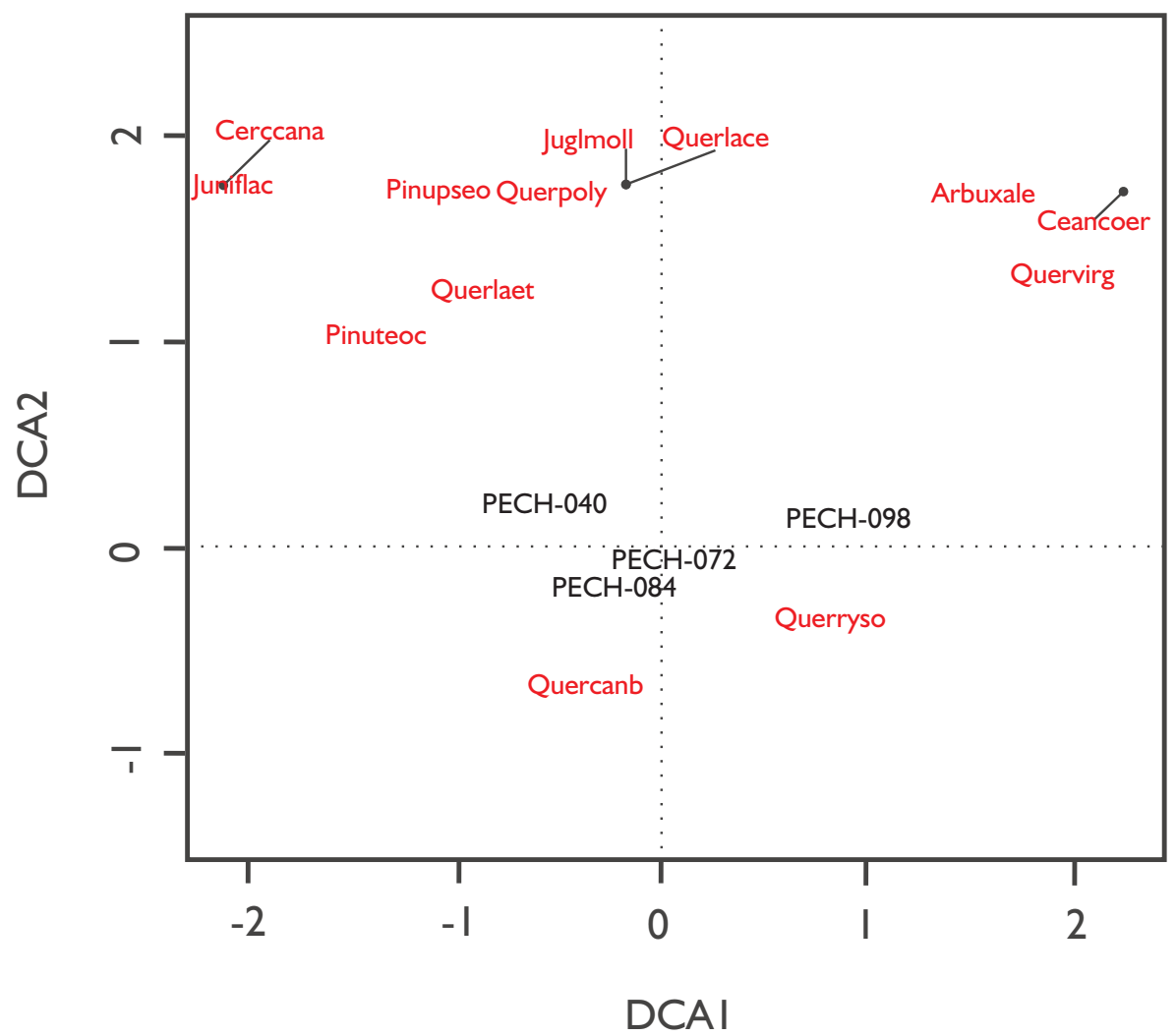

Figure 4.24: DCA diagram for the post-fire cohorts and species for the south-facing slope.

All the species located at the edge of the diagram, occurred as a singletons or rare species. These species generally are associated with the preference or occurrence to some extreme conditions. This was proofed by additional external variables in a Canonical correspondence analysis. 


\subsubsection{Direct Gradient Analysis}

In this analysis the species were arranged according to the age of the stand. The species score was defined as the value most preferred and on the stands and was calculated by averaging the abundance values of the sites in which the species were present. Environmental variables were standardized to mean 0 and variance 1 and the dispersion of the species scores after standardization was taken to express how well a variable explains the species abundance.

The CCA produced three sets of ordination scores: species scores, sample score as weighted averages of species (WA-scores), and sample scores predicted by the regression on the environmental variables (LC scores). These sets revealed the strong influence of the time after fire on the species abundance and diversity in the PECH (Table 4.14). The CCA applied for both the north- and the south-facing slope gives a first eigenvalue of 0.27 , a second eigenvalue of 0.15 , and a third eigenvalue of 0.07 . These three eigenvalues indicate that most of the extractable variance $(56 \%)$ in species abundance and composition can be accounted for the three first axes (Table 4.14).

Table 4.14: Summary statistics for canonical correspondence analysis.

\begin{tabular}{lccccccc}
\hline & CCA1 & CCA2 & CCA3 & CCA4 & CCA5 & P model & $\begin{array}{c}\text { Explained } \\
\text { variation }\end{array}$ \\
\hline lambda & 0.275 & 0.159 & 0.070 & 0.016 & 0.004 & 0.002 & $65.2 \%$ \\
accounted & 0.355 & 0.560 & 0.652 & 0.674 & 0.680 & & \\
\hline LC scores & & & & & & & \\
PECH-098 & -0.58 & 0.65 & -1.05 & -0.65 & -0.11 & & \\
PECH-084 & -1.06 & 0.01 & 0.04 & 0.76 & -0.99 & & \\
PECH-072 & -0.42 & -0.55 & 1.39 & -1.97 & 0.49 & & \\
PECH-040 & -0.44 & -1.47 & 0.40 & -0.85 & 1.30 & & \\
PECH-868 & 0.78 & -3.21 & -1.51 & 0.55 & -0.03 & & \\
PECH-098s & -0.57 & 0.43 & 1.98 & 1.86 & 1.54 & & \\
PECH-084s & 1.52 & 1.11 & 0.36 & -0.65 & -0.58 & & \\
PECH-072s & 0.93 & 0.55 & -0.93 & 0.71 & 1.52 & & \\
PECH-040s & 1.85 & -0.62 & 1.03 & 0.53 & -1.59 & \\
\hline
\end{tabular}


The Mantel test, based on the Pearson's product-moment correlation, was employed in order to measure the spatial autocorrelation between the data (species abundance) and the environmental variables. The results of the Mantel test show a significant correlation of $\mathrm{r}=0.41$, at $p<0.002$. A significant relationship between environmental variables and species distribution was also detected. The environmental variables selected accounted for $27.5 \%$ (southness, slope, and tree.density) and $15 \%$ for (Vegmeadow and time since fire) of the total variation in species abundance and composition. The third canonical variate (CCA3) did not have a strong correlation with measured environmental variables (Table 4.15).

Table 4.15: Summary statistics for canonical correspondence analysis of species abundance and environmental variables.

\begin{tabular}{llll}
\hline & CCA1 & CCA2 & CCA3 \\
\hline vegmeadow & 0.01626 & -0.75917 & 0.42639 \\
southness & 0.77421 & 0.38195 & 0.26076 \\
fire (time since fire) & 0.39894 & -0.89829 & -0.14606 \\
tree.density & -0.66313 & 0.36491 & -0.28494 \\
slope & -0.60857 & 0.04841 & 0.04089 \\
\hline
\end{tabular}

The simultaneous ordinations of samples and species in the same space were summarized in a joint plot in which species and sites were located by their weighted average scores. The regression based sample scores (Linear combinations) were added to the interpretation. In addition, CCA provided a direct plotting of the environmental variables into the same space, yielding a biplot of correlation vectors. The ordination diagram showed that species are mainly discriminated along the first axis (Southness, slope, and tree density) and to a lesser extent by the second axis (Vegmeadow and fire) (Fig. 4.25). For each environmental variable, the length of the arrow (vector) indicates its importance to the ordination and how much these variables contributed to the axes.

The right angled projection of a species to a vector approximates the magnitude of that species' influences over the formation of the axis. For instance, the species Quercus laeta, Q. canbyi, Q. polymorpha, Q. rysophylla, Q. virginiana, and Arbutus xalepensis had a large influence over axis 1 . The situation was reversed and species 
such as Quercus laceyi, Cercis canadensis, Prunus serotina, Pinus teocote, P. pseudostrobus, Ceanothus coeruleus, and Juglans mollis had a strong influence over axis 2. The angles between environmental vectors, species, and stand vectors were equivalent to the correlation between them. The smaller the angle, the larger the correlation.

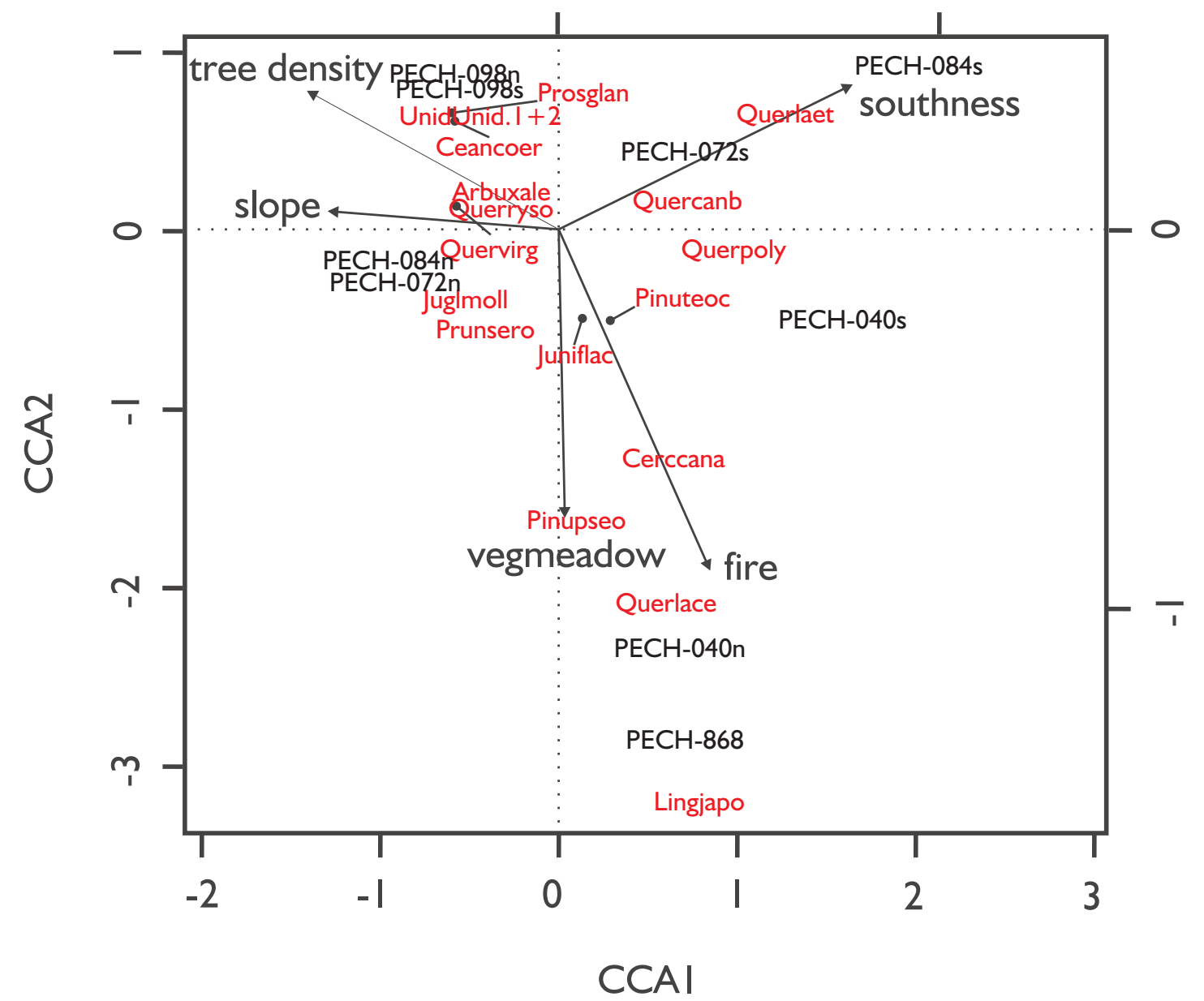

Figure 4.25: CCA diagram for the post-fire cohorts and species for the PECH, north and south-facing slope. For abbreviations c.f. Table A.2

Figure 4.25 shows the species-environment biplot from the north- and south-facing slopes. There were some major trends: A close association of two oak species, $Q$. canbyi and $Q$. laeta, with both of them showing the effects of the variable southness. These two species were also correlated to stands PECH-084s and PECH-072s. On the opposite side, the species Juglans mollis and Prunus serotinus, had a preference for stands oriented on a north-facing slope (PECH-084 and PECH-072).

The variable tree density showed a strong correlation with the youngest post fire stands (PECH-098 north and south). Almost diagonally opposite to the variable tree 
density, the species L. japonicum, appeared as a rare species. The variable time since fire was located opposite to tree density; effectively pointing to the oldest post-fire stands. Here, five species were identified by the CCA and are mentioned in order of appearance according to time since fire: Juniperus flaccida, Pinus teocote, Cercis canadensis, Pinus pseudostrobus, and Q. laceyi.

The variable Vegmeadow (mean potential solar radiation at the growing season) had a significant correlation with just three species, Pinus pseudostrobus, Pinus teocote, and Juniperus flaccida.

Post-fire stands with steep slopes were associated with the intermediate post-fire stands PECH-084 and PECH-072, which were also correlated to the species Quercus virginiana and Quercus rysophylla. The species Quercus canbyi and Quercus polymorpha were correlated to stands with flat sites (PECH-040 south). This was indicated by the slope position vector. 


\section{Chapter 5}

\section{Discussion}

\subsection{Fire History and Management Implications}

One of the aims of this research was to determine how often mixed pine oak forests have burned in the PECH. Most of the forest fire history studies rely on a series of inferences based on a set of physical evidence left by fire. This includes even-aged, post-fire regeneration cohorts (e.g. Johnson 1992) [78] and anomalies in the tree-ring structure of individuals, such as fire scars (Stephens 2003, Swetnam 2001a, 2001b) $[136,140,142]$. In this study, the master forest fire chronology reconstructed for the $\mathrm{PECH}$ was possible because of remaining trees with traces of fire incidence. Consistent patterns of past forest fire occurrence were emerging as many sites were collected and cross-dated from a broad array of areas in the PECH. Through construction of a general frame of fire history by sampling and dating fire-scarred trees, five forest fire events could be established in the period from 1868 to 2002 .

Identified burned area over a landscape generally represent a minimal area burned by a particular wildland fire or several wildland fires in a given year. This is because the presence of a scar is a definitive record of the occurrence of a forest fire, while the possible lack of a scar does not necessarily indicate the lack of a forest fire event. The absence of fire scars could be either $(i)$ the area has not burned, $(i i)$ a forest fire has not left records because it was superficial and of low intensity, hence the heat was not enough to scar trees, or (iii) the fire scar was not documented, since the scared trees were destroyed by subsequent forest fires. 
Concerning forest fire ecology in North American literature two key periods are recognized: Prior and post to Euroamerican settlement around 1900 (Everett 2000, Paysen 2000, Rodriguez-Trejo 2003) [37, 146, 126]. Before to Euroamerican settlement, periodic wildland fires tended to be of low to moderate severity and mean wildland fire return intervals of four to six years were common. Moreover, these wildland fires had many ecological functions within the ecosystem. Frequent surface fires in many vegetation types minimized fuel accumulation, while their variable nature helped to create diverse landscapes and variable forest conditions (Fire and Fuel Management Plans 2003) [9]. Many species and communities now reflect a clear evidence of adaptation to recurrent wildland fire, demonstrating that fire occurred regularly and frequently. (Fire and Fuel Management Plans 2003, Fulé 1996, Swetnam 2001) $[9,46,142]$.

The nearly entire exclusion of widespread wildland fire of low to moderate severity in the later half of the nineteenth century, affected drastically the structure and composition of the forest in northern America. The initial change in wildland fire regime in the 1860s appears to be result of the impact of intense grazing pressure on fine fuels important for the spread of fire (Caprio 1993, Nystrom 1999, Pyne 1996) $[21,107,122]$.

Fire-scar records have been collected in only a few mountain areas in northern Mexico. A research carried out in the Sierra de los Ajos in the state of Sonora, has proved that surface forest fires had occurred in these forests every four to seven years since the middle of the 14 century (Swetnam 2001a) [142]. An interesting and important characteristic of the wildland fire history in three sites investigated in the Sierra de los Ajos in the state of Sonora by Swetnam (2001a) [142], is the continuously occurrence of surface wildland fires until the year 1930 .

Researches on wildland fire history conducted by Fulé and Covington (1996) [46] have produced a similar continuation of widespread surface and low intensity fire regimes (four to six years intervals) in pine forest in the state of Durango until the $30 s$ of the past century. After this epoch large livestock herds began to consume fine fuels. Fulé (2000) [49] mentioned that in ecosystems with frequent wildland fires, the occurrence of intense wildland fires is rare, since recurring burns keep low fuel levels and an open vegetation. Both studies from northern Mexico suggested that the changes of wildland fire regime and behavior in these forests were related to the 
development of the ejidos (communal land) in 1940, as well as the increment of grazing livestock, road building, logging activities, and the suppression of wildland fire. Although an organized suppression of fires by Mexican land management agencies did not exist or has been limited to some private and communal lands in most of the forests of northern Mexico (Dieterich 1983, Swetnam 2001a) [31, 142].

In contrast to Swetnam's study in Sonora (2001a) [142] as well as Fulé and Covington's $(1996,2000)[46,49]$ results from Durango, an evidence of forest fire occurrence could not be found in the PECH between 1868 to 1940. However, this period of reduced fire occurrence coincides with a general period of reduced wildland fire occurrence in many regions in the southwestern United States, northern Mexico, and southern South America (Stephens 2003) [136]. At the end of the 19th and the beginning of the 20th century, many sites have experienced less frequent wildland fires (Stephens 2003) [136]. Consequently the results about intervals without forest fire occurrence in the PECH correspond with the general pattern of wildland fire free intervals at the time.

A research conducted by Kitzberger et al. (2001) [84] produced that the decrease in wildland fire occurrence was related to a decline in the frequency and amplitude of the El Niño-Southern Oscillation. The fact that similar changes had take place coincidentally in both North and South America suggested that climate is a likely contributor to wildland fire occurrence.

From 1940 to 2002 forest fire frequency ranged in the PECH from 14 to 20 years. The length of these fire intervals is not clear. Probably weather conditions might have inhibited fire ignition in the past. Longer intervals between wildland fires resulted in an abundant and continuous fuel accumulation in some areas, that though provoked wildland fires burning the area under dry and warm conditions. Moreover it is also possible, that the forest fire frequency registered in the PECH between 1940 and 2002 was related to land-use history. Road building, logging, and livestock grazing in some areas of the PECH might have inhibited an effective fire ignition. Most of the woodlands in Mexico, especially at the base of the mountains, were heavily cut for fuel-wood and domestic uses since the 19th century (Bahre 1984) [5]. Kaib's (1998) [81] investigation of historical records, revealed an increase in livestock grazing in northern Mexico after the World War II, associated with the development of the United States' markets at the time. 
Fulé (1994) [47] mentioned an increase in infrastructure for timber exploitation and the initiation of campaigns to prevent, detect, and suppress forest fires, since increasingly awareness of the value of timber arose in communal and private lands. However, tree harvesting appears to have a lesser effect in the study area, at least during the last 16 to 20 years, since the establishment of the PECH and its protection status. In the Sierra Madre Occidental, long periods of forest fire absence have lead to an accumulation of fuels and by that an increasing probability of the outbreak of an high intensity wildland fire with extensive tree mortality (Fule 1996) [46]. This fact is confirmed by observations done in National Parks in the United States, where forest fire exclusion has led to high intensity and stand killing wildland fires (Fulé 1996) [46].

Attributes of pre-Euroamerican fire regimes provide information about the changes in natural ecosystems during the last 150 years. The reconstructed forest fire chronology has shown a change of fire regime within the PECH after 1940. After this date, the observed forest fire regime is characterized by moderate interval lengths and standreplacing fires in mixed pine-oak forests in the research area. This pattern might be related with the indirect elimination of frequent surface forest fires due to permanent livestock grazing activities, and subsequent accumulation of living and dead fuels. Like the increasing changes in fire occurrence patterns registered by CONABIO and CONAFOR $(2004,2004)[25,28]$, the historical fire regime for the PECH shows clearly, that severe fire events have occurred more frequently during the last fifty years. But, the alterations of fire occurrence in mixed pine-oak forest may not entirely be a result of wildland fire suppression in these forests but may partially be a result of settlement policy and rural development in lower elevation zones, which prohibited the spread of wildland fires in these areas. Therefore, historic fire regimes and events should not be perceived as solely a feature of a specific vegetation type, but should be viewed in the context of a variety of interacting vegetation types covering a landscape through which wildland fire may spread (Caprio 1993) [21].

The consequences of wildland fires, such as erosion, and timber loss, are widely acknowledged in Mexico, but the effects of wildland fire suppression have received less attention (Fulé 1996) [46]. Several authors (Fulé and Covington 1996, Fulé 2000, Stephens 2003) [46, 49, 136] have mentioned that systematic wildland fire suppression has not been experienced in many conifer forests in northern Mexico, that's why 
these forests may serve as models for further investigations. Furthermore, these forests may also provide valuable information for the development of adequate management regimes for similar forests in the United States. Several researches mentioned also the beneficial aspects of forest fires as a silvicultural tool and as a natural ecological disturbance factor (Agee 1993, Goldammer 2003, Pyne 1996) [1, 60, 121]. The awareness of the ecological role of forest fire has risen among Mexican scientists, especially after several extraordinary wildland fires in 1998 (Fulé 2000) [49]. Unfortunately, the public perception remains influenced by wildland fire suppression publicity (Jardel 2003, Jiménez 1997, Rodríguez Trejo 2003) [74, 77, 126].

The historical reconstruction and perspectives of forest fires have a great value, since they serve to identify extreme, unsustainable changes and their causes (Swetnam 2001) [142]. In addition, the historical documentation of wildland fire events provides critical information for natural resource managers and policy makers about natural processes and the causes of ecological changes (Kaufmann et al. 1994) [82]. Therefore, further research should focus on possible causes and the reconstruction of forest fire history, unless forest fire occurrence should be included in the development of forest management plans.

Nowadays, resource management faces the pressure of a mostly not well informed society. Different interests amongst policy makers, and legislature, land owners or other users and nature conservationists are leading to conflicts. The pressure caused by certain economical and ecological realities, and the increased demand for multiple use of resources, requires the implementation of modern fire management policy, respecting natural wildland fire occurrence. The evidence that fire can play a positive role in certain ecosystems (Agee 1993, Brown 1996, Landsberg 1997, Pyne 1984, 1996 Whelan 1995) $[1,15,88,121,122,152]$ and that forest resources must be managed under a multiple-use and sustained-yield management concept (Gadow 2004, Jiménez 2001) [51, 76] required the inclusion of wildland fire in the planning of land management.

Monitoring and experimentation provide sufficient expertise that should be accessible and available for advising decision makers at both, wildland fire policy and management levels, in order to develop adequate measures for wildland fire management.

In conclusion, fires started from a variety of causes in Mexico, about $94 \%$ of the 
wildland fires originate from human activities (CONABIO 2004) [25] such as agricultural burning, campfires, discarded cigarettes, or arson. Most human-caused fires occur near populated areas, often along roadways. In case they occur in populated areas, where an early detection is possible and the accessibility good, they are often extinguished while still very small. The remaining $6 \%$ of wildland fires started naturally, mainly by lightning and they occurred mostly in remote areas during extended periods of dry weather. Thus lightning caused fires are often not detected until they have already grown to a significant size. By that time, professional equipped personnel cannot reach remote locations to control the wildland fire, why these fires may continue growing and extending.

Fire management requires an understanding of the origin of wildland fires, their behavior and possible impacts on the ecosystem and human properties, to be in the right position to decide either a forest fire can be accepted as a natural event and take its course, or actions of suppression have to be taken. For the right evaluation of the wildland fire situation and adequate reactions, the relationship between wildland fire, vegetation, climatical conditions, and various socioeconomic aspects of forest fire events need to be investigated further and finally considered. Nevertheless, most of the decisions on land management are subjective and based upon human desires and practical constrains (Swetnam 2001) [142].

Although it is unnecessary to suppress all natural fire occurrence, it is still possible to predict forest fires to some degree and to react by sending equipped professionals in case it is necessary to save the life of people. By respecting natural fire occurrence and an adequate management of the fuels in the forests, the likelihood of human-caused and naturally originated wildland fires growing out of control can be reduced notably (BLM 2003) [9]. In addition, peoples' habits to burn agricultural fields or rather other activities provoking wildland fires should be conducted or regulated by modified legal requirements. These regulations should not only include the protection of peoples' life and properties, but also natural processes of a healthy environment. Hence, a strict settlement policy is required that does not allow to settle down or cultivate in areas, where wildland fires occur naturally or rather frequently. Concerning the wildland fire management and nature conservation strategies in Mexico, further challenges are the consideration of forest fires as a social and cultural phenomenon, and to point out to the public that wildfires are part of the natural disturbance regime in many 
forest in North Mexico.

\subsection{Changes in Forest Structure after Fire}

The present investigation also includes the analysis of different development stages in forests after having burned, with regard to the diameter and height distribution, the volume, and the number of stems. As a fact different successional stages have their own specific stand structure. Initially, the findings demonstrated significant differences in mean diameter, mean height, basal area, and stand volume, between the gradients north- and south-facing slopes (c.f Tables 4.1, 4.2, and 4.3).

In early successional stages, a high establishment of samplings and sprouts occurring in forest stands after wildland fire events, have been documented by several authors (Bell 1980, Fox 1988, Fulé 1944, 2000, Huag 1997) [8, 41, 47, 49, 145]. Due to the openness of the canopy, light reaches and with this warms the forest floor, enhancing the conditions for species diversity in these areas. As a response to this fact, the understory growth is stimulated and species with the ability to sprout, start to colonize the area (Schneider 2001) [128]. The results of the investigation carried out in the PECH confirm the explained reaction of vegetation.

Comparing the number of individuals on the north-facing slopes and south-facing slopes over time, the tree numbers decreased significantly of about $75 \%$ on the northfacing slopes. Thus 4097 trees/ha were counted on the north-facing slope of the youngest post-fire cohort and only 1059 trees/ha were registered in the post-fire cohort PECH-898, representing a period of 134 years after forest fire occurrence. Whereas, the tree density on the south-facing slopes was not decreasing significantly over time.

The fact, that many species on the north-facing slopes had the ability to sprout from the root collar, is amongst others, one explanation for the produced results in the PECH (Miller 2000) [97]. Others studies have proved that much of the tree density and a major part of tree establishment occur within three to seven years after forest fire events (Fulé 1996, 1999) [46, 48]. Plant community composition after forest fire disturbance was attributed to the sprouting ability of dominant species, the resounding ability of subdominant species to increase in number, and to the failure of invasive species to become established (Elliot 1999, McDonald 2003) [35, 94]. In the youngest post-fire cohort identified in the PECH, all oak species sprouted 
from the root collar, while the density varied among the species. Early studies on pioneer species in the PECH after the severe forest fires in 1998, were conducted by Jiménez and Aguirre (1999) [75]. The highest number of individuals registered in their study had Quercus rysophylla with 3,300 individuals/ha, which accounted for $64 \%$ of all the individuals registered. The majority of oak individuals resulted here from sprouts. Furthermore, van Lear and Waldrop (1989) [148] noticed that oaks resprout more frequently than most other hardwood species after burning. Similar sprouting patterns were documented by Müller-Using (1994) [102] for the species Q. laceyi and Q. rysophylla in Nuevo León. Moreover, earlier findings confirmed the effects of forest fires on species, colonizing recently burned areas (Langdon 1981, Jiménez and Aguirre 1999) $[89,75]$.

Hence, the youngest post-fire stand (PECH-098) was dominated by sprouts of Q. rysophylla, Q. canbyi, and Q. virginiana on the north-facing slope. While Q. rysophylla showed in general a maximum abundance and dominance in the early successional stages, but especially on the north-facing slopes. On the south-facing slopes in comparison, Q. rysophylla, Q. virginiana and $Q$. canbyi were the species with the highest dominance. These results were in accordance with Elliot's findings (1999) [35] in the Nantahala National Forest situated in the southern Appalachians in North Carolina. Elliot (1999) [35] found, that two oak species in the understory and herb layer had increased in density due forest fires. Although fire reduced the abundance of species, it promoted though the growth and recruitment of Quercus species.

The structure of young forest stands in process of succession is in the main determined by the structural legacy influenced by pioneer species colonizing a burned area at the first time (Schneider 2001) [128]. As a consequence of multiple influences, structural diversity in young stands is intermediate between that of old or rather mature stands (Schneider 2001) [128]. Typical successional species registered in the PECH are the conifers Pinus teocote and P. pseudostrobus, that appeared on both slopes at the first time 18 years after forest fire disturbance. Remarkable was the ability of basal sprout of a few individuals of P. pseudostrobus and P. teocote on both slopes sides. Sprouting pines could be identified due to unusual traits, such as the formation of a basal crook, a typical sprouting indicators. This unusual ability was also reported by Rodríguez Trejo (2003) [126] in stands of P. hartwegii under the influence of frequent surface fires in central Mexico. 
Another interesting feature was the high variation coefficient in diameter (89.5\%) calculated for the north-facing part of the 18 years old post-fire cohort. This is attributed to the numerous individuals of $P$. teocote with large diameters, surviving the forest fire in 1984. The relatively high residual basal area of $P$. teocote (19.5 $m^{2} /$ ha) left after the forest fire, may have been too high for many shade intolerant species to become established. No recently seedlings from conifer species were noted at this particular stand age and most of the small individuals had a diameter higher than $10 \mathrm{~cm}$.

The successional transition of intermediate stands to mature stages is marked by the closure of canopy (Stelfox 1995) [135]. The mature stands in the PECH were characterized by a dense growth of relatively even-aged trees and reduced understory development. The early successional structure of oak species has diminished and were replaced by large diameter conifers. These major pine stands have shown the lowest structural diversity and greatest loss of species. This fact was substantiated by the decreasing dominance of the species $Q$. virginiana and may be explained by the successional model of tolerance. The mentioned model, bases on the fact that pioneer species, due to their shade intolerance, do not invade overgrown sites. Hence in late successional stages, such as represented by (PECH-040), no significant differences were produced regarding the comparison of diameters on north and south-facing slopes. Similar results were registered by Gallegos and Villavicencio (1997) [53] in even-aged stands of $P$. oocarpa and Q. resinosa in the state of Guadalajara, Mexico. Likewise, Schmidt (2003) [127] had registered significant differences in tree density between burned and unburned areas in adjacent stands of P. silvestris in Germany.

Finally the transition from major to old stands was gradual, and key changes were the breakup of the canopy, the decreased presence of understory plants, and the emergence of secondary canopies composed of species such as Q. laceyi and Q. polymorpha. Consequently, the structural diversity of late successional stands was higher than the one in intermediate and major stands within the PECH. Therefore the structural diversity is reflected by the richness of woody species. In comparison to younger stages, old-aged and large canopy trees are more frequent in old forest stands. Thus the diversity of forest species was a consequence of interaction between forest fires and successional processes (Bunnnell 1995) [17]. Confirming findings were produced also in old boreal forest (Schneider 2001) [128]. Though contrary results form Scandi- 
navia, produced a simplification of forest structure and pattern as well as a decline in species diversity in long-term traditional forests (Niemela 1999) [104]. Consequently not all forest types follow the structural diversity patterns revealed in the PECH.

\subsection{Forest Biodiversity}

\section{Alpha and Beta Diversity}

The detection of changes in plant diversity in time after fire occurrence has been made according to the "Chronological Community Ordination". A natural chronosequence of 134 years was reconstructed for the PECH.

In general, the highest species richness was observed in young post-fire cohorts and above all on the north-facing slopes. Excluding the oldest post-fire (PECH-868), the species richness tended to decline in intermediate and major post-fire cohorts, as the biomass and cover of woody plants continued to increase. Jiménez and Aguirre (1999) [75] have found 34 plant species in the PECH one year after the forest fire disturbance in 1998.

One of the longest time sequences examined, was the one in southwest Tasmania, where changes from woodland to mixed forests were linked with the time past after a forest fire (Brown and Podger 1982) [12]. After the initial colonization of species, the peak of species richness (24 species) was obtained in less than six years and declined to about eight species in approximately 300 year sequence. Furthermore, Burrows and Christensen (1990) [19] related that only five to seven species were found in more than 20 years old stands in the Gibson Desert (Australia), but up to 26 species in stands burned just two years before examination. A curve for species richness in the "Jarrah Forest" was constructed in the Darling Range near Perth (Australia) by Bell and Koch (1980) [8], using a series of forest sites from different forests. There, the species richness peaked with 30 species five years after a forest fire, and then declined to 19 species 50 years after the fire disturbance. Similar results of decreasing species richness were also found by Guo (2001) [63] in the Californian chaparral. On sandy coastal soils in the Myall Lakes National Park (Australia), an open forest of Eucaliptus pilularis showed a maximum species richness two years after wildland fire occurrence (Fox 1988) [41]. Also there, the species richness started declining after three years, while a second increase of species occurred 16 years after the disturbance 
again, representing the longest fire-free period in the sequence (Fox 1988) [41].

The decline of species richness in time after forest fire disturbance might be caused primarily by the elimination of some early species, which were overtopped and shaded out by rapidly growing woody plants, especially resprouters (Miller 2000) [97]. The effect of declining species richness was also documented by Gill (1999) [59] as a characteristic in arid and semi-arid forested regions, such as the studied mixed pine-oak forest in the PECH. Furthermore, species, invading after fire occurrence, must be able to tolerate a wide range of established circumstances or rather require some condition present in established communities (Gill 1999) [59].

In general, the north-facing slopes were covered by more trees and shrub species leading to a higher stand complexity, than the south-facing slopes in the PECH. This was also consistent with observations done on the chaparral vegetation on north-facing slopes in California, where north-facing slopes showed also a higher plant species richness and plant abundance than the south-facing ones (Guo 2001) [63]. Compared with south-facing slopes, higher species turnover rates on north-facing slopes within the research area, may be explained with the larger species pool of 17 species compared with only 13 on south-facing slopes. Concerning species richness, a high number of species results with in higher community stability or rather resilance (Guo 2001) [63].

In summary, species diversity at the alpha level (within post-fire cohorts) was higher on north-facing slopes compared to the natural diversity in stands on southfacing slopes. Furthermore the diversity increased in time, reaching a peak in mature post-fire stands.

Analysis of beta diversity along the time gradient showed that the community composition was changing at an accelerated time interval on the north-facing slopes in the PECH. The similarity coefficient (Sorensen $C_{s}$ ) was used to demonstrate changes along this chronosequence. The beta diversity for the chronosequence on the northfacing slopes was high, since the species turnover was also relatively high, as species responded to changing environmental circumstances in young post-fire stands. But, the beta diversity was reduced on the south-facing slopes in time, suggesting a stable rate of species turnover. By comparing plot similarities, it was observed that the young post-fire cohorts on the north-facing slopes were more dissimilar than mature forest stands. On the south-facing slopes in comparison, the young post-fire cohorts were similar to post-fire cohorts of advanced succession. 
Changes of species abundance and composition during succession after forest fire events resulted in a higher beta diversity (between post-fire cohorts) proved by the comparison of the north-facing slopes and the south-facing slopes. Each successional stage is important in the overall concept of biodiversity. Thus all stages should be retained across a landscape, resulting in a wide range of natural serial stages, considering that a maximum diversity can be achieved only by the presence of different successional stages. Consequently, not only old post-fire stands or valuable forest should be focused, but all post-fire stands or natural stages are required for an optimal biodiversity. Hence, a natural recolonization of disturbed areas is only possible, when burned areas are surrounded by intact forests, serving as seed sources.

\section{Abundance Models}

A species abundance distribution utilizes all the information gathered in a community and is the most complete mathematical description of the available data (Magurran 2004) [92]. In temperate forests, species abundance distributions have been used to detect ecosystem disturbances. For instance, in undisturbed habitats, distributions are generally claimed to fit log-normal models, whereas in disturbed habitats, distributions fit log-series models (Hill 1998) [68].

The species abundance of all the north-facing slopes fitted best the log series and the $\log$ normal distributions. The log series distributions is generally related to a small number of abundant species and a large proportion of rare species. Data that fit into this distribution, generally indicate that one or a few factors dominate the ecology of a community, like the model of geometric series (Magurran 1988) [91].

The post-fire stands situated on the south-facing slopes fitted in contrast best the broken stick model. This model or rather expression of distribution, indicates that an important ecological factor is being shared more or less evenly between the species recorded (Magurran 1988) [91]. The fact that post-fire stands fitted the broken stick model, reflects a much more equitable state of succession than the one in stands fitting the log series, log normal, and geometric series.

Nummelin (1998) [106] studied a tropical forest stand 20 years after logging activities and species abundance distributions from this formerly disturbed habitat fitted log normal distributions. In comparison, the species abundance in a forest stand five years after logging fitted only the log series distributions (Hill 1995) [69]. 
The log normal distribution indicates a large, mature, and varied natural community (Magurran 1988) [91]. Regarding the interpretation of the truncated log normal distribution there are different opinions: (1) the distribution is an artifactual mathematical result with little or no biological importance, (2) the distribution represents underlying evolutionary and ecological processes. For example, Shaguira (1980) [133] argued that the artifactual explanation was inadequate and proposed an alternative hypothesis. Supporting an explanation based on a hierarchical community structure represented by sequentially divided niche spaces, Shaguira's investigation raised the intriguing possibility that the truncated log normal distribution is a direct consequence of the process of speciation. In addition, this implies that each successive species involved has a smaller portion of the total niche space to use. This would lead furthermore to fewer resources and lower abundances (Shaguira 1980) [133].

Another, less biological oriented explanation, is the nature of the log distribution, which results from the mathematical tendency for the distribution of errors. Log distributions tend to aggregate many independent errors to be approximately normal (Box, et. al. 1978) [10]. From a biological perspective, this tendency is explained by the fact that the survival of species is depending on many variables (e.g. solar radiation, temperature, etc). In case one or more variables depart from the optimum the species becomes less abundant. Due to the diversity of variables, there are correspondingly many reasons or possibilities for a species to be uncommon. It is obviously unlikely that all the requirements of a species will be satisfy or supplied. Thus only a few species are able to be common (Magurran 1988) [91]. Despite the different existing arguments about the distribution models, these models are nevertheless a powerful tool for the description of community structure (Shaguira 1980) [133] and should be wider used in mixed pine-oak ecosystems.

In general, forest species vary widely regarding their habitat requirements. For instance importance value indices for understory, shrub, and tree strata reached peaks at different successional stages. A sequential progression of increasing plant size, life span, and overall competitive advantage occurred along the chronosequence. The understory stratum dominated the early stages of succession, in comparison the dominance of the shrub and tree strata was increasing over time. According to which a decrease of the understory stratum initiated an increase in the shrub and tree strata. With this, diverse plant strategies for obtaining resources, avoiding predation, and 
supplying other requirements are reflected (Schneider 2001) [128]. Concluding the diversity analysis, all indices and models used for describing the forest stands had generally an important role in environmental assessment, since they provide information about changing community structures (Gaines 1999, Hill 1998, Magurran 1988) $[52,68,91]$.

Extensive management plans considering the diverse successional stages, and with this the ecological role of forest fires contributing to a multi-patched landscape, could provide the variety of resources required by the human population.

\subsection{Multivariate Analysis and Factors Influencing Succession after Fire}

\section{Canonical Correspondence Analysis}

The Canonical Correspondence Analysis offered a direct gradient analysis designed to detect the patterns of variation in the species composition that can be explained best by the observed environmental variables (Jongman 1995) [80]. For the analysis of the PECH data set, five control variables were employed: The potential solar radiation during the vegetation period (Vegmeadow), the inclination of the slope (slope), the exposition north- or south-facing side (southness), the tree density per ha (tree.density), and the time past since the last forest fire (fire). The Mantel test showed significant correlations between the environmental variables for this study. With exception from the potential solar radiation, the Rank-sum test (Kruskal-Wallis test) indicated significant differences in height, diameter, basal area, and tree density between the stands on the north- and south-facing slopes.

In mountainous terrain, vegetation is often closely associated with topography (Chang 2004) [22]. In this study, using the gradient analysis method (CCA) the topographic position (variables slope and southness) was found to be the most important factor determining species composition in the PECH. Similar studies have shown that the importance of the topographic position may be further associated with the moisture gradient or wind exposure, that are highly influenced by topography (Chang 2004) [22]. 
Other important factors explaining the variance of vegetation composition include the total amount of solar radiation (Vegmeadow) and the time since forest fires (fire). Other environmental variables, such as temperature and soil parent material, may also explain the unknown variance for the gradients in vegetation composition. However, these variables were not measure in the PECH. For instance, Peet (1998) [116] studied the geographical distribution of Pinus ponderosa in the Rocky Mountains and revealed, that the occurrence of this species was not only controlled by moisture and temperature, but also by soil and others conditions. So, an common occurrence of resprouters was documented on north-facing slopes in the Californian chaparral (Meentemeyer 2001) [95] and with that confirms the results produced for the PECH. There, two sprouting species, Q. rysophylla and Q. virginiana, were common on north-facing slopes. A certain composition or presence of plant species reflects in turn the site conditions. Resprouters for example indicate high site requirements, since their seeds depend on moist and cool soil conditions and react very sensitively to drought and high soil temperatures (Meentmayer 2001) [95]. Therefore, high numbers of resprouters may indicate a lower abundance in hot sites. In contrast, some seeds of most disturbance-dependent shrubs have the ability to remain dormant even under hot and dry conditions for several decades until the first growing season begins (Keeley 1991) [83].

Complementary factors underlying these patterns may relate to the effect of regeneration conditions on seedling survival during summer drought (Keeley 1991) [83]. Miller (2001) [97] found that resprouters generally have poorer stomatal control and are therefore vulnerable to water stress. While the deep root system of mature resprouters can prevent water stress, superficially rooted seedlings must persevere months of water limitation (Müller-Using 1986, 1994) [103, 102]. Thus, the establishment of resprouters is quite limited by the sites conditions. Especially sufficient moist is required during the fire post-germination dry season (Meentmayer 2001) [95].

The species Q. laeta, a resprouter that occurred on the south-facing slopes, is an exception to this pattern, because it seems to be less sensitive to water stress. The micro-site conditions with partial shading that operate at a finer scale might also explain the ability of $Q$. laeta to resprout under the present site conditions (Meentmayer 2001)[95]. Also Davis and Goetz (1990) [30] have registered vegetation patterns significantly associated with slope and exposure in the Coast Live Oak Forest 
in California.

The abundance of the drought-tolerant species Ceanothus coeruleus present in the young post-fire cohorts within the PECH may be related to light requirements. As documented by Meentmayer (2001) [95], some species of Ceanothus need high illumination for an optimal photosynthesis. Likewise these species have shown smaller heights, experienced greater mortality, and reduced seed production on north-facing slopes, whereas they grew better on south-facing slopes, even under drier conditions (Meentmayer 2001) [95].

Studies that explicit model radiation in topographically heterogeneous areas often found an important correlation between radiation effects and vegetation pattern (Chang 2004, Davis and Goetz 1990, Fu 1999, Gallegos 1997) [22, 30, 44, 53]. The association between vegetation and calculated radiation for the growing season in the PECH was as well relatively strong. This indicates that species such, as P. pseudostrobus, have a significant correlation with the Vegmeadow vector, followed by P. teocote and Juniperus flaccida.

Three species, P. teocote, Cercis canadensis, and Q. laceyi, showed a strong correlation with the variable past time since fire event (namely fire in the ordination diagram). A redundancy analysis, carried out in forests of the Sierra Madre Occidental in the state of Durango, revealed also a strong correlation of $P$. teocote and the time past after forest fire disturbance in stands (Park 2001) [112]. Trees of the species $P$. teocote are thick-barked and from that well protected against superficial forest fires. Furthermore, its seedlings commonly germinate after forest fires, which indicates the great adaptation of $P$. teocote to fire. Moreover, the species $C$. canadensis and $Q$. laceyi seemed to be associated with the variable time past after fire occurrence, since mostly found in the oldest post-fire cohorts. An explanation might be the shade tolerance of these species and the preference for sites where forest fires occur seldom or after a long time.

Most landscape-scale studies are limited by the scope and scale of their data. Also the results of this study, particulary those of the potential solar radiation, were limited by the scope of data. The fact that no significant differences were found between the post-fire stands on both slope sides, might be a result of relatively small data sample and the narrow distance between the cohorts sampled. Therefore the effects of sharpness or smoothed topography could not be included in the analysis 
with the digital elevation model, due to the small size area of the research.

In summary, the statistical framework used in this study allowed to detect the influence of environmental variables on the species composition among and within post-fire cohorts. The main interest of such an analysis was to estimate the relative importance of these environmental variables, which is very new and has not been attempted in ecological studies so far in northern Mexico. The multiple regression of the Constrained Correspondence Analysis (CCA) provided an efficient way to relate variations of species composition and descriptive variables. Therefore, the use of CCA in species abundance and composition has been a valuable technique for the investigation of factors responsible for population divergence. In addition, it can be used in fundamental research to orientate and design further experiments (Jongman 1995) [80]. 


\section{Chapter 6}

\section{Summary}

Scientific investigations on wildland fires are carried out in many countries, especially in the USA, Canada and Australia. These countries have developed strategies to manage and suppress wildland fires, but have also learned to accept wildland fires as a natural occurrence that must be integrated into restoration programs, conservation, and management. In contrast, the ecology of wildland fires and their impact on Mexican mixed forest ecosystems has hardly been investigated. Hence, there is a great demand for research on wildland fire ecology in Mexico (Jardel 2003, Jiménez 1997, Rodriguez-Trejo 2003) [74, 77, 126].

Nowadays, human activities influence natural fire regimes either by increasing wildland fire occurrence in forests that would seldom burn or by suppressing natural wildland fires, which causes ecological impacts that lead to infrequent, catastrophic fires due to a build up of flammable material (Arborvitae 2003) [155].

Especially in mixed pine-oak forest in northern Mexico, the frequency of wildland fires has increased due to human activities. These forests have important ecological and social functions, such as the prevention from erosion, the protection of valuable water reservoirs, production of valuable timber, and they provide recreation areas for the local population.

Hence it is important to investigate the ecological processes after wildland fires, in order to develop sustainable forest management strategies, considering the multiple interests of different sectors. Particularly after the unusual and extraordinary wildland fires in 1998, detailed knowledge about wildland fire ecology and fire history is even more required by the Mexican government. 
The Ecological Park Chipinque (PECH) has a protected status, where logging activities have been prohibited and anthropogenic influences minimal. Therefore, the PECH provides an excellent research area for the evaluation of undisturbed succession and changes in species composition after a forest fire event. Owing to the current state of knowledge and the increasing demand for detailed information about wildland fires in Mexico, this research describes and generates information with regard to forest fire ecology, including natural succession and biodiversity in pine-oak forests in northeast Mexico. The scope of the research is divided in two sections:

1. Documentation of forest fire frequency in pine-oak forests using dendrochronological analysis.

2. Evaluation of forest succession patterns after a forest fire.

(a) How does succession take place in different plant communities after forest fires, distinguishing between north- and south-facing slopes?

(b) How do environmental factors (potential solar radiation) affect the species richness and the composition of a pine-oak forest?

To answer these questions, the spatial-temporal variation of species and density of forest on north- and south-facing slopes were monitored in the Ecological Park Chipinque.

\section{Material and Methods}

The investigation was carried out in the Ecological Park Chipinque (PECH), which is part of the National Park "Cumbres de Monterrey" in the northern part of the mountain range "Sierra Madre Oriental" in northeast Mexico.

Since historical documents provided not sufficient information about past forest fire events in the PECH, formerly burned areas, so called post-fire cohorts, had to be identified in the forest stands. Once post-fire cohorts were identified, an inventory was carried out by using concentric circular sample plots.

For the estimation of the potential solar radiation, the program employed for the calculation of the precise solar inclination was developed by Wittmann from the observatory in Göttingen (Schulz 2003) [129]. 
Ecological diversity, namely the Alpha Diversity $(\alpha)$, portraying the number of species within a single community, and the Beta Diversity $(\beta)$, depicting the ascertainment of turnover in species composition along transect or gradient, usually measured as the number of species which differs between the ecosystems, were analyzed by using common indices.

Multivariate analysis serves to understand community ecology by discovering structures in a data set and by providing a fairly objective summarization of the data (Huag 1997) [145]. Multivariate statistics does not base on given hypotheses like the classical statistics, but begins with no specific hypotheses, while dealing with several variants. The purpose is to elicit some internal structure from the data and from which hypotheses can be derived. Three basic multivariate strategies were used for the data analysis: (1) classification, (2) ordination, and (3) direct gradient analysis (Pielou 1984) [119].

\section{Results}

Five post-fire cohorts of different ages, namely 4, 18, 30, 62 and 134 years old, could be identified in the PECH.

The fire chronology based on fire scars produced a chronosequence of forest fires in the PECH over a period of 134 years. As a result of this reconstructed forest fire history, five forest fire events were identified between 1868 and 2002.

Comparing the mean diameter of each post-fire cohort by using the parametric t-test, significant differences were found only in the young ( 4 to 18 years old) and intermediate (30 years old) forest stands. The elder stands in comparison have not shown significant differences concerning the mean diameter. Although the nonparametric Kruskal-Wallis test showed significant differences between north- and south-facing slopes.

Using the t-test, the values for the mean height of the post-fire cohorts were contrasted and significant differences in height were found among the forest stands and between the north- and south-facing slopes. In the youngest stand, the mean height was significantly larger on the south-facing slope. In comparison, in the elder stands, the mean height was significantly larger on the north-facing slopes. Compared with the Kruskal-Wallis test, significant differences between north- and south-facing slopes were produced. 
Tree density decreased from 4,000 trees/ha in the youngest post-fire cohort to 1,059 trees/ha in the oldest stand. Consequently, the total tree density in the mixed pine-oak forests was reduced $75 \%$ in 134 years after the wildland fire disturbance. Compared with the south-facing slope, here the tree density in the intermediate stands (2,185 trees/ha and 2,303 trees/ha) was higher than in the youngest one (1,335 trees/ha). In the 134 years old stand, 1,420 trees/ha were registered. Comparing the mean basal area of each post-fire cohort by using the parametric t-test, significant differences were found only in the young (4 to 18 years old) and intermediate (30 years old) forest stands. The elder stands in comparison have not shown significant differences concerning the mean basal area.

In the horizontal distribution, Quercus rysophylla is the most abundant species with highest IVI values (Important Value Index) followed by Pinus teocote and Quercus canbyi on the north-facing slope. On the south-facing slope, $Q$. canbyi is the most abundant species followed by $Q$. rysophylla and P. teocote. With focus on the age of the stands, the ranking changes slightly: on the north-facing slope, Q. rysophylla has the highest IVI value in the young and intermediate cohorts (4 to 30 years old), while $P$. teocote has the highest IVI in the 62 years old stand and P. pseudostrobus in the 134 years old cohort. On the south-facing slope, Q. rysophylla has the highest IVI value in two cohorts (4 and 62 years old), while $Q$. canbyi has the highest IVI in the 30 years old stand and $P$. teocote in the 134 years old cohort.

There were no significant differences between the potential solar radiation values calculated for the south-facing or rather north-facing slope. Two maps of potential solar radiation were created, one for the whole year and another for the growing period.

Significant differences regarding the species diversity $(\alpha)$ of each post-fire cohort and its two expositions, north- and south-facing, were produced. The comparison of north and south-facing slopes has produced higher levels of species richness $(S)$ on the north-facing slopes. The highest species richness value was recorded in the four and 134 years old cohorts. On the south-facing slopes, the peak of species richness occurred 30 years after a forest fire.

The species abundance of all post-fire stands in both, south- and north-facing slopes, fitted the log series and the log normal models. Moreover, the species abundance distribution showed that most species were rare or rather singletons and only 
a few species were abundant.

Frequent changes in species composition over time cause higher beta diversity $(\beta)$ values. Thus, the value obtained for the north-facing slope was $\beta_{w}=0.9$, which signifies that the species composition is dissimilar in the north-facing cohorts. The beta diversity $(\beta)$ for the south-facing cohorts is $\beta_{w}=0.8$, hence frequent changes in species composition happen over time on the south-facing slopes.

The highest degree of species similarity (0.97) was observed between the youngest stands (4 and 18 years old) on the north-facing slopes. As could be expected, the lowest degree of similarity was produced by comparing the youngest with the oldest post-fire stands facing the North. For the comparison on south-facing slopes a relatively high similarity index among the different post-fire cohorts was produced.

The classification of the post-fire cohorts using abundance data emphasized the importance of the time past after forest fire disturbance as an indicator of species assemblages and turnover. The ordination technique Detrended Correspondence Analysis (DCA) was used as an interpretative and exploratory tool (or rather indirect gradient analysis) in order to ordinate the species according to the known disturbance variable in the $\mathrm{PECH}$, such as the time past since forest fires. Applying the DCA for the north-facing slopes, the first and the second eigenvalues were given 0.25 and 0.05 respectively. Indicating that most of the extractable variance in species composition was accounted by the first two DCA axes. Hence these first two ordination axes displayed trends which were biologically relevant; the variance explained by these eigenvalues was $29 \%$ for cohorts on north-facing slopes.

For the Canonical Correspondence Analysis (CCA), a Mantel test based on the Pearson's product-moment produced significant correlations between species abundance and the environmental variables measured. The variables exposition, inclination of the slope, and tree density were the principal variables in determining the species composition in the $\mathrm{PECH}$. The potential solar radiation during the growing season and the time past since fire occurrence were related to the second CCA axis. For instance, one of the trends detected by the canonical analysis in the early successional stages was the tendency of oak species to clump. This feature decreased in time after forest fire occurrence. 


\section{Conclusion}

The historical documentation of wildland fire events in the PECH showed that five forest fires have occurred in 134 years. A shift in the fire regime has been observed. At first, the fire regime was characterized by widespread surface fires of probably low intensity, with a fire interval from four to six years. Later on, the fire regime changed and was characterized by less frequent, but more severe forest fires. Hence fire intervals of 14 to 20 were detected after 1940. This change seemed to be highly influenced by human activities.

Changes of the forest structure and biodiversity were registered in different successional stages. A high species diversity was generally found in young post-fire cohorts, while the intermediate and major stands showed the lowest diversity. In old stands, diversity was increased again. In turn, the forest structure was less divers in young stands compared to intermediate, major and old stands, where structural diversity was highest. Comparing north- and south-facing slopes, stands facing the North were generally more diverse, in structure as well as in species.

Furthermore, landscape patches and thereupon the diversity on landscape-scale ( $\beta$ diversity) seemed to be influenced by forest fire occurrence or rather even depended on fire disturbance. So, fire-dependent species were registered within the research area and fire occurrence has been natural part of ecological processes in pine-oak forests of northeast Mexico over many decades.

Nevertheless, people still tend to combat and suppress forest fires, feeling endangered by wildland fires. Therefore, an exchange of information about fire ecology and fire management suggestions is required between fire ecologists and decision makers.

At last, fire management plans, considering natural succession after fire disturbances as well as human requirements, are required for a sustainable use of resources in mixed pine-oak forests covering the Sierra Madre Oriental in northeast Mexico. 


\section{Chapter 7}

\section{Zusammenfassung}

Wissenschaftliche Untersuchungen über Wildfeuer (natürliche Feuer) werden in vielen Ländern durchgeführt, an vorderster Spitze sind diesbezüglich die USA, Kanada und Australien zu nennen. Wissenschaftlerinnen und Wissenschaftler dieser Länder haben einerseits zahlreiche Strategien zur Kontrolle und Unterdrückung von natürlichen Feuern entwickelt, andererseits aber auch gelernt, wild Feuer als natürliche Vorkommnisse zu akzeptieren und diese in Restaurierungs-, Schutz- und Bewirtschaftungspläne mit einzubeziehen. Dagegen wurden die Wirkungen von Wildfeuer und deren Ökologie in mexikanischen Mischwäldern kaum untersucht. Demnach besteht im Bereich der natürlichen Feuer großer Forschungsbedarf in Mexiko (Jardel 2003, Jiménez 1997, Rodriguez-Trejo 2003) [74, 77, 126].

Heutzutage wird das natürliche Feuerregime von antropogenen Aktivitäten deutlich beeinflusst. Als Folge brennen solche Wälder häufiger, in denen Wildfeuer eher selten oder gar nicht vorkommen, und in jenen Wäldern werden Brände unterdrückt, in denen natürliche Feuer natürlicher Bestandteil des Ökosystems sind. Dies führt wiederum, unter anderem wegen der Akkumulation von brennbarem Material, zu unregelmäßigen, katastrophalen Waldbränden (Arborvitæ 2003) [155].

Besonders im Norden Mexikos hat aufgrund menschlicher Aktivitäten die Häufigkeit von natürlichen Feuern in Kiefern-Eichenmischwäldern zugenommen. Diese Wälder haben jedoch wichtige ökologische und soziale Funktionen, unter anderem tragen sie zum Schutz vor Erosion bei, schützen wichtige Trinkwasserreservoirs und dienen der lokalen Bevölkerung als Naherholungsgebiet. 
Demzufolge ist es äußerst wichtig, die ökologischen Prozesse nach Waldbrandereignissen $\mathrm{zu}$ erforschen und nachhaltige Waldbewirtschaftungspläne zu entwickeln, die die vielseitigen Nutzungsansprüche berücksichtigen. Vor allem nach den außergewöhnlich intensiven und zahlreichen Waldbränden im Jahr 1998, ist die Nachfrage nach detailliertem Wissen über die Geschichte und Ökologie von Wildfeuern nicht nur auf Seiten der mexikanische Regierung enorm gestiegen.

Der Naturpark Chipinque (PECH) steht unter Schutz, es darf folglich kein Holz geschlagen werden und die anthropogenen Störungen sind demnach minimal. Daher bietet der PECH optimale Voraussetzungen für die Beobachtung und Erfassung ungestörter Sukzession nach einem Waldbrand. Aufgrund des aktuellen, unbefriedigenden Wissensstand und der enormen Nachfrage nach detaillierten Informationen über natürliche Feuer in Mexiko, beschreibt und liefert die vorliegende Arbeit sowohl neue Erkenntnisse über die Ökologie von unkontrollierte Waldbrände, als auch über die natürliche Sukzession und Biodiversität in Kiefern-Eichenmischwäldern NordostMexikos. Die Forschungsschwerpunkte wurden dabei folgendermaßen festgelegt:

1. Bestimmung und Dokumentation der Waldbrandhäufigkeiten in Kiefern- Eichenmisch-wäldern anhand dendrochronologischer Untersuchungen.

2. Untersuchung und Interpretation von Waldentwicklung (Sukzession) nach Störungen durch Waldbrand.

(a) Wie verläuft die Sukzession nach Waldbränden in verschiedenen Waldtypen unter Berücksichtigung der Exposition (Nord- versus Südhang)?

(b) Wie beeinflussen Umweltfaktoren (potentielle Sonnenscheindauer) den Artenreichtum und die Artenzusammensetzung in Kiefern-Eichenmischwäldern?

Um diese Fragen zu beantworten, wurden die räumlichen und zeitlichen Variationen der Artenzusammensetzung und Bestandesdichte auf Nord- und Südhängen im Naturpark Chipinque untersucht.

\section{Material und Methoden}

Die Untersuchung wurde im Naturpark Chipinque (PECH) durchgeführt, der Teil des Nationalparks "Cumbres de Monterrey" am nördlichen Ende der Bergkette "Sierra Madre Oriental" im Nordosten Mexikos ist. 
Da historische Dokumente keine zufriedenstellenden Informationen über vergangene Waldbrände im PECH lieferten, mussten in der Vergangenheit abgebrannte Waldflächen, sogenannte "Post-Feuer Kohorten", in den Waldbeständen identifiziert werden. Nach der Identifizierung von Post-Feuer Kohorten, wurden diese Bestände anhand einer Inventur mit konzentrischen Probekreisen erfasst.

Zur Bestimmung der potentiellen Sonneneinstrahlung wurde das Programm zur Berechnung des präzisen Sonnenstands von Wittmann angewandt (Schulz 2003) [129].

Die Artenanzahl innerhalb einer Pflanzengesellschaft und die Wahrscheinlichkeit des "Turnover" der Artenzusammensetzung entlang von Transekten oder Gradienten wurden unter Verwendung gängiger Indizes ( $\alpha, \beta$ diversität) analysiert.

Anhand von multivariaten Analysen lassen sich Strukturen im Datensatz erkennen und liefern damit Informationen über die Ökologie von Pflanzengesellschaften. Weiter dienen diese Analysen der objektiven Zusammenfassung von Datensätzen (Huag 1997) [145]. Zweck der multivariaten Analyse ist es, Strukturen in komplexen Datensätzen zu ermitteln, und anhand derer Hypothesen zu entwickeln. Drei grundlegende multivariate Strategien wurden für die Datenanalyse angewandt: (1) Klassifizierung, (2) Ordination und (3) direkte Gradientenanalyse (Pielou 1984) [119].

\section{Ergebnisse}

Die auf Brandnaben basierende Waldbrandchronologie ergab fünf identifizierte Waldbrandereignisse, die 1968, 1940, 1972, 1984 and 1998 stattgefunden haben.

Beim Vergleich des durchschnittlichen Durchmessers eines jeden Post-Feuer Kohorts wurden anhand des parametrischen t-Tests nur in den jungen (4 bis 18 jährigen) und mittelalten (30 jährigen) Waldbeständen signifikante Unterschiede festgestellt. Die älteren Waldbestände wiesen dagegen keine signifikanten Unterschiede bezüglich des Durchmessers auf.

Ein Vergleich der durchschnittlichen Bestandeshöhe in den Post-Feuer Kohorten ergab bei Berechnung des t-Tests signifikante Unterschiede zwischen den einzelnen Kohorten. Im jüngsten Bestand war die durchschnittliche Bestandeshöhe signifikant höher auf dem Südhang als auf dem Nordhang. Dagegen war die durchschnittliche Bestandeshöhe in älteren Beständen auf den nord-exponierten Hängen signifikant höher als auf den süd-exponierten Flächen. 
Die Bestandesdichte der Sud-exponierten Bestände nahm mit dem Alter der Bestände von 4.000 Bäumen/ha im jüngsten Post-Feuer Kohort auf 1.059 Bäume/ha im ältesten Bestand ab. Folglich reduzierte sich die Bestandesdichte in den Kiefer-Eichenmischwäldern nach einem Waldbrand um 75\% über einen Zeitraum von 134 Jahren. Auf den nordexponierten Hängen war die Bestandesdichte in den mittelalten Beständen (2.185 Bäume/ha und 2.303 Bäume/ha) höher als in den jungen (1.335 Bäume/ha). Im ältesten Bestand (134 Jahre) wurde eine Bestandesdichte von 1.420 Bäume/ha aufgenommen.

Ein Vergleich der durchschnittlichen Grundfläche eines jeden Post-Feuer Kohorts, ergab sich bei der Berechnung des parametrischen t-Test nur in den jungen (4 bis 18 jährige) und mittelalten (30 jährigen) Waldbeständen signifikante Unterschiede. Die Berechnungen für die älteren Bestände haben dagegen keine signifikanten Unterschiede bezüglich der durchschnittlichen Grundfläche ergeben.

Die Artenhäufigkeit wurde mit den IVI (Important Value Index) Wert charakterisiert. Quercus rysophylla mit einem hohen IVI Wert die häufigste Art auf den nord-exponierten Hängen gefolgt von Pinus teocote und Quercus canbyi. Auf den Südhängen ist $Q$. canbyi die häufigste Art gefolgt von $Q$. rysophylla und P. teocote. Unter Berücksichtigung des Bestandesalters, ändert sich die Rangordnung leicht: auf den Nordhängen hat dann Q. rysophylla den höchsten IVI-Wert in den jungen und mittelalten Beständen (4 bis 30 jährigen), wohingegen $P$. teocote den höchsten IVIWert in dem 62 Jahre alten Bestand hat und P. pseudostrobus in dem 134 Jahre alten Waldbestand. Auf den Südhängen ist Q. rysophylla mit dem höchsten IVI-Wert die häufigste Art in zwei Kohorten (4 und 62 jährige), dagegen ist Q. canbyi in dem 30 jährigen Bestand am häufigsten und P. teocote in dem 134 Jahre alten Kohort.

Es wurden keine signifikanten Unterschiede bezüglich der potentiellen Sonnenstrahlung beim Vergleich der Bestände auf Süd- und Nordhängen festgestellt.

Ein Vergleich der Artenvielfalt ( $\alpha$ diversität) zwischen Post-Feuer Kohorten sowie der Vergleich zwischen Süd- und Nordhängen ergab signifikante Unterschiede. So ist die Artenvielfalt bzw. der Artenreichtum $(S)$ in den nord-exponierten Waldbeständen höher als in den süd-exponierten. Auf dem Nordhang wurde der höchste Artenreichtum zum einen in dem vierjährigen Kohort als auch in dem 134-jährigen Bestand festgestellt. Auf süd-exponierten Hängen war der Artenreichtum in dem 30-jährigen Bestand am höchsten. 
Das Artenvorkommen in allen Post-Feuer Kohorten zusammen, sowohl auf den Süd- als auch auf den Nordhängen, entsprach der log-Serie und dem log-Normalmodell. Zudem ergab die Analyse des Artenvorkommens und der Artenverteilung, dass die meisten Arten selten bzw. Einzelvorkommen waren und nur einige wenige Arten häufig waren.

Der hohe Beta-wert von $\beta_{w}=0.9$ in den nord-exponierten Beständen, bedeutet dass sich die Artenzusammensetzung im Laufe der Zeit deutlich geändert hat. Ebenso auf den Südhängen hat sich die Artenzusammensetzung im Laufe der Zeit verändert $\left(\beta_{w}=0.8\right)$.

Die höchste Überlappung (Ähnlichkeit) des Artenvorkommens (0.97) wurde zwischen den jüngeren Beständen (4 und 18 Jahre alt) auf den Nordhang festgestellt. Wie erwartet ergab sich der geringste Grad an Überlappung bezüglich des Artenvorkommens zwischen dem jüngsten und dem ältesten Post-Feuer Kohort in den nordexponierten Hängen. Beim Vergleich der süd-exponierten Bestände, wurde ein relativ hoher Grad an Überlappung des Artenvorkommens in allen Post-Feuer Beständen festgestellt.

Mit Hilfe der Cluster Analyse wurde ermittelt dass, die Zeit, die seit dem letzten Waldbrand vergangen ist, von großer Bedeutung hinsichtlich der Artenzusammensetzung und des Arten-Turnover ist, und daher als Indikator für diese Größen herangezogen werden kann. Die "Detrended Correspondence Analysis" (DCA) wurde als interprätatives und untersuchendes Werkzeug angewandt, um die Arten unter Berücksichtigung der bekannten Umwelt- bzw. Störungsvariablen (z.B. vergangene Zeit nach einem Waldbrand) im PECH zu ordnen. Die Anwendung der DCA für die nord-exponierten Bestände ergab für die ersten beiden Eigenwerte 0,27 bzw. 0,15. Dies bedeutet wiederum, dass die größte Varianz in der Artenzusammensetzung den ersten beiden DCA-Achsen zugeordnet wird. Demnach zeigen diese beiden ersten Ordinaten Trends auf, die von biologischer Relevanz waren. Die Varianz, die durch diese Eigenwerte beschrieben wird, betrug 29\% für die nord-exponierten Waldbestände.

Die "Canonical Correspondence Analysis" (CCA) unter Anwendung des MantelTest, basierend auf Pearson's product-moment correlation, ergab signifikante Korrelationen zwischen dem Artenvorkommen und gemessenen Umweltfaktoren. Die Variablen Exposition, Hangneigung und Bestandesdichte erwiesen sich als die einflussreichsten Variablen, die die größte Wirkung auf die Artenzusammensetzung im 
PECH ausgeübt zu haben schienen. Die zweite CCA-Achse bezog sich auf die potentielle Sonneneinstrahlung während der Vegetationsperiode und den Zeitraum nach einem Waldbrand. Beispielsweise enthüllte die CCA, dass im frühen Sukzessionstadium die Eiche dazu neigte zu klumpen. Diese Eigenschaft nahm im Laufe der Zeit ab.

\section{Schlußfolgerung}

Die Rekonstruktion historischer Wildfeuer für den PECH ergab, dass fünf Waldbrände in einem Zeitraum von 134 Jahre, 1868 bis 2002, vorkamen. Auffällig war dabei Veränderungen des Feuerregimes mit der Zeit. So war das Regime anfangs von häufigen (alle vier bis sechs Jahre), vermutlich großflächigen Bränden von wahrscheinlich geringer Intensität charakterisiert, alle vier bis sechs Jahre, und später durch weniger häufige, jedoch intensive und zerstörerische Brände gekennzeichnet. Nach 1940 bestimmten Intervalle von 14 bis 20 Jahren zwischen Waldbränden das Feuerregime, was höchstwahrscheinlich auf anthropogene Aktivitäten zurückzuführen ist.

Veränderungen der Waldstruktur und Biodiversität wurden in den unterschiedlichen Sukzessionsstadien festgestellt. Eine große Artenvielfalt wurde generell in den jungen Post-Feuer Kohorten beobachtet, wohingegen die etwas älteren Bestände eine geringere Diversität aufwiesen. In alten Beständen stieg die Biodiversität wiederum an. Dagegen war die Bestandesstruktur weniger vielseitig. Junge Bestände waren weniger vielseitig strukturiert als mittelalte und reife sowie alte Bestände zeigten die höchste strukturelle Vielfalt. Der Vergleich von Nord- und Südhängen ergab, dass Waldbestände, die nord-exponiert waren, im Allgemeinen diverser waren, sowohl was die Struktur als auch die Artenvielfalt betraf.

Zudem scheinen Landschaftmuster und damit die $\beta$ Diversität vom Feuer beeinflusst zu werden bzw. scheinen sogar teilweise davon abzuhängen. Dafür spricht beispielsweise das Vorkommen von feuerabhängigen Pflanzenarten, die im Untersuchungsgebiet aufgenommen wurden, und die Tatsache, dass Waldbrände über viele Jahrzehnte natürlicher Bestandteil von ökologischen Prozessen in Kiefern- Eichenmischwälder in Nordost-Mexiko waren.

Dennoch neigen Menschen noch immer dazu, Waldbrände zu bekämpfen und zu unterdrücken, da Waldbrände für sie eine große Bedrohung darstellen. Daher 
ist ein Wissens- und Informationsaustausch zwischen Feuer-Ökologen und Entscheidungsträgern über die Ökologie von Waldbränden und ein angemessenes Feuer- Management mehr als überfällig.

Schließlich werden Bewirtschaftungspläne gefordert, die Waldbrände als natürliches Ereignis akzeptieren sowie die natürliche Sukzession nach einem Waldbrand berücksichtigen, als auch die Interessen der Bevölkerung. Nur unter diesen Voraussetzungen lassen sich die natürlichen Ressourcen der Kiefern-Eichenmischwälder in der Sierra Madre Oriental im nordöstlichen Mexiko nachhaltig nutzen. 
Appendix A

\section{Tables}


Table A.1: Occurrence of the species recorded on both north- and south-facing slopes during 1860-1998. (*Wildfire 1860 was found only on north-facing slopes).

\begin{tabular}{|c|c|c|c|c|c|c|c|}
\hline \multirow[b]{2}{*}{ Species } & \multirow[b]{2}{*}{ key } & \multirow[b]{2}{*}{ Slope } & \multicolumn{5}{|c|}{ Ocurrence } \\
\hline & & & $1860^{*}$ & 1940 & 1972 & 1984 & 1998 \\
\hline Arbutus xalapensis & Sp1 & Both & $\mathrm{x}$ & & $\mathrm{x}$ & $\mathrm{x}$ & $\mathrm{x}$ \\
\hline Ceanothus coeruleus & $\mathrm{Sp} 2$ & Both & & & & & $\mathrm{x}$ \\
\hline \multirow[t]{2}{*}{ Cercis canadensis } & Sp3 & North & $\mathrm{x}$ & & & $\mathrm{x}$ & $\mathrm{x}$ \\
\hline & & South & & $\mathrm{x}$ & & & \\
\hline \multirow[t]{2}{*}{ Juglans mollis } & Sp6 & North & $\mathrm{x}$ & & $\mathrm{x}$ & $\mathrm{x}$ & \\
\hline & & South & & & $\mathrm{x}$ & & \\
\hline \multirow[t]{2}{*}{ Juniperus flaccida } & Sp7 & North & & & $\mathrm{x}$ & $\mathrm{x}$ & \\
\hline & & South & & $\mathrm{x}$ & & & \\
\hline Lingistrum japonicum & $\mathrm{Sp} 8$ & North & $\mathrm{x}$ & & & & \\
\hline \multirow[t]{2}{*}{ Pinus pseudotrobus } & Sp10 & North & $\mathrm{x}$ & $\mathrm{x}$ & $\mathrm{x}$ & $\mathrm{x}$ & \\
\hline & & South & & & $\mathrm{x}$ & $\mathrm{x}$ & \\
\hline Pinus teocote & Sp11 & Both & $\mathrm{x}$ & $\mathrm{x}$ & $\mathrm{x}$ & $\mathrm{x}$ & \\
\hline Prunus serotina & Sp12 & North & & & $\mathrm{x}$ & & \\
\hline Prosopis glandulosa & Sp13 & North & & & & & $\mathrm{x}$ \\
\hline Quercus canbyi & Sp14 & Both & $\mathrm{x}$ & $\mathrm{x}$ & $\mathrm{x}$ & $\mathrm{x}$ & $\mathrm{x}$ \\
\hline \multirow[t]{2}{*}{ Quercus laceyi } & Sp15 & North & $\mathrm{x}$ & & $\mathrm{x}$ & & \\
\hline & & South & & & $\mathrm{x}$ & & \\
\hline Quercus laeta & Sp16 & South & & $\mathrm{x}$ & $\mathrm{x}$ & $\mathrm{x}$ & $\mathrm{x}$ \\
\hline \multirow[t]{2}{*}{ Quercus polymorpha } & Sp17 & North & $\mathrm{x}$ & & $\mathrm{x}$ & & \\
\hline & & South & & & $\mathrm{x}$ & $\mathrm{x}$ & \\
\hline \multirow[t]{2}{*}{ Quercus rysophylla } & Sp18 & North & $\mathrm{x}$ & $\mathrm{x}$ & $\mathrm{x}$ & $\mathrm{x}$ & $\mathrm{x}$ \\
\hline & & South & & $\mathrm{x}$ & & $\mathrm{x}$ & $\mathrm{x}$ \\
\hline \multirow[t]{2}{*}{ Quercus virginiana } & Sp19 & North & $\mathrm{x}$ & $\mathrm{x}$ & $\mathrm{x}$ & $\mathrm{x}$ & $\mathrm{x}$ \\
\hline & & South & & $\mathrm{x}$ & & $\mathrm{x}$ & $\mathrm{x}$ \\
\hline unidentified 1 & $\mathrm{Sp} 4$ & North & & $\mathrm{x}$ & & & $\mathrm{x}$ \\
\hline unidentified 2 & Sp5 & North & & & & & $\mathrm{x}$ \\
\hline Agave americana & Sp9 & North & & & & & $\mathrm{x}$ \\
\hline
\end{tabular}


Table A.2: Scientific names and abbreviations List of species found in the PECH

\begin{tabular}{lll}
\hline Scientific name & Key & Abbreviation \\
\hline Arbutus xalepensis & $\mathrm{Sp} 1$ & Arbuxale \\
Ceanothus coeruleus & $\mathrm{Sp} 2$ & Ceancoer \\
Cercis canadensis & $\mathrm{Sp} 3$ & Cerccana \\
Juglans mollis & $\mathrm{Sp} 6$ & Juglmoll \\
Juniperus flaccida & $\mathrm{Sp} 7$ & Juniflac \\
Lingistrum japonicum & $\mathrm{Sp} 8$ & Lingjapo \\
Pinus pseudotrobus & $\mathrm{Sp} 10$ & Pinupseo \\
Pinus teocote & $\mathrm{Sp} 11$ & Pinuteoc \\
Prunus serotina & $\mathrm{Sp} 12$ & Prunsero \\
Prosopis glandulosa & $\mathrm{Sp} 13$ & Prosglan \\
Quercus canbyi & $\mathrm{Sp} 14$ & Quercanb \\
Quercus laceyi & $\mathrm{Sp} 15$ & Querlace \\
Quercus laeta & $\mathrm{Sp} 16$ & Querlaet \\
Quercus polymorpha & $\mathrm{Sp} 17$ & Querpoly \\
Quercus rysophylla & $\mathrm{Sp} 18$ & Querryso \\
Quercus virginiana & $\mathrm{Sp} 19$ & Quervirg \\
Unidentified 1 & $\mathrm{Sp} 4$ & UnidUnid.1 \\
Unidentified 2 & $\mathrm{Sp} 5$ & UnidUnid.2 \\
Agave americana & $\mathrm{Sp} 9$ & Agaveame \\
\hline & & \\
\hline
\end{tabular}




\section{Bibliography}

[1] Agee, J. K. Fire Ecology of Pacific Northwest forest, vol. ISBN 1-55963-229-1. Washington, DC Island Press, 1993.

[2] Aguirre, O., Hui, G., von Gadow, K., And Jiménez, J. An analysis of spatial forest structure using neighbourhood-based variables. Forest Ecology and Management 183 (2003), 137-145.

[3] Alanís, G., And GonzÁlez, M. Flora representativa de Chipinque. Árboles y arbustos. Primera parte. Universidad Autonoma de Nuevo León, Julio 1995. ISNN 0188-5774.

[4] Alberta-Community-Development-Parks. The Boreal Forest and Protected Areas. Internet Source, August 2004. http://collections.ic.gc.ca/abnature/boreal/boreal.htm.

[5] BAHre, C. Effects of fuelwood cutting on the semidesert woodlands of the Arizona-Sonora Borderlands. In History of Sustained Yield Forestry, A sympsosium, Western Forestry Center, Portland, Oregon (1984), F. H. Society, Ed., H. K. Steen, pp. 101-110.

[6] Ballesteros, A. C. Incendios en Jalisco 1998. Ecologia (internet journal): http:// www2.planeta.com/mader/ecotravel/mexico/ecologia/, September 2004 .

[7] Beers, T., Press, P., And Wensel, L. Aspect transformation in site productivity research. Journal of Forestry, 64 (1966), 691-692.

[8] Bell, D., ANd Koch, J. Post-fire succession in the northern Jarrah forest of Western Australia. Aust. Journal of Ecology, 5 (1980), 9-14. 
[9] BLM. Fire and Fuels Management Plan Amendment and Environmental Assessment for BLM lands in New Mexico and Texas. Tech. rep., Bureau of Land Management, 2003.

[10] Box, G., Hunter, W., And Hunter, S. Statistics for Experimenters: An Introduction to Design, Data Analysis and Model Building. John Wiley and Sons, 1978.

[11] Brown, D. Predicting vegetation types at treeline using topography and biophysical disturbance variables. Journal of Vegetation Science, 5 (1994), 641656.

[12] Brown, M., And Podger, F. Floristics and fire regimes of a vegetation sequence from sedgeland heath to rainforest at Bathurst Harbour, Tasmania. Australian Journal of Botany, 30 (1982), 659-676.

[13] Brown, P., Kaufmann, M., And Shepperd, W. Long-term landscape patterns of past fire events in a montane ponderosa pine forest of central Colorado. Landscape Ecology 14 (1999), 513-532.

[14] Brown, P., And Sieg, C. Historical variability in fire at the ponderosa pine Northern Great Plains prairie ecotone, southeasterns Blach Hills, South Dakota. Ecoscience 6, 4 (1999 a), 539-547.

[15] Brown, P., And Sieg, C. H. Fire history in interior ponderosa pine forest of the Black Hills, South Dakota, USA. International Journal of Wildland Fire 6, 3 (1996), 97-105.

[16] Brown, P., And Swetnam, T. A cross-dated fire history from coast redwood near Redwood National Park, Californa. Can. J. For. Research 24 (1994), 2131.

[17] Bunnell, F. Forest-dwelling vertebrate faunas and natural fire regimes in Brithis Columbia: patterns and implications for conservation. Conservation Biology, 9 (1995), 636-644.

[18] Burrough, P., And McDonell, R. Principles of geographical information systems for land resources assessment. Clarendon Press, Oxford, 1998. 
[19] Burrows, N., And Christensen, P. A survey of aboriginal fire patterns in the western desert of Australia. Gen. tech. rep. se 69, USDA For. Serv, 1990.

[20] Caprio, A. Fire History, 2000 Annual Fire Report on Research, Monitoring and Inventory. The first National Congress on Fire Ecology, Prevention and Management, San Diego California, 2000.

[21] Caprio, A., and Swetnam, T. Historic fire regimes along a elevational gradient on the west slope of the sierra Nevada, California. Proceedings; Symposium on Fire in Wildreness and Park management: Past Lessons and Future Oportunities (March 30 - April 1 1993). Gen. Tech. Rep. INT-GTR-320.

[22] Chang, C.-R., Lee, P.-F., Bai, M.-L., And Lin, T.-T. Predicting the geographical distribution of plant communities in complex terrain - a case study in Fushian Experiment Forest, northeast Taiwan. Ecography, 27 (2004), 577588.

[23] CNA. Comisión Nacional del Agua. Internet Source, August 10, 2004. www.cna.gob.mx.

[24] CONABIO. Internet Source, August 10, 2004, last modified Mat 09, 2002. www.conabio.gob.mx/institucion/conabio-espanol/doctos/chipi.html.

[25] CONABIO. Biodiversitas: Detección temprana de incendios. Boletin bimestral de la CONABIO 52, Comisión Nacional para el Conocimiento y uso de la Biodiversidad, January 2004.

[26] CONABIO. Program for heat points detection using remote sensing techniques. Internet Source, August 10, 2004 Last update: May 132004. http://www.conabio.gob.mx/conocimiento/hotspots/doctos/puntoscalor.html.

[27] CONAFOR. Strategic Forestal Program 2025, 2001.

[28] CONAFOR. Reporte semanal de resultados estadísticos de incendios forestales. Datos acumulados del 1 enero al 20 mayo de 2004. Tech. rep., CONAFOR Coordinación general de Conservación y Restauración. Gerencia de Incendios Forestales, 2004.

[29] DalgaARD, P. Introductory Statistics with R. Springer Verlag, 2002. 
[30] Davis, F., And Goetz, S. Modelling vegetation pattern using digital terrain data. Landscape Ecology 4, 1 (1990), 69-80.

[31] Dietrich, J., And Swetnam, T. Dendrochronology of fire-scarred ponderosa pine. Forest Science 30 (1984), 238-247.

[32] DoLIĆ, D. Statistik mit R. Oldenburg Verlag, 2004.

[33] Dubayah, R. Modeling a solar radiation topoclimatology for Rio Grande River Basin. Journal of Vegetation Science, 5 (1994), 627-640.

[34] Dubayah, R., And Rich, P. Topographic solar radiation models in GIS. International Journal of Geographical Information Systems, 9 (1995), 405-419.

[35] Elliott, K., Hendrick, R., And et Al. Vegetation dynamics after a prescribed fire in the southern Appalachians. Forest Ecology and Management, 114 (1999), 199-213.

[36] ESRI-EsPAÑA. GIS and mapping software. internet 12.10.2004, 2004. http://support.esri.com/.

[37] Everett, R., And SchellhaAs, R. Fire history in the ponderosa pine/douglas-fir forest on th east slope of the wasihington cascades. Forest Ecology and Management 129 (2000), 207-225.

[38] FALL, J. G. Reconstructing the historical frequency of fire: A modeling approach to developing test methods. Report no. 225, School of resource and Environmental Management, University of Victoria, Canada, 1998.

[39] FAO. Global Forest Fire Assessment 1990-2000, vol. Working Paper 55. FAO Forestry Departament Rome, 2001. Forest Resources Assessment Programme.

[40] Fernández, J. C., And García-Gil, G. Los incendios forestales en sureste de México y Centroamérica. Ecologia (internet journal): http://www2.planeta.com/mader/ecotravel/mexico/ecologia/., September 2004 .

[41] Fox, M. Understorey changes following fire at Myall Lakes, New South Wales. Cunninghamia 2, 1 (1988), 85-95. 
[42] Frank, E., And Lee, R. Potential solar beam irradiation on slopes: Tables for 30 and 50 latitude. Ge. tech. report, U.S.D.A Forest Service Rocky Mountain Forest Range Experimental Station, 1996.

[43] Franklin, J. Predictive vegetation mapping: Ggraphic modelling of biospatial patterns in relation to environment gradients. Progress in Physical Geography 4, 19 (1995), 474-499.

[44] Fu, P., AND Rich, P. Design and implementation of the solar analyst: An Arcview extension for modelling solar radiation at landscape scales. In Proccedings of the 19th Annual ESRI User Conference, San Diego, USA. (1999).

[45] Fu, P., AND RICH, P. M. A geometric solar radiation model and its application in agriculture and forestry. Departament of Geography, University of Kansas and Kansas applied remote sensing program (1999).

[46] FulÉ, P., AND C., W. Changing fire regimes in mexican pine forest. ecological and management implications. Journal of Forestry, 94 (1996), 33-38.

[47] Fulé, P., And Covington, W. Fire-regime disruption and pine-oak forest structure in the Sierra Madre Occidental, Durango, Mexico. Restoration Ecology 2, 4 (1994), 261-272.

[48] Fulé, P., And Covington, W. Fire regime changes in la Michilía Biosphere Reserve, Durango, Mexico. Conservation Biology 13, 3 (1999), 640-652.

[49] Fulé, P., García Arevalo, A., And Wallace, C. Effects of an intense wildfire in a Mexican oak-pine forest. Forest Science (46), 1 (2000), 52-61.

[50] Gadow, K. V. Waldsruktur und Wachstum, Beilage zur Vorlesung im Wintersemester 2003-2004. Universitätsdrucke Göttingen, 2003.

[51] Gadow, K. V., Orois, S., And Aguirre, O. Manejo forestal con bases científicas. Madera y Bosques 10, 2 (2004), 3-16.

[52] Gaines, W. L., Harrod, R., and Lehmkuhl, J. Monitoring biodiversity: Quantification and interpretation. General technical report pnw-gtr-443, Forest Sevice, Pacific Northwest Research Station, 1999. 
[53] Gallegos, A., Villavicencio, R., Schulz, R., And Müller-Using, B. Wachstum von Pinus oocoarpa, Quercus resinosa und Clethra rosei in abhängigkeit von reliefparamern in westmexiko. Forstarchiv 68 (1997), 262269.

[54] Gauch, H. Multivariate analysis in community ecology. Cambridge University Press, Cambridge, 1982.

[55] Gauch, H., and Whittaker, R. Hierarchical classification of community data. Journal of ecology, 69 (1981), 135-152.

[56] General-Libraries. Perry castañeda Map collection, atlas of Mexico, board of regents - The University of Texas system, 1975, Physiographic Provinces. Authors: Arbingast, S.A.; Blair, C.P.; Bonine, M.E.; Buchanan, J.R.; Gill, C.C.; Holz, R.K.; Marin R., C.A.; Ryan, R.H.; Weiler, J.P. Internet Source, August 2003. www.lib.utexas.edu/maps/atlasmexico.htm.

[57] GFMC. A brief history of forest fires in Mexico. Global Fire Monitoring Center. International Forest Fire Notes 19, 19 (1998), 32-35.

[58] GFMC. Mexican fires of 1998. Global Fire Monitoring Center. International Forest Fire Notes, 20 (1999), 61-63.

[59] Gill, M., Woinarski, J., And York, A. Australia's biodiversity responses to fire. Biodiversity Technical Report No. 1, Enviroment Australia, 1999.

[60] Goldammer, J. G. Fire ecology of the recent antrophocene. UN International Strategy for Disaster Reudction (ISDR) (2003).

[61] Goldammer, J. G. Towards developing a global wildland fire strategy. 2nd symposium on fire economics, planning and policy: A global view, Cordoba, Spain (April 2004).

[62] Goldammer, J. G., And Furyaev, V. V. Fire in Ecosystems of Boreal Euroasia, vol. 48. Kluwer Academics Publishers, 1996.

[63] Guo, Q. Early post-fire succession in California chaparral: Changes in diversity, density, cover and biomass. Ecological Research, 16 (2001), 471-485. 
[64] Gurnell, J., Shirley, M., And Rushton, S. Conserving red squirrels (Sciurus vulgaris): mapping and forecasting habitat suitability using GIS. Biological Conservation, 105 (2002), 53-64.

[65] Hartung, J. Statistik, Lehr- und Handbuch der angewandten Statistik. Oldenburg Verlag, 2002.

[66] Heyerdahl, K., AND Alvarado, E. Influence of climate and land use on the historical surface fire in pine-oak forest, Sierra Madre Occidental, Mexico. In Fire and climatic change in temperate ecosystems of the Western Americas., edited t. veble and w. baker and g. montenegro and t. swetnam ed. SpringenVerlag New York, 2002.

[67] Hildebrandt, G. Fernerkundung und Luftbildmessung (für Forstwirtschaft, Vegetationskartierung und Landschaftökologie). Wichmann Verlag, Heidelberg, 1996.

[68] Hill, J., And Hammer, K. Using species abundance models as indicators of habitat disturbance in tropical forests. Journal of Applied Ecology, 35 (1998), $458-460$.

[69] Hill, J., Hammer, K., Lace, L., and Banham, W. Effects of selective logging on tropical forest butterflies on Buru, Indonesia. Journal of Applied Ecology, 32 (1995), 754-760.

[70] Hill, M., AND Gauch, H. Detrended correspondence analysis, an improved ordination technique. Vegetation, 42 (1980), 47-58.

[71] Holmes, J., AND Kirkwood, A. Community ecology. Internet source, January 2005. Lecture Notes BGYC61H3S http://www.utoronto.ca/env/jah/ace/commlecs.htm.

[72] INEGI. (Instituto Nacional de Estadística Geografía e Informática). Internet source, Nuevo León, Información Geográfica, August 10, 2004. www.inegi.gob.mx/geo.htm. 
[73] Jardel, E., AND ET. AL., R. R. Manejo del fuego y restauración ecológica en la reserva de la biosfera sierra de Manatlan. V Congreso mexicano sobre recursos forestales, Guadalajara, Jal. Mx (Noviembre 2001).

[74] Jardel, E., Ramírez-Villeda, R., and Castillo, F. Fire management and restoration plan in the Sierra de Manatlan Biosphere Reserve, Mexico. Proceddings of the 2nd International Wildland Fire Ecology and Fire Management Congress, Coronado Springs Resort, Orlando (November 2003).

[75] JimÉnez, J., And Aguirre, O. Especies pioneras en las areas incendiadas del Parque Chipinque en 1998. Tech. rep., Facultad de Ciencias Forestales, 1999.

[76] Jimenéz, J., Aguirre, O., And Kramer, H. Análisis de la estructura horizontal y vertical en un ecosistema multicohortal de pino-encino en el norte de México. Investigación Agraria, Sistemas y Recursos Forestales 10, 2 (2001), $355-366$.

[77] Jiménez, J., Aguirre, O., Treviño, E. Jurado, E., And González Tagle, M. Estudio de la dinámica de crecimiento de Pinus culminicola Andresen \& Beaman mediante la aplicación de sitios de evaluación continua en el Cerro Potosí, Galeana, Nuevo León. Revista Ciencia UANL 2, 2 (1997).

[78] Johnson, E. Fire and vegetation dynamics: Studies from the North American Boreal Forest. Cambridge University Press, 1992.

[79] Johnson, E. A. Fire regimes and vegetation dynamics: studies from North American Boreal Forest. Cambridge University Press, 1992.

[80] Jongman, R. H., ter Braak, C., And van Tongeren, F. Data analysis in community and landscape ecology. Cambridge University Press, Cambridge, 1995.

[81] KAIB, H. Fire history in riparian canyon pine-oak forest and the intervening desert grasslands of the southwest borderlands: A dendrocecological, historical and cultural inquiry. Master's thesis, School of Renewable Natural Resources, The University of Arizona, Tucson, 1998. 
[82] Kaufmann, M., And et Al., D. G. An ecological basis for ecosystem management. General technical report rm-246, USDA, Fores Service, 1994.

[83] KeEley, J. Seed germination and life history syndromes in the California chaparral. Botan rev, 57 (1991), 81-116.

[84] Kitzberger, T., And swetnam, T. Interhemispheric synchrony of forest fires and the Nino -Southern Oscillation. Global Ecology and Biogeography, 10 (2001), 315-326.

[85] Klein, S. Calculation of monthly average insolation on tiled surfaces. Solar Energy, 19 (1997), 325-329.

[86] KöPPEN, W. Klassifikation der klimate nach temperatur, Niederschlag und jahreslauf. Petermanns Georg. Mittlg., 1918.

[87] Lamprecht, H. Silviculture in the tropics. Deutsche Gesellshaft für technische Zussamenarbeit (GTZ), GmbH, Eschborn, Gemany, 1989.

[88] Landsberg, J. D. Fire and forest: fire -a good servant or a bad master. XI World Forestry Congress, Antalya, Turkey (1997).

[89] Langdon, O. Some effects of prescribed fire on understory vegetation in loblolly pine stands. In Prescribed fire and wildfire in southern forest (1981), S. C. Clemson University, Ed., pp. 143-153.

[90] Loetsch, F., AND Heller, K. Forest Inventory. BLV Verlagsgesellschaft München, 1973.

[91] Magurran, A. E. Ecological Diversity and its Measurement. Princenton University Press, 1988.

[92] MagurRan, A. E. Measuring Biological Diversity, vol. ISBN 0-632-05633-9. Blackwell Publishing, 2004.

[93] Maindonald, J., And Braun, J. Data Analysis and Graphics Using R. Cambridge Series in Statistical and Probabilistic Mathematics, 2004. 
[94] McDonald, R., And Peet, K. Spatial patterns of Quercus regeneration limitation and Acer rubrum invasion in a Piedmont forest. Journal of Vegetation Science, 14 (2003), 441-450.

[95] Meentmeyer, R., And Moddy, A. Landscape-scale patterns of shrubspecies abundance in California chaparral. Plant Ecology, 156 (2001), 19-41.

[96] Mexico-Desconocido. Naturaleza, Parques, Chipinque. Internet Source, version invierno 1996-1997. www.mexicodesconocido.com.mx/espanol/index.cfm.

[97] Miller, M. Fire autoecology. Tech. rep., USDA Forest Service Gen. Tech. Rep. RMRS-GTR-42 Vol 2, 2000.

[98] Moore, P. Forest fire. Serie of position papers produced as WWF's (January, 2002).

[99] Moreno, C. E. Métodos para medir la biodiversidad, vol. 1. M \& T-Manuales y Tesis Sociedad Entomológica Aragonesa (SEA), 2001.

[100] MühlenberG, M. Freilandökologie, vol. 3. Auflage. Quelle and Mayer UTB fur Wissenschaft, 1993.

[101] Müller-Dombois, D., And Goldammer, J. G. Fire in tropical ecosystem and global environmental change. In: Fire in the tropical biota. Ecosystem processes and global changes. Springen-Verlag Berlin-Heidelberg-New York, 1990.

[102] Müller-Using, B. Contribuciones al conocimiento de los bosques de Pino y Pino-Encino en el noreste de México. Facultad de Ciencias Forestales, 1994.

[103] Müller-Using, B., And Wachtel, G. Estructura del Estrato arbóreo, estado de la regeneración e intensidad luminosa en un bosque de alta montaña en el noreste de Mexico. Sauerländer's Verlag, 1986.

[104] Niemela, J. Management in relation to disturbance in the Boreal Forest. Forest Ecology and Management, 115 (1999), 127-134.

[105] Norton, D. A., And De LAnge, P. Fire and vegetation in a temperate peat bog: Implications for the managemenmt of threatened species. Conservation Biology 17, 1 (February 2003), 138-148. 
[106] Nummelin, M. Log-normal distribution of species abundance is not universal indicator of rainforest disturbance. Journal of Applied Ecology, 35 (1998), 454457.

[107] Nystrom, J., FulÉ, P., AND ET AL. Restoration of presettlement age structure of an Arizona ponderosa pine forest. Ecological Applications 9, 1 (1999), $228-239$.

[108] Odum, E. P. The strategy of ecosystem development. Science, 164 (1969), $262-270$.

[109] Oksanen, J. Community ecology package - The vegan package-Ordination methods and other usal functions for community and vegetation ecologist. Ver. 1.6. R- statistics, GPL2, March 2004.

[110] Pacala, S., And Rees, M. Models suggesting field experiments to test two hypotheses explaining successional diversity. American Nature, 152 (1998), 729737.

[111] Pacific-Biodiversity-Institute. Fire ecology. Fire Ecology Project (2003). Wildfire-Information-Center.

[112] PARK, A. Environmental influences on post-harvest natural regeneration in Mexican pine-oak forest. Forest Ecology and Management 144 (2001), 213-228.

[113] Parque-Nacional-Cumbres-Monterrey. Programa de conservación y manejo (borrador). Areas Naturales Protegidas, www.conanp.gob.mx.

[114] Pascual Prado, J. R. E. A. Caracterización de la relación entre la insolación y la regeneración vegetal tras incendios forestales en ámbitos mediterráneos, universidad politécnica de valencia ed. Departamento de Ingeniería Cartográfica, Geodesia y Fotogrametría.

[115] PEet, R. Forest vegetation of the Colorado front range: patterns of species diversity. Vegetation 37 (1978), 65-78.

[116] Peet, R. Putting things in order: the advantages of Detrended Canonical Analysis. American Nature, 131 (1988), 924-934. 
[117] Pielou, E. Species-diversity and pattern-diversity in the study of ecological succeession. Journal of Theoretical Biology, 10 (1966), 370-383.

[118] Pielou, E. An Introduction to Mathematical Ecology. Wiley, New York, 1969.

[119] Pielou, E. The interpretation of ecological data. John Wiley \& Sons New York, 1984.

[120] Pierce, K., Lookingbill, T., And Urban, D. A simple method for estimating potential relative radiation (PRR) for landscape-scale vegetation analysis. Nicholas School of the Environment and Earth Sciences, Duke University, Februar 2004.

[121] Pyne, S. World fire. The culture of fire on Earth. University of Washington Press. Seattle, 1996.

[122] Pyne, S., Andrew, P., And Laven, R. D. Introduction to wildland fire. John Wiley Nueva York, 1996.

[123] Pyne, S. J. Introduction to Wildland Fire. Fire management in the United States. John Wiley Nueva York, 1984.

[124] Respectfully-Quoted:. A dictionary of quotations requested from the congressional research service. edited by Suzy Platt. Washington D.C.: Library of Congress, 1989; Bartleby.com, 2003. www.bartleby.com/73/ [12.10.2004].

[125] Rodríguez-Trejo, D. Fire ecology of the mountain pine, Pinus hartwegii. Proceddings of the 2nd International Wildland Fire Ecology and Fire Management Congress, Coronado Springs Resort, Orlando (2003).

[126] Rodríguez-Trejo, D., And Fulé, P. Fire ecology of mexican pines and a fire management proposal. International Journal of Wildland Fire, 12 (2003), 23-37.

[127] Schmidt, L., Hille, M., And Gadow, K. Analyse eines bodenfeuers. veränderungen des bestandestruktur und des wachstums. Allgemeine Forst und Jagdzeitung, 4-5 (April-Mai 2004). 
[128] SchneIDER, R. Old-growth forests in Alberta: Ecology and Management. Tech. rep., Alberta Center for Boreal Studies, November 2001.

[129] Schulz, R. Flächenbezogene Modelle zur Unterstützung der Forstlichen Standortkartierung in Nidersächsen Bergland. PhD thesis, Dissertation des Mathematisch-Naturwissenschaflichen Fakultäten. Universität Göttingen, 2003.

[130] SEMERNAP. Fire management in Mexico, in Global Forest Fire Assessment 1990-2000. Working paper 55, Forestry Departament, FAO, 2001.

[131] SEMERNAP. Secretaria de Medio Ambiente y Recursos Naturales. Reporte en Incendios Forestales. Tech. rep., SEMERNAP, 2002.

[132] SEMERnAT-Canadian-Forest-Service. Sistema de información de incendios forestales. internet, September 2004. http://fms.nofc.cfs.nrcan.gc.ca/mexico/index.html.

[133] Shaguira, G. Minimal community structure: an explanation of species abundance patterns. American Nature, 116 (1980), 770-787.

[134] Skinner, C., And Chang, C. Fire regimes, past and present. in Sierra Nevada Ecosystem project. Tech. rep., Center for Water and Wildland Resources, University of California, Davis, Calif., 1996.

[135] Stelfox, J. Relationships between stand age, stand structure, and biodiversity in aspen mixwood forest in Alberta. Tech. rep., Alberta Environmental Centre, Vegreville, www.borealcentre.ca/reports.html, 1995.

[136] Stephens, S., Skinner, C., And Gill, S. Dendrochronology-based fire history of jeffrey pine - mixed conifer forest in the Sierra San Pedro Martir, Mexico. 1090-1101 33, Can. J. For. Research, 2003.

[137] Stephens, S. L. Fire history differences in adjacent jeffrey pine and upper montane forest in eastern Sierra Nevada. International Journal of Wildland Fire, 10 (2001), 161-167.

[138] Stephenson, N. Actual evapotranspirationand deficit: biologically meaningful correlates of vegetation distribution across spatial scales. Journal of Biogeography, 25 (1998), 855-870. 
[139] Swanson, F., Kratz, T., Caine, N., and Woodmansee, R. Landform effects on ecosystem patterns and proccesses. Biosience, 38, 92-98.

[140] Swetnam, T., And Allen, C. Fire scars histories. Ecological Applications 9, 4 (2001), 1189.

[141] Swetnam, T., And Baisan, C. Fire regimes in sierran miexed-conifer forest. Werstern Ecological Research Center (2000).

[142] Swetnam, T., Baisan, C., And Kaib, M. Forest fire histories of La Frontera: Fire-scar reconstructions of fire regimes in the United States/Mexico Borderlands. In press, Vegetation and Flora of La Frontera: Historical vegetation Change Along the United States/Mexico Boundary, 2001a.

[143] The-Nature-Conservancy. The Nature Conservancy's Fire Initiative. Tech. rep., The Nature Conservancy, 2003.

[144] Thonicke, K., Venevsky, S., Sitch, S., And Cramer, W. The role of fire disturbance for global vegetation dynamics: coupling fire into a Dynamic Global Vegetation Model. Global Ecology and Biogeography, 10 (2001), 661-667.

[145] Thrasher-Haug, J., And Redmanm, R. Plant species diversity patterns after fire and clearcutting disturbance in the Southern Boreal forest of Saskatchewan. PhD thesis, Departament of Crop Science and Plant Ecology, University of Saskatchewan, 1997.

[146] Timothy Paysen, E. A. Fire in western shrubland, woodland, and grassland ecosystem. Tech. rep., USDA Forest Service Gen. Tech. Rep. RMRS-GTR-42 Vol 2, 2000.

[147] VAn LaAR, A., AND AKÇA. Forest Mensuration. Cuvellier Verlag, Göttingen, 1997.

[148] VAn Lear, D., AND WALDrop, T. History, uses, and effects of fire in the Appalachians. General technical report se-54., Asheville, NC: U.S. Department of Agriculture, Forest Service. Southeastern Forest Experiment Station, 1989. 
[149] Vartessy, R., Wilson, C., Silburn, D., Connolly, R., and Ciesiolka, C. Predicting erosion hazard areas using digital terrain analysis. In in Proceedings of IAHS Intl. Symposium on Research Needs and Applications to reduce Erosion and Sedimentation in Tropical Steeplands. SUva, Fiji (1990).

[150] Vogiatzakis, I. Gis- based modelling and ecology: A review of tools and methods. Geographical paper No. 170.

[151] Walter, H., And Lieth, H. Klimadiagramm-Weltatlas. Third Volume . Gustav Fischer Verlag Jena, 1960-1967.

[152] Whelan, R. J. The Ecology of Fire. Cambridge University Press, 1995.

[153] Whittaker, R. H. Evolution of species diversity in land communities. Evolutionary Biology, 10, 1-67.

[154] Whittaker, R. H. Evolution and measurement of spices diversity. Taxon 21, 2-3 (1972), 213-251.

[155] World-Conservation-Union. Future fires, perpetuating problems of the past. Arborvitae Specials (2003). 


\section{Curriculum vitae}

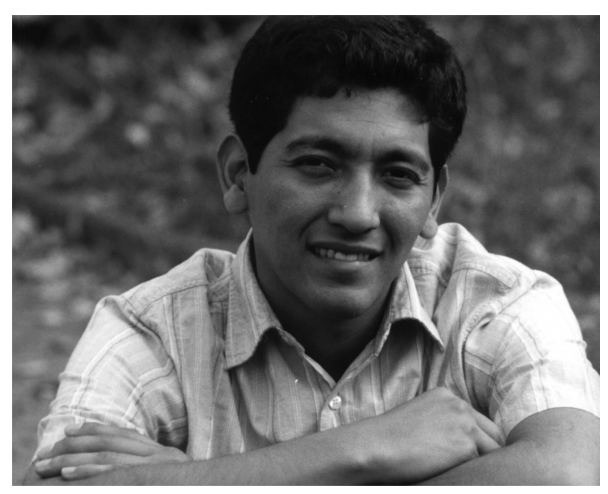

Born in Ciudad Victoria, Mexico, the $27^{\text {th }}$ of May 1973, Marco Aurelio González Tagle started his studies in Forest Sciences at the Faculty of Forestry at the Autonomous University of Nuevo León (UANL) in 1990. In 1996, he graduated successfully with the Bachelor of Science and continued his studies by entering the Master Program "Forest Sciences and Natural Resource Management". After the graduation as Master of Science in 1998, he worked as advisor for ecological matters at the city council of Linares in Nuevo León. Later on, he was offered a grant by CONACYT (Mexican National Council for Science and Technology) to continue his academic career as Ph.D.-Student at the Georg-AugustUniversity Göttingen in Germany. Before he started his doctorate at the partner university, he deepened his German language knowledge as a DAAD (German Academic Exchange Service) scholarship holder at the Goethe Institute in Göttingen for six months. In the winter semester 2000/01, he finally started his investigation within the Ph.D.-Program "Forest Sciences" at the Faculty of Forest Sciences and Forest Ecology in Göttingen. The following four years, Mr. González Tagle was concerning himself with important aspects of fire research, mainly the reconstruction of fire history and the investigation of natural forest succession after wildland fire events. In February 2005, he graduated his doctorate successfully.

Contact: marco.gonzalez@web.de 